UNIVERSIDADE DE BRASÍLIA

FACULDADE UNB PLANALTINA

PROGRAMA DE PÓS-GRADUAÇÃO EM CIÊNCIA DE MATERIAIS

ELTON JOHN NUNES DE ARAÚJO

SÍNTESE EM REATOR DE HIDROMETALURGIA DE NANOPARTÍCULA DE FERRITA DE COBALTO

BRASÍLIA 
ELTON JOHN NUNES DE ARAÚJO

\section{SÍNTESE EM REATOR DE HIDROMETALURGIA DE NANOPARTÍCULA DE FERRITA DE COBALTO}

Dissertação de mestrado apresentada ao Programa de Pós-Graduação em Ciência de Materiais, da Universidade de Brasília, como parte dos requisitos para a obtenção do título de Mestre em Ciência de Materiais.

Área de concentração: Materiais Nanoestruturados Avançados

ORIENTADOR: Renata Aquino da Silva de Souza 


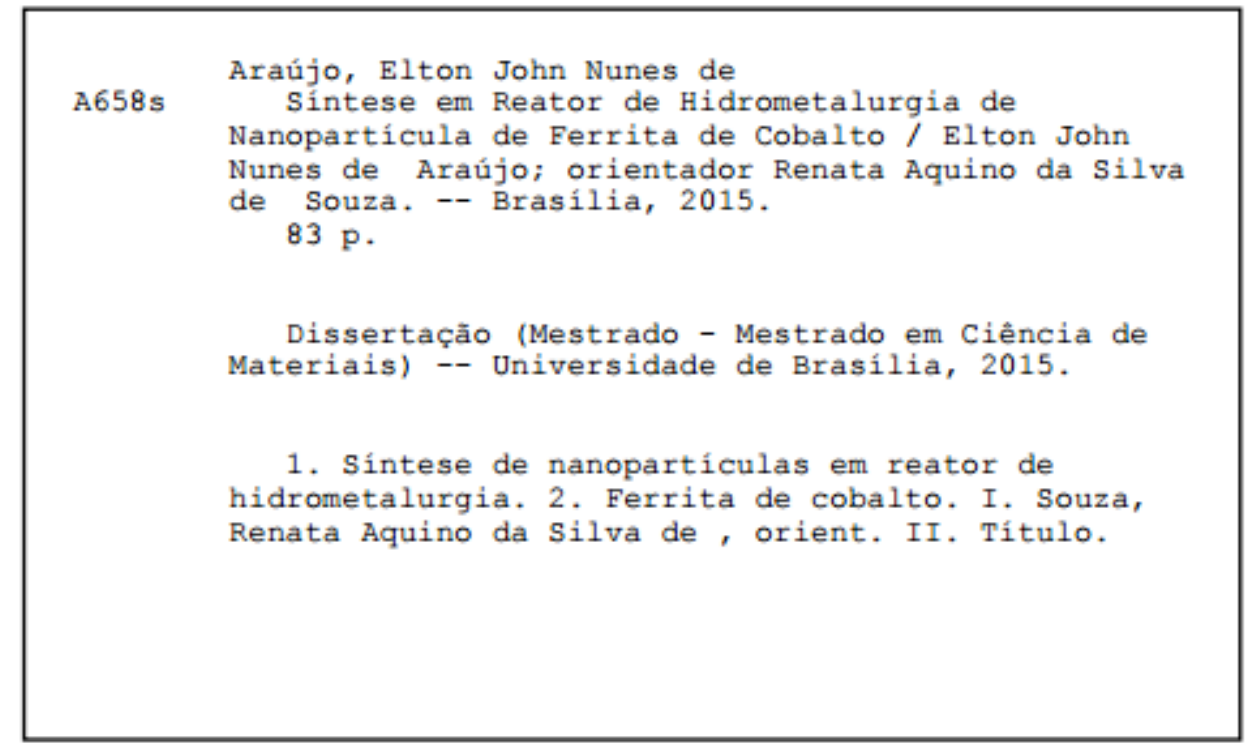




\section{UNIVERSIDADE DE BRASÍLIA \\ FACULDADE UnB PLANALTINA \\ MESTRADO EM CIÊNCIA DE MATERIAIS}

Termo de Aprovação

"Síntese em reator de hidrometalurgia de nanopartículas de ferrita de cobalto".

Elton John Nunes de Araújo

Banca Examinadora

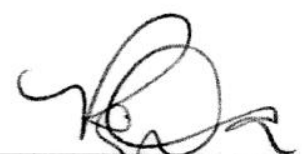

Profa. Dra. Renata Aquino da Silva de Souza Presidente (FUP/UnB)

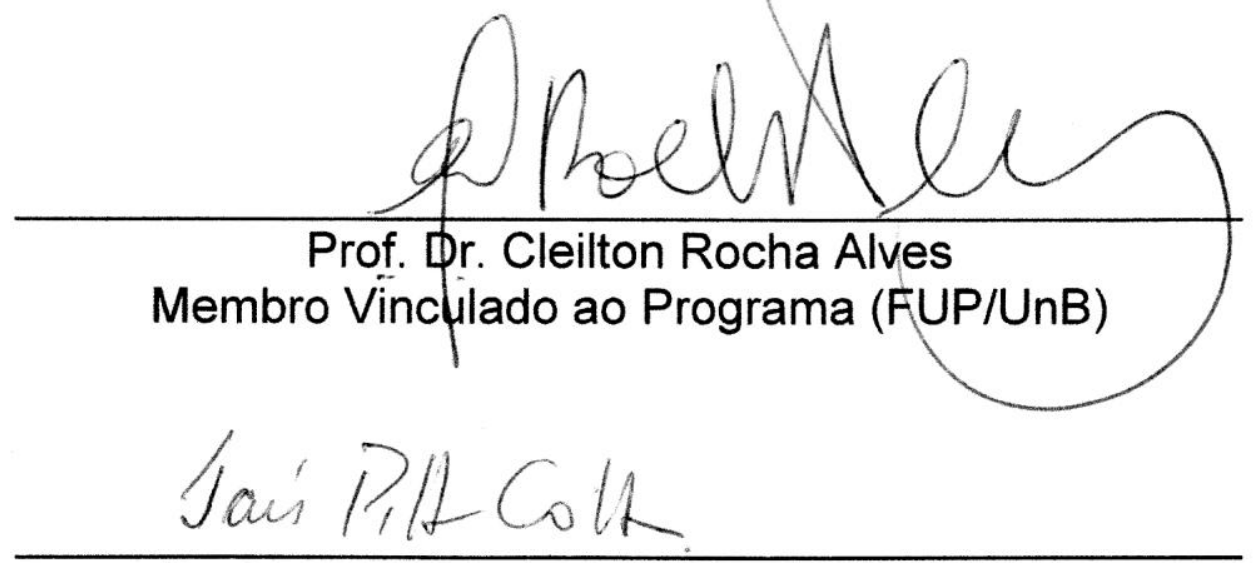

Profa. Dra. Tais Augusto Pitta Garcia Cotta

Membro não Vinculado ao Programa (IQ/UnB) 
Dedico esse trabalho aos meus pais Elton e Lia, minha força, minha inspiração. 


\section{AGRADECIMENTOS}

A Deus acima de todas as coisas por ter me dado a oportunidade de chegar até aqui.

Aos meus pais, Elton e Lia, por ter me dado a vida, educação e todo o suporte necessário para chegar até aqui.

Ao meu irmão Emerson por toda ajuda, amizade e companheirismo de toda uma vida.

Ao meu amor, Nayane Cantallops, por estar ao meu lado durante toda graduação e mestrado, entendendo todos meus momentos de ausência, com muito amor e carinho.

A minha orientadora professora Renata Aquino, pelo privilégio de sua orientação desde a graduação até aqui, por todos seus ensinamentos, auxílios, entusiasmo e dedicação a pesquisa, além de seu excelente trabalho com o programa.

Ao professor Alex Fabiano Cortez Campos, pelo auxílio na interpretação dos dados, nas medidas de Espectroscopia de Absorção Atômica e por todo conhecimento passado.

Ao professor Franciscarlos Gomes da Silva, por todas as conversas, auxílios nas medidas de Microscopia Eletrônica de Transmissão.

Ao Grupo de Fluidos Complexos da Universidade de Brasília (GFC-UnB), por permitir o desenvolvimento do meu trabalho.

A professora Taís Augusto P. G. Cotta por ter aceitado compor a banca examinadora de minha dissertação.

Ao professor Cleilton Rocha Alves por ter aceitado compor a banca examinadora de minha dissertação e seus ensinamentos.

Aos colegas de laboratório, Tatiane, Dyego, Guilherme pelas conversas, discussões e pelos momentos de descontração que tornaram os dias no laboratório mais agradáveis. E 
todos aos demais colegas do Laboratório de Fluidos Complexos que por ventura não foram citados;

Aos meus colegas e amigos do mestrado em ciência de materiais, pela convivência, amizade, companheirismo, auxílio nas tarefas desenvolvidas durante o curso, apoio e luta durante estes dois anos.

Ao meu amigo Thiago Carvalhedo, por todos os momentos de conversa e descontração, sempre com bons conselhos.

Ao técnico Josué, pela a ajuda no laboratório.

Ao Programa de Pós-Graduação em Ciência de Materiais, PPGCIMA, pela oportunidade de realização de trabalhos em minha área de pesquisa.

À CAPES pelo apoio financeiro. 


\section{RESUMO}

Investigamos a síntese de nanopartículas de ferrita de cobalto por precipitação hidrotérmica, em reator de hidrometalurgia em temperaturas entre 100 e $250^{\circ} \mathrm{C}$. Foram variados os parâmetros: temperatura de síntese, composição do meio reacional, concentração da base e presença de agente complexante. As nanopartículas obtidas foram caracterizadas do ponto de vista estrutural por difração de raios-X, sua composição foi verifica por medidas de espectroscopia por energia dispersiva de raios-x (EDX) e espectroscopia de absorção atômica (AAS). Algumas amostras foram também estudadas por microscopia eletrônica de transmissão (TEM). Amostras de fase única do tipo ferrita de cobalto, foram obtidas em 250 ${ }^{\circ} \mathrm{C}$ em meio básico, em meio reacional com 43,55\% de glicerol. Ainda, a presença do glicerol reduziu a velocidade de difusão no meio levando a um produto com forma mais homogênea e menor polidispersão. Por fim, verificamos que nas mesmas condições de concentração da base e temperatura a presença do ácido cítrico diminuiu o tamanho médio das partículas, evidenciando o favorecimento no processo de nucleação pela presença do ácido cítrico como complexante. 


\begin{abstract}
We investigate the sinthesis of cobalt ferrite nanoparticles by hydrotermic precipitation, in hydrometallugy reactor in heats from $100^{\circ}$ to $250^{\circ} \mathrm{C}$. Many different patterns were used: temperatures of sinthesis, reaction mean composition, basis concentration and complexing agent presence. The taken nanoparticles were typified from the strutural point of view by $x$-ray diffraciton. It's composition were verified by measures of spectroscopy of $x$ ray dispersive energy (EDX) and atomic absortion spetroscopy (AAS). Some samples were also studied eletronic microscopy of transmiton (TEM). Ferrite cobalt one-stage samples were taken in temperatures of $250^{\circ}$ in basic mean; in reactional mean with $43,55 \%$ glycerol. Yet, the presence of glycerol reduced the difusion speed in the mean, changing it into a product with a more homogenic form and reduced polidispertion. Finally, we verfied that in the same concentrations of the basis and temperatures the citric acid presence diminished the regular size of the particles, showing the favouring in the nucleation process due to the citric acid as complexing element.
\end{abstract}




\section{ÍNDICE DE FIGURAS}

Figura 1- Fluido magnético submetido a um campo magnético, apresentando o fenômeno de instabilidade de pico.

Figura 2- Representação do momento magnético atômicos em região monodomínio orientado paralelamente à direção de fácil magnetização................................................... 17

Figura 3- Estrutura do tipo espinélio.

Figura 4-Taça de Lycurgus: uma das mais famosas antiguidades romanas, data do século IV d.C. fabricada com vidro contendo nanopartículas de ouro. .................................222

Figura 5- Diagrama esquemático de elaboração de ferrofluido do tipo EDL-MF. ..................24

Figura 6- Mecanismo de formação de partículas uniformes baseados no modelo clássico de LaMer e Dinegar ${ }^{102}$

Figura 7- Primeira radiografia humana da mão da esposa de Röntgen ..................................34

Figura 8- Esquema de difração em um cristal. .................................................................... 36

Figura 9- Curva de calibração com respectiva equação linear da reta obtida na determinação de ferro.

Figura 10- Curva de calibração com respectiva equação linear da reta obtida na determinação de cobalto.

Figura 11- Tipos de espalhamento do feixe incidente utilizado no TEM ..............................44

Figura 12- Reator Hidrotermal da Parr usado nas Sínteses - pertencente ao Laboratório de Fluidos Complexos do Instituto de Física da Universidade de Brasília (UnB).

Figura 13-Difratogramas das sínteses realizadas no reator de hidrometalurgia a partir da mistura estequiométrica de Fe e Co: amostra ECo 150(a), ECo150(b) e ECo 250(c)

Figura 14- Difratogramas das sínteses realizadas no reator de hidrometalurgia a partir da mistura estequiométrica de $\mathrm{Fe}$ e $\mathrm{Co}$ na presença de $\mathrm{NaOH}$ : amostra $\mathrm{ECoB}$ 100(a),

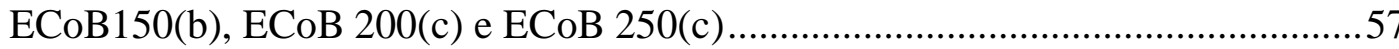

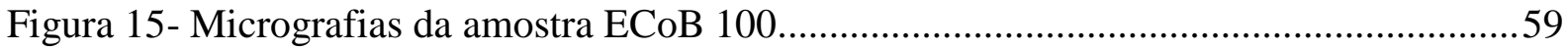

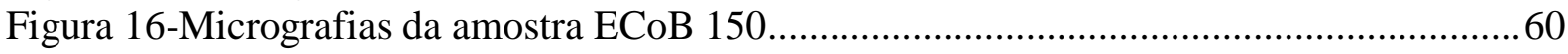

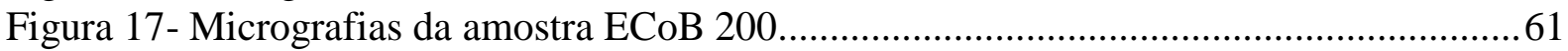

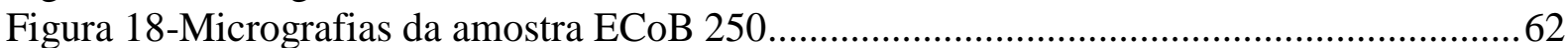

Figura 19- Difratogramas das sínteses realizadas no reator de hidrometalurgia a partir da mistura estequiométrica de Fe e Co na presença de $\mathrm{NaOH}$ em uma solução 43,55\% em glicerol: amostra ECoBG100(a), ECoBG150(b), ECoBG200(c) e ECoBG250(d)

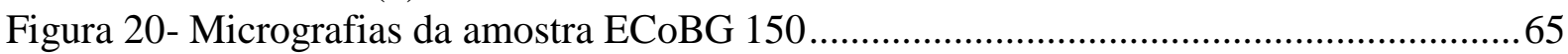

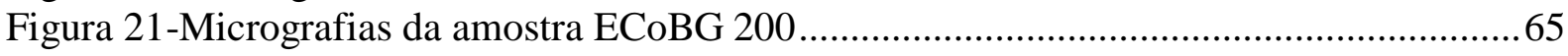

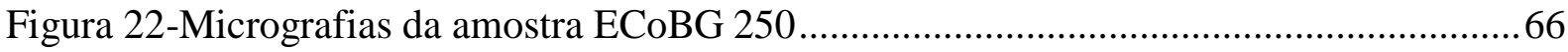

Figura 23- Difratogramas das sínteses realizadas no reator de hidrometalurgia a partir da mistura estequiométrica de $\mathrm{Fe}$ e $\mathrm{Co}$ na presença de $\mathrm{NaOH}$ em uma solução 43,55\% em glicerol: amostra ECoBG100(a), ECoB2G150(b), ECoB2G200(c) e ECoBG250(c) 
Figura 24-Micrografias da amostra ECoB2G 200.

Figura 25-Micrografias da amostra ECoB2G 250 e o histograma de distribuição em tamanho

Figura 26- Difratogramas das sínteses realizadas no reator de hidrometalurgia a partir da mistura estequiométrica de $\mathrm{Fe}$ e $\mathrm{Co}$ na presença de $\mathrm{NaOH}$ e ácido cítrico em uma solução 43,55\% em glicerol: amostra, ECoBA150(a), ECoBA200(b) e ECoBA250(c)

Figura 27-Micrografias da amostra ECoBA 250 


\section{ÍNDICE DE TABELAS}

Tabela 1- Resultado de AAS para as amostras selecionadas.................................................43

Tabela 2- Descrição dos materiais usados nas sínteses ..........................................................46

Tabela 3- Metodologia do processo de síntese no reator de hidrometalurgia ..........................53

Tabela 4- Resultado de $\mathrm{D}_{\mathrm{RX}}$ do $1^{\circ}$ conjunto-mistura de cobalto e ferro em $\mathrm{pH}$ ácido. .............55

Tabela 5- Resultado de EDX do $1^{\circ}$ conjunto- mistura de cobalto e ferro .................................56

Tabela 6- Resultados de $\mathrm{D}_{\mathrm{RX}}$ do $2^{\circ}$ conjunto- mistura estequiométrica de Fe e Co na presença

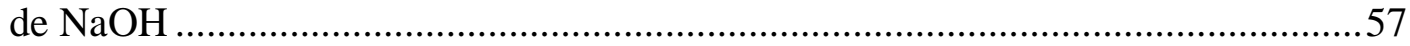

Tabela 7- Resultado de EDX e AAS do $2^{\circ}$ conjunto- mistura estequiométrica de Fe e Co na

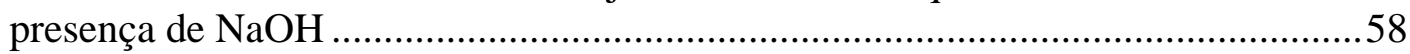

Tabela 8- Resultado de $\mathrm{D}_{\mathrm{RX}}$ para o $3^{\circ}$ conjunto- mistura estequiométrica de Fe e Co na presença de $\mathrm{NaOH}$ e glicerol 43,55\% ..............................................................63

Tabela 9- Resultado de EDX e AAS do $3^{\circ}$ Conjunto- Mistura estequiométrica de Fe e Co na presença de $\mathrm{NaOH}$ e glicerol 43,55\% .................................................................64

Tabela 10- Resultado de $\mathrm{D}_{\mathrm{RX}}$ do $4^{\circ}$ conjunto- mistura estequiométrica de Fe e Co na presença de $\mathrm{NaOH}$ e glicerol 43,55\%

Tabela 11- Resultado de EDX e AAS do $4^{\circ}$ Conjunto- Mistura estequiométrica de Fe e Co na presença de $\mathrm{NaOH}$ e glicerol 43,55\%

Tabela 12- Resultado de $\mathrm{D}_{\mathrm{RX}}$ do $5^{\circ}$ conjunto-mistura dos metais na presença de $\mathrm{NaOH}$ e do Ácido Cítrico em uma relação molar de 1:2:11:10 ..................................................72

Tabela 13- Resultado de EDX $5^{\circ}$ Conjunto-mistura dos metais na presença de $\mathrm{NaOH}$ e do Ácido Cítrico em uma relação molar de 1:2:11:10 ................................................74 


\section{SUMÁRIO}

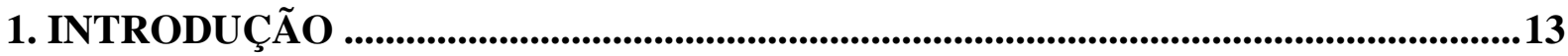

2. NANOCOLÓIDES MAGNÉTICOS ....................................................................13

3. PROPRIEDADES MAGNÉTICAS ........................................................................16

4. ESTRUTURA CRISTALINA ............................................................................................19

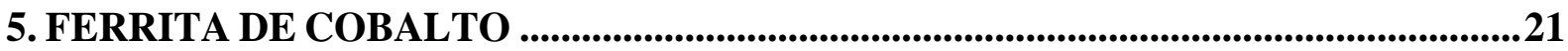

6. NANOPARTÍCULAS MAGNÉTICAS ........................................................................22

7. SÍNTESE DE FLUIDOS MAGNÉTICOS DO TIPO EDL..................................................23

7.1. OBTENÇÃO DAS NANOPARTíCULAS ...........................................................................24

7.2. TRATAMENTO DE SUPERFÍCIE ..................................................................................25

7.3. PEPTIZAÇÃ

8. SÍNTESE DE NANOPARTÍCULA POR COPRECIPITAÇÃO HIDROTÉRMICA ..25

8.1 MÉTODo HIDROTÉRMICO ............................................................................................26

8.2 MÉTODO DE COPRECIPITAÇÃO ........................................................................................27

9. CARACTERIZAÇÃO DAS NANOPARTÍCULAS …...................................................34

9.1. DIFRAÇÃO DE RAIO-X....................................................................................................34

9.2. ESPECTROSCOPIA POR ENERGIA DISPERSIVA DE RAIOS-X...........................................38

9.3. ESPECTROMETRIA DE ABSORÇÃo ATÔMICA ................................................................39

9.4. Microscopia EleTrôNICA DE TRANSMISSÃo- TEM...................................................43

10. MATERIAIS E MÉTODOS..................................................................................46

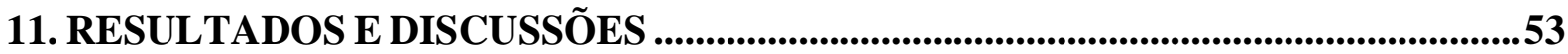

12. CONCLUSÕES E PERSPECTIVAS..............................................................................76 


\section{INTRODUÇÃO}

$\mathrm{O}$ surgimento de algumas propriedades inesperadas e a possibilidade da manipulação de materiais na escala atômica, tornou viável o desenvolvimento da nanociência e da nanotecnologia. E espera-se que seus avanços estimulem não apenas a exploração de novos fenômenos e novas teorias, mas também conduza a uma revolução industrial, se tornando a nova força motora do crescimento econômico neste século ${ }^{1}$.

Atrelando ao interesse científico existem grandes investimentos financeiros, estimado em 1 trilhão de dólares em $2015^{2}$, o que possibilita o crescimento do domínio científico e tecnológico em escala nanométrica, através de novas ferramentas de pesquisas e desenvolvimentos experimentais e teóricos.

A nanociência e a nanotecnologia tem provocado uma revolução em diversos setores da ciência e da tecnologia, com o desenvolvimento e crescimento de centros de pesquisa e institutos em todo mundo. Resultando em um ponto de convergência de diversas áreas de estudo como: química, física, biologia, engenharias, medicina, computação e ciência de materiais.

Dentro desse cenário promissor, materiais que despertam interesse são as nanopartículas e os nanocolóides magnéticos, devido a seu potencial tecnológico, características físico-químicas, estruturas complexas, tamanhos cada vez menores, baixas toxicidades para os seres humanos e biocompatibilidade ${ }^{3}$.

\section{NANOCOLÓIDES MAGNÉTICOS}

Os nanocolóides magnéticos também chamados fluidos magnéticos (FM), ou ferrofluidos, são dispersões coloidais de nanopartículas magnéticas em um líquido portador ${ }^{4}$, 
em sua maioria, de óxidos de ferro ${ }^{5}$. Este tipo de material não existe na natureza, visto que, os materiais magnéticos naturais quando aquecido perdem suas propriedades magnéticas ao ultrapassar a Temperatura de Curie, que é bem inferior ao ponto de fusão do material. Graças à conjunção original de propriedades líquidas e magnéticas, esses materiais respondem a um parâmetro externo extremamente potente, o campo magnético, podendo assim ser confinados, deslocados, deformados e controlados, o que os distinguem dos fluidos comuns. Contudo estes materiais não retêm magnetização na ausência do campo, portanto, costumam ser classificados como materiais superparamagnéticos ${ }^{6}$.

Do ponto de vista fundamental, a ferrohidrodinâmica, por exemplo, estuda o acoplamento entre os graus de liberdade hidrodinâmicos e magnéticos, que em certas condições, dá origem a fenômenos macroscópicos espetaculares. Observa-se ainda, macroscopicamente, fenômenos de instabilidade na presença de campo externo, tais como as instabilidades de pico (Figura 1) ou de labirinto, quando confinada em uma célula de HeleShaw $^{7}$.

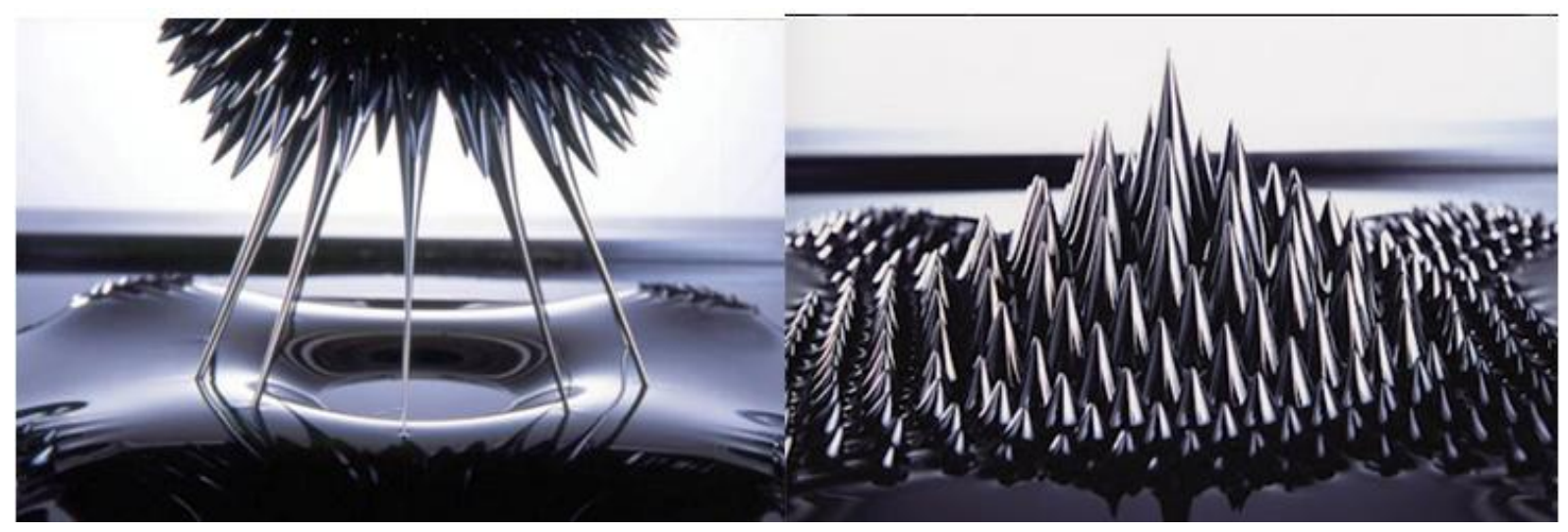

Figura 1- Fluido magnético submetido a um campo magnético, apresentando o fenômeno de instabilidade de pico.

Historicamente, a obtenção de fluidos magnéticos instáveis é datada de 1779 e atribuída a Wilson ${ }^{7}$. Bitter em $1932^{8}$ e Elmore ${ }^{9}$ também obtiveram FM instáveis. Com o desenvolvimento tecnológico na década de 60, a NASA (National Aeronautics and Space 
Administration $)^{4}$, com o objetivo de possibilitar o transporte de combustíveis na ausência de gravidade, desenvolve um fluido magnético estável ${ }^{10}$.

Na década de 70, o método de produção de FM se tornou mais fácil e mais barato, graças ao método químico ${ }^{11}$. No entanto, ainda se tratava de Fluidos Magnéticos Surfactados (S-MF), obtidos em meio apolar ou polar (dupla surfactação), que se baseia na presença de surfactantes adsorvidos na superfície das partículas, introduzindo uma repulsão do tipo estérica para contrabalançar as atrações interpartículas.

No inicio da década de 80 , foi proposto ${ }^{12}$ um método, chamado de bottom-up, de estabilização em meio aquoso que utiliza a criação de uma densidade de carga ajustável na superfície das nanopartículas e a consequente, formação de uma dupla camada elétrica (Electric Double Layered Magnetic Fluids ${ }^{13}$, EDL-MF). Inicialmente à base de partículas de magnetita sintética, esses fluidos tinham um tempo de estabilidade limitado devido à oxidação da magnetita em maguemita $\left(\gamma-\mathrm{Fe}_{2} \mathrm{O}_{3}\right)$. Entretanto, um processo de oxidação forçado efetuado antes das partículas serem peptizadas permitiu a obtenção de sois estáveis ${ }^{14}$.

$\mathrm{O}$ aprimoramento da síntese química ${ }^{15}$ resultou, em um primeiro momento, na elaboração de ferrofluidos à base de nanopartículas de ferrita de manganês e de cobalto. Isto permitiu ampliar a possibilidade de utilização destes materiais em aplicações específicas, pela diversidade de propriedades magnéticas e magneto-óticas decorrentes da modificação na composição das partículas. O que proporcionou o desenvolvimento de inúmeros tipos de fluidos magnéticos ${ }^{16}$.

A variedade de tipos de fluidos magnéticos proporciona inúmeras aplicações em diversos ramos da ciência e tecnologia de ponta. Dentre elas podemos destacar: impressoras que utilizam tintas magnéticas ${ }^{17}$, aeronaves invisíveis aos radares, lacre ou selo magnético de discos rígidos ${ }^{18}$, sistemas de armazenamento de informações, ímãs permanentes, refrigeração magnética, dispositivos acústicos, na indústria automotiva ${ }^{19}$, na construção industrial e civil ${ }^{20}$, 
na separação de minérios, separação de diamantes ${ }^{21}$, dispositivos ópticos ${ }^{22}$, na vetorização magnética de drogas ${ }^{23}$, em separação de $\operatorname{células}^{24}$, diagnósticos rápidos que requerem diminutas amostras biológicas ${ }^{25}$, em diagnóstico de tumores por imagem de ressonância magnética ${ }^{26}$, no tratamento localizado de alguns tipos câncer por hipertermia ${ }^{27}$. Ainda visando aplicações biomédicas, muito recentemente ${ }^{28,29,30}$ tem sido discutida e sugerida uma nova classe de portadores magnéticos que contenham tanto propriedades magnéticas quanto radioativas, entre outras.

Porém, toda essa variedade de fluidos magnéticos e aplicações só são possíveis graças ao enorme esforço que se tem empenhado na pesquisa relativa ao controle e aperfeiçoamento dos métodos de síntese, pois é durante a preparação que se determinam as propriedades estruturais e morfológicas as quais definem o tipo de aplicações possíveis.

\section{PROPRIEDADES MAGNÉTICAS}

O grande interesse dos fluidos magnéticos se justifica por suas propriedades magnéticas e magneto-óticas. Mais exatamente, a associação das propriedades líquidas do solvente e das propriedades magnéticas características das partículas, que confere aos ferrofluidos uma resposta magnética macroscópica singular. Sob a ação de um campo magnético externo, os ferrofluidos mudam facilmente de forma $^{31}$, assim como podem mudar sua viscosidade ${ }^{32}$. Ainda, as propriedades magneto-óticas estão diretamente relacionadas com as aplicações de FM em sistemas de modulação de intensidade luminosa ou de detecção de campo magnético. Mais recentemente, no que diz respeito às aplicações biomédicas, foi proposto um controle do "grafting" de agentes biológicos à superfície da partícula 33 a partir da investigação destas propriedades que se originam nos mesmos processos microscópicos responsáveis pelo fenômeno de magnetização. 
Para compreender o comportamento global magnético e magneto-ótico dos FM, é necessário um estudo aprofundado das características magnéticas individuais das nanopartículas, bem como a investigação das propriedades magnéticas e magneto-óticas do fluido diluído.

As partículas em suspensão nos fluidos magnéticos possuem estrutura cristalina, do tipo mineral espinélio, em que, devido à diferença entre o número de sítios $\mathrm{A}$ e $\mathrm{B}$, o ordenamento magnético resultante é ferrimagnético. Devido ao seu tamanho nanométrico, inferiores à parede de $\mathrm{Block}^{34}$, as partículas são monodomínios magnéticos e possuem um momento magnético resultante $\mu$, da ordem de $10^{4} \mu \mathrm{B}$ (magnéton de Bohr). No equilíbrio termodinâmico, o momento magnético é orientado paralelamente à direção de fácil magnetização devido à barreira de anisotropia como pode ser visto na Figura 2.

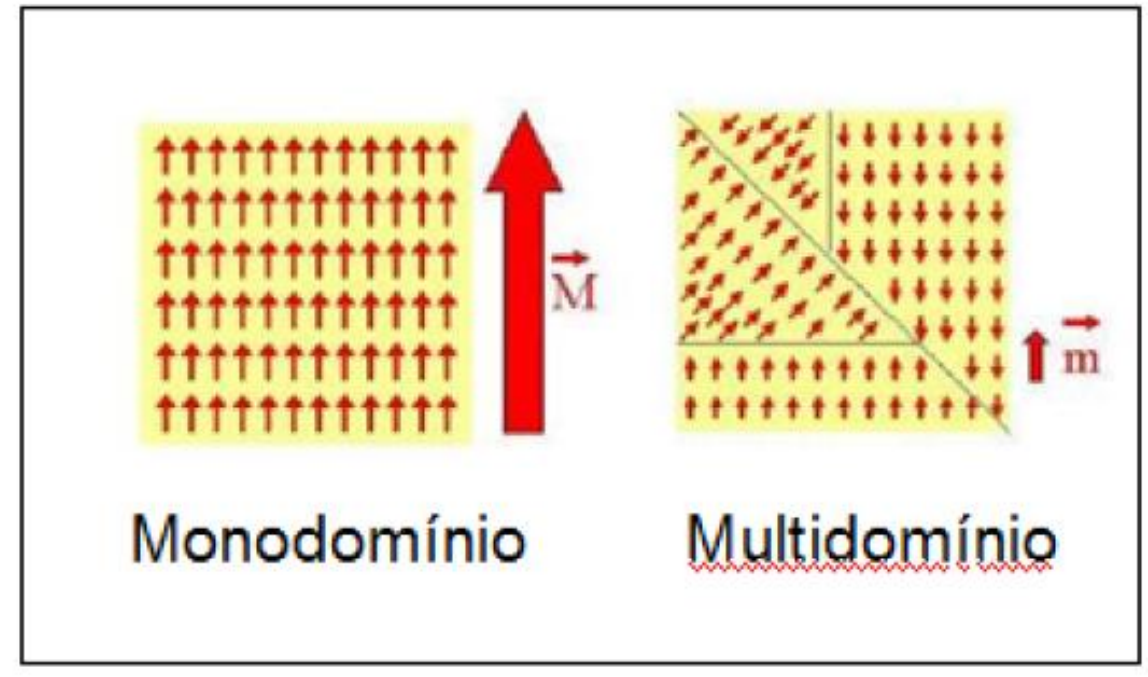

Figura 2- Representação do momento magnético atômicos em região monodomínio orientado paralelamente à direção de fácil magnetização.

A energia que bloqueia o momento nessa direção é dada por $\mathrm{KV}$, onde $\mathrm{K}$ é a constante de anisotropia e V o volume da partícula monodomínio. O mecanismo de relaxação do momento é um processo termicamente ativado caracterizado por um tempo de relaxação: 


$$
\tau_{\mathrm{N}}=\tau_{0} \exp \left(\mathrm{KV} / \mathrm{k}_{\mathrm{B}} \mathrm{T}\right)
$$

em que $\tau_{0}$ é o tempo de relaxação de spin, da ordem de $10^{-6} \mathrm{~s}$. Se KV >> $\mathrm{k}_{\mathrm{B}} \mathrm{T}$, o momento está bloqueado na direção de fácil magnetização e o material é classificado de dipolo rígido. Se $\mathrm{KV}<<\mathrm{k}_{\mathrm{B}} \mathrm{T}$, o momento pode flutuar no interior da partícula e o material é classificado de dipolo não rígido.

Por outro lado, em soluções coloidais magnéticas, os graus suplementares de liberdade associados à rotação mecânica da partícula dentro do líquido, conduzem a um segundo mecanismo de rotação do momento magnético: a rotação Browniana caracterizada por um tempo de relaxação, que depende da viscosidade $\eta$ do líquido portador e escreve-se ${ }^{35}$ :

$$
\tau_{\mathrm{B}}=3 \eta \mathrm{V}_{\mathrm{H}} / \mathrm{k}_{\mathrm{B}} \mathrm{T}
$$

em que $\eta$ é a viscosidade do líquido portador, $T$ à temperatura e $V_{H}$ é o volume hidrodinâmico da partícula.

Os dois mecanismos de relaxação podem ser concomitantes em um fluido magnético. O processo predominante corresponde aquele associado ao tempo de relaxação mais curto. Por outro lado, as partículas menores relaxam por um processo de Néel enquanto as maiores relaxam por rotação mecânica (relaxação Browniana), ou seja, o processo de relaxação depende do tamanho das nanopartículas.

Devido à existência destes dois processos possíveis de relaxação, a resposta típica de um FM a um campo externo $\mathrm{H}$ é paramagnética, e devido a magnitude dos momentos magnéticos associados às partículas dizemos que os colóides magnéticos possuem comportamento paramagnético gigante a temperatura ambiente. De fato, este comportamento, pode ser bem descrito pelo formalismo de Langevin ${ }^{36}$ inicialmente proposto no caso de um conjunto de spins clássicos sem interação ${ }^{37,38}$. 


\section{ESTRUTURA CRISTALINA}

As partículas que compõem os coloides magnéticos do tipo EDL-MF possuem estrutura cristalina do tipo espinélio (Figura 3), elucidada por Bragg em $1915^{39}$. Formado por um empacotamento cúbico compacto de 32 anions de oxigênio, criando 64 interstícios de simetria tetraédrica e 32 interstícios de simetria octaédrica. Esses sítios são parcialmente ocupados: 1/8 dos sítios tetraédricos e 1/2 dos sítios octaédricos são preenchidos por cátions metálicos ${ }^{40}$.

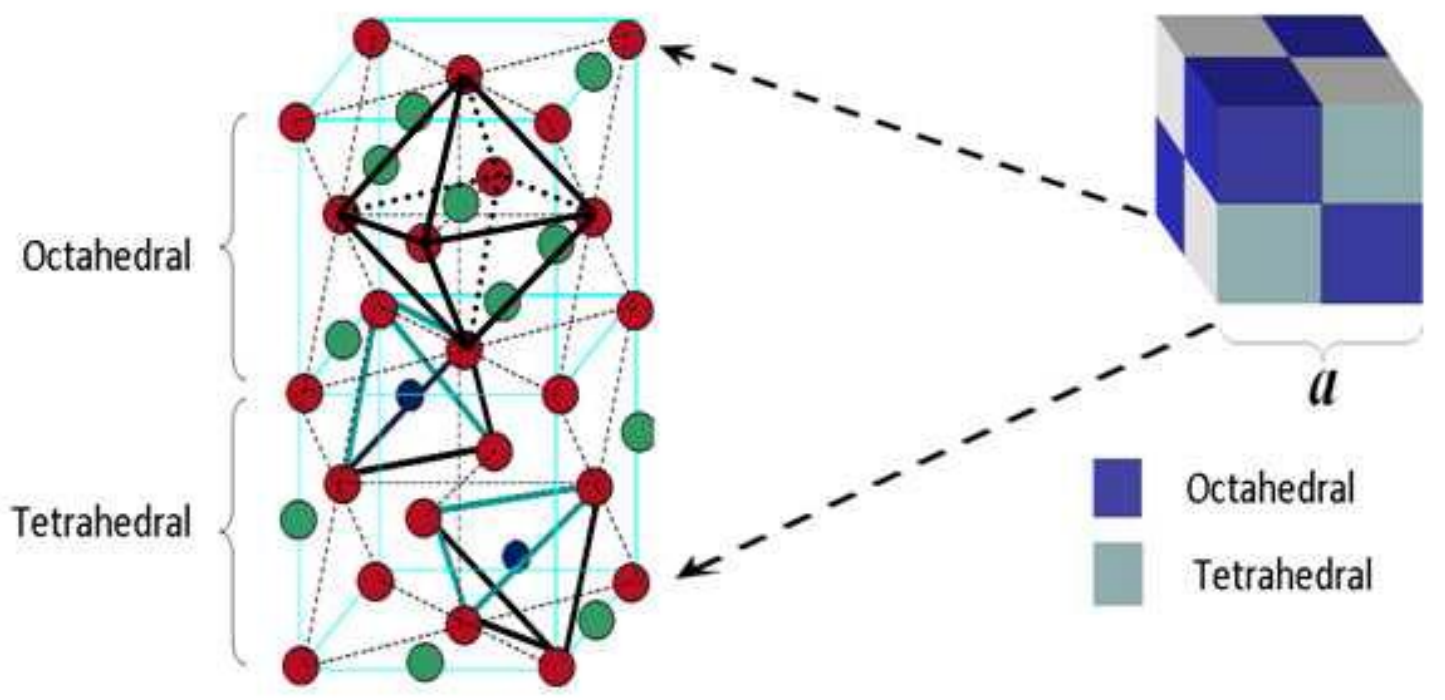

Figura 3- Estrutura do tipo espinélio.

Quando um dos cátions metálicos é o ferro trivalente, esses materiais são chamados de ferritas. As ferritas do tipo espinélio tem formula geral $\mathrm{MFe}_{2} \mathrm{O}_{4}$, sendo considerada bastante complexa, onde M, no caso dos EDL-MF, é um metal de transição, geralmente do grupo do ferro $\left(\mathrm{Fe}^{2+}, \mathrm{Co}^{2+}, \mathrm{Ni}^{2+}, \mathrm{Cu}^{2+}, \mathrm{Zn}^{2+} \mathrm{e} \mathrm{Mn}^{2+}\right)$ ou, uma combinação entre eles, formando uma estrutura de rede cúbica de face centrada (CFC), com íons de oxigênio.

Os espinélios podem ser classificados como diretos, inversos ou mistos de acordo com a disposição dos cátions nos interstícios, de tal maneira que a fórmula química é 
insuficiente para representar, de forma correta, a relação entre os constituintes de um espinélio. A representação cristalográfica é mais completa e pode ser utilizada para indicar os componentes de um espinélio, bem como a disposição destes nos interstícios:

$$
\left[M_{1-x}^{2+} \mathrm{Fe}_{x}^{3+}\right]_{A}\left[\mathrm{M}_{x}^{2+} \mathrm{Fe}_{2-x}^{3+}\right]_{B} \mathrm{O}_{4}^{2-}
$$

onde x é chamado de parâmetro de inversão ou grau de inversão.

Pela representação cristalográfica, vemos que quando existem somente os íons divalentes $\mathrm{M}^{2+}$ nos sítios tetraédricos e íons $\mathrm{Fe}^{3+}$ nos sítios octaédricos $(\mathrm{x}=0)$, o espinélio é dito normal ou direto e sua fórmula pode ser representada por $\left(\mathrm{M}^{2+}\right)_{\mathrm{A}}\left(\mathrm{Fe}^{3+}\right)_{\mathrm{B}} \mathrm{O}_{4}$ metade dos sítios $\mathrm{B}$ e os íons divalentes a outra metade dos sítios $\mathrm{B}(\mathrm{x}=1)$, o espinélio é dito inverso, podendo ser representado por $\left(\mathrm{Fe}^{3+}\right)_{\mathrm{A}}\left(\mathrm{Fe}^{3+} \mathrm{M}^{2+}\right)_{\mathrm{B}} \mathrm{O}_{4}{ }^{41}$. Quando a distribuição catiônica é intermediária a ferrita é dita mista.

A cristalização em uma estrutura espinélio, normal ou inversa, pelos metais estudados é governada pela energia de estabilização, que resulta da influência do campo cristalino ${ }^{40}$. No caso das ferritas, o metal trivalente é o ferro, de configuração $\mathrm{d}^{5}$, que não tem preferência entre os sítios A e B. Se $M^{2+}$ tem uma configuração $d^{6}, d^{7}, d^{8}$ ou d $d^{9}$, a estrutura inversa é preferida e se a configuração é $\mathrm{d}^{10}$, a estrutura normal é privilegiada. Em algumas ferritas, o grau de inversão é variável e depende do tratamento térmico sofrido pela amostra ${ }^{42}$.

As propriedades magnéticas associadas a uma ferrita estão ligadas às interações que podem existir entre os spins dos metais. As interações que podem ocorrer no interior de um sólido metálico são interações de troca e podem induzir alinhamentos paralelos ou antiparalelos dos spins, caso a interação aconteça entre sítios adjacentes. No caso das ferritas, sempre haverá um oxigênio entre os metais de sítios adjacentes. Dessa forma, as interações ocorrerão por intermédio dos orbitais p do ânion e nesse caso é denominada interação de 
super-troca $^{43,44}$. Os íons dos sítios A, assim como os íons dos sítios B, ocupam os nós de duas sub-redes de spins com ordenamento ferro ou antiferromagnético. As interações de supertroca entre estas duas sub-redes favorecem o alinhamento antiparalelo dos spins conduzindo a uma ordem antiferromagnética. Entretanto, devido à diferença entre o número de sítios $\mathrm{A}$ e $\mathrm{B}$, o comportamento global é ferrimagnético ${ }^{45}$.

\section{FERRITA DE COBALTO}

A ferrita de cobalto é um óxido com uma estrutura cristalina do tipo espinélio inverso, que tem uma alta coercitividade $^{46}$ e elevada remanência ${ }^{47}$, bem como baixa permeabilidade, magnetização de saturação moderada (cerca de $4.105 \mathrm{~J} / \mathrm{m}^{3}$ ) ${ }^{48}$, alta performance eletromagnética. Além disso, apresenta elevada anisotropia magnetocristalino cúbica, alta Temperatura de Curie $790 \mathrm{~K}^{49}$, excelente estabilidade química e mecânica, resistência ao desgaste e isolamento elétrico, magneticamente duro, ou seja, apresenta grande resistência à magnetização e desmagnetização, enquanto todas as outras ferritas são magneticamente macias ${ }^{50,51}$, a direção de fácil magnetização é a $\langle 100\rangle^{47}$, o que também é observado em ferritas mistas que contêm uma alta porcentagem de cobalto ${ }^{50}$ e com parâmetro de rede de aproximadamente $\mathrm{a}=0,835 \mathrm{~nm}$.

Diante de todas essas propriedades a ferrita de cobalto tem se mostrado promissora para diversas aplicações como: a gravações em discos digitais de alta densidade ${ }^{52}$, fluídos magnéticos, para a produção de ímãs permanentes ${ }^{53}$, diagnósticos médicos, liberação controlada de fármacos e sensores ${ }^{54}$, transporte de enzimas, tratamento de tumores por hipertermia, aplicações de alta frequência e catálise ${ }^{55}$, aparelhos de microondas, dispositivos magnético-óticos, entre outras aplicações discutidas anteriormente. A comercialização das ferritas envolve um investimento de milhões de dólares por ano ${ }^{56}$. 


\section{NANOPARTÍCULAS MAGNÉTICAS}

A síntese e aplicação das nanopartículas já estão presentes na história do homem desde muito tempo, mesmo que de forma empírica, como pode ser visto na Taça de Lycurgus (4 d.C.), que muda de cor de acordo com a luz incidente devido a nanopartículas de ouro ${ }^{57}$ mostrada na Figura 4. No século XIII já se utilizavam pigmentos à base de ouro, cobre, ferro e outros metais em escala nanométrica, nos vitrais de catedrais européias.

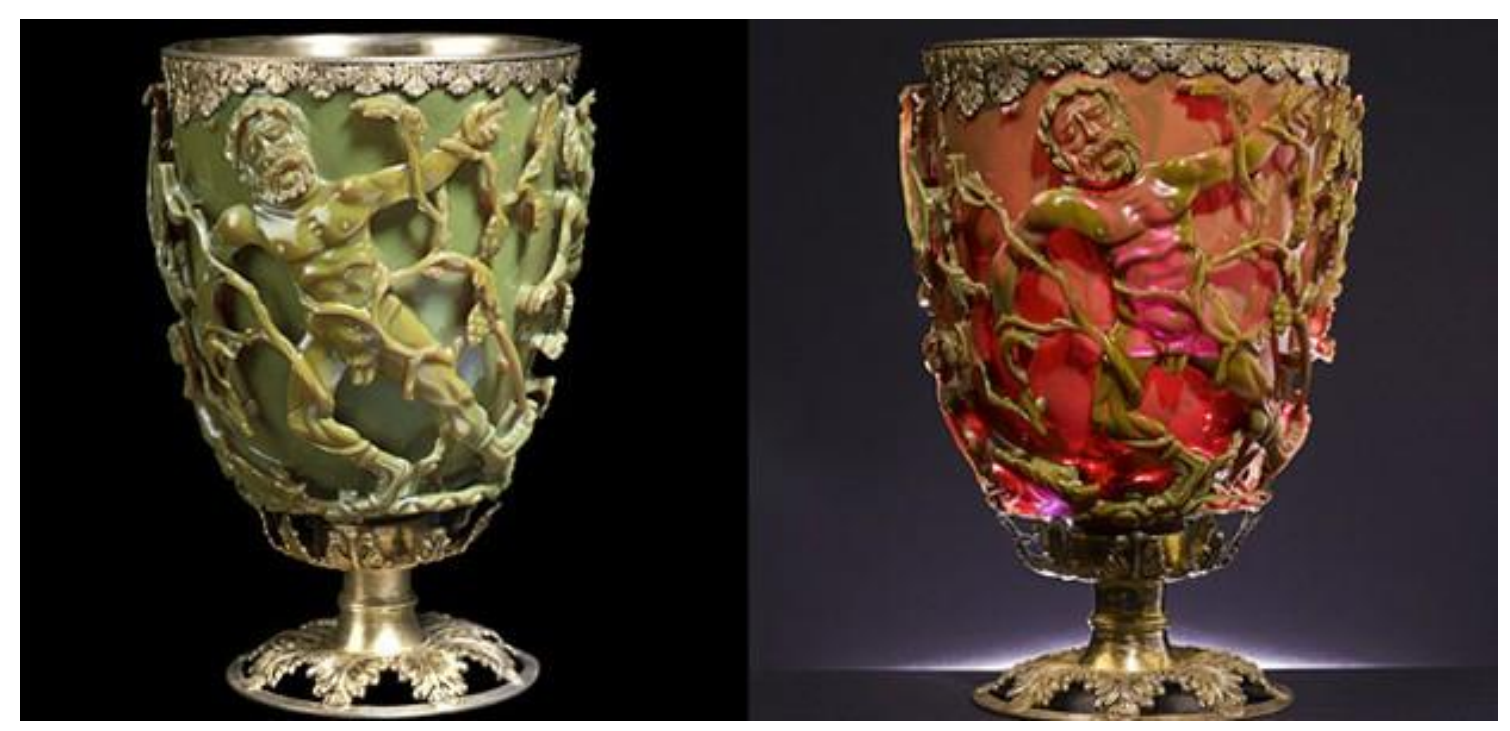

Figura 4-Taça de Lycurgus: uma das mais famosas antiguidades romanas, data do século IV d.C. fabricada com vidro contendo nanopartículas de ouro.

As nanopartículas magnéticas estão presentes na vida cotidiana mais do que se imagina. O espaço interestelar, amostras lunares e meteoritos possuem nanopartículas magnéticas em sua composição. A navegação geomagnética ajuda os animais que contém nanopartículas magnéticas em seus corpos, como pássaros migratórios e espécies marinhas. Uma proteína com propriedades magnéticas, a ferritina, está presente em quase todas células de plantas e animais, incluindo os seres humanos. O cérebro humano contém mais de $10^{8}$ nanopartículas magnéticas por grama de tecido ${ }^{58}$. 
Em contrapartida, o interesse pelo estudo e desenvolvimento sistemático de objetos e dispositivos em escala nanométrica é muito recente, muitos associam a palestra de Richard Feyman em $1959^{59}$ como marco da nanociência e nanotecnologia como atividade científica, com a palestra intitulada: "Há muito espaço lá embaixo". A partir de então, a busca pelo domínio dos métodos de síntese, destes materiais, tem sido uma constante, seja pelo primeiro método top down, nas décadas de 60 e 70, onde supermoinhos trituravam blocos de materiais magnéticos, até dimensões nanométricas, ou pelo método bottom-up, em uma reação de policondensação, por meio químico de síntese, que é mais rápido, barato e versátil, conseguindo partículas de diâmetros menores.

A grande motivação para o desenvolvimento de inúmeros métodos de controle da síntese está na possibilidade de controlar propriedades dos materiais tais como diâmetro, forma da partícula, características no interior da partícula, polidispersão em tamanho e reatividade química da superfície, através do controle dos parâmetros da síntese de nanopartículas. E consequentemente as propriedades magnéticas, anisotropia ótica, estabilidade coloidal, o que influenciará as possíveis aplicações tecnológicas.

Recentemente, muitos métodos de síntese foram relatados na literatura, como: Hidrotérmico $^{60,61} ; \quad$ Coprecipitação $^{62,63,64,65} ; \quad$ Pechinni $^{66} ; \quad$ Sol-Gel $^{67,68,69} ; \quad$ Microondas $^{70}$; Sonoquímico $^{71,72}$; Microemulsão $^{73,74,75,76}$.

\section{SÍNTESE DE FLUIDOS MAGNÉTICOS DO TIPO EDL}

Preparados a partir de nanopartículas obtidas por coprecipitação, os fluidos magnéticos, podem ser do tipo surfactado (utilizando ácido oléico para dispersar as nanopartículas em hidrocarbonetos) $)^{77,78}$ ou do tipo EDL, sendo disperso em meio aquoso ${ }^{79}$. 
O processo de elaboração de um nanocolóide magnético, do tipo EDL-MF, compreende três etapas simplificada na Figura 5, a saber: 1) Obtenção das nanopartículas; 2) Tratamento de superfície; 3) Peptização.

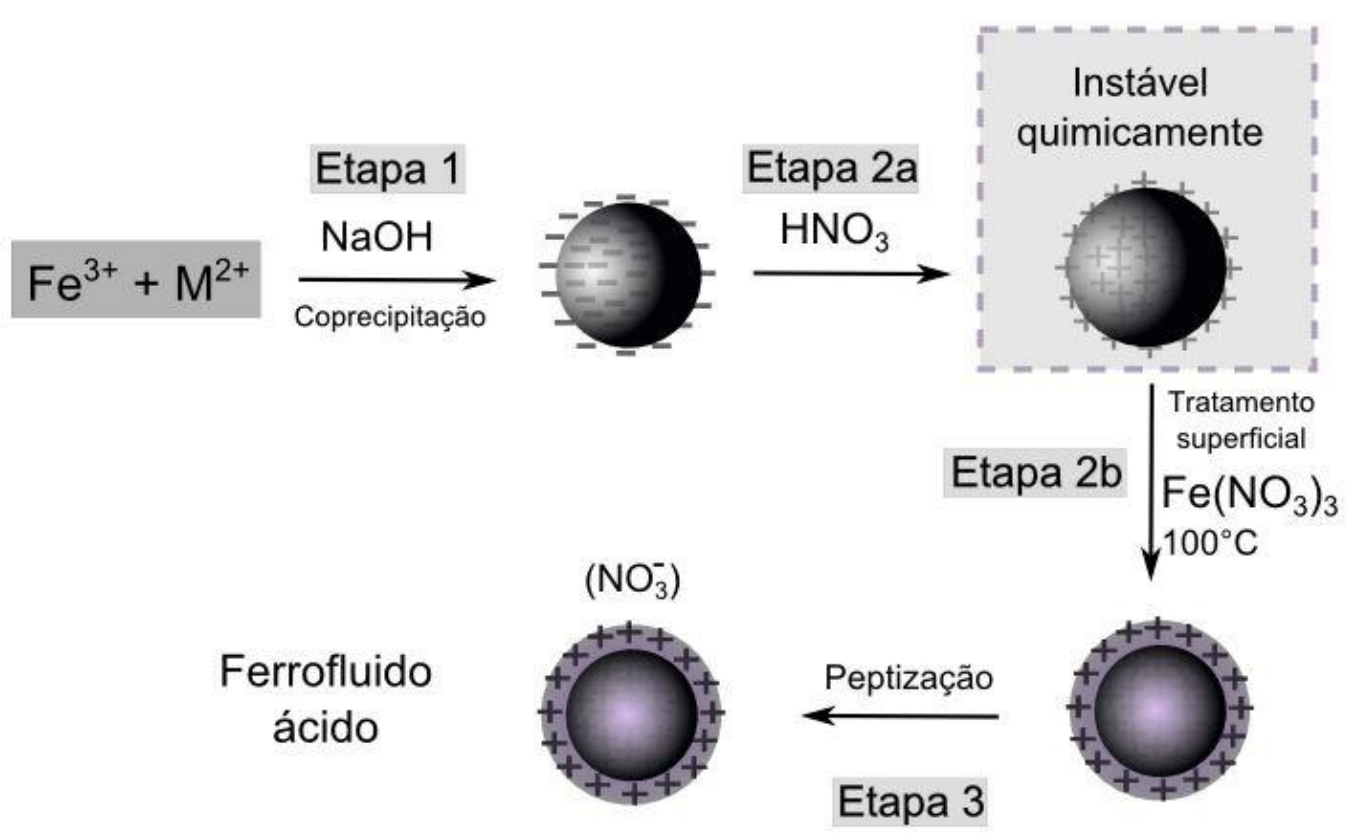

Figura 5- Diagrama esquemático de elaboração de ferrofluido do tipo EDL-MF.

\subsection{Obtenção das Nanopartículas}

A etapa 1 mostra a síntese química, bottom-up, obtida pela coprecipitação de uma mistura 2:1 de ferro trivalente $\left(\mathrm{Fe}^{3+}\right)$ e metal divalente $\left(\mathrm{M}^{2+}\right)$ das partículas de ferrita em meio alcalino hidrotérmico, onde $\mathrm{M}$ é um metal do tipo d-block (ferro, cobalto ${ }^{80}$, mangnes ${ }^{80}$, niquel $^{81}$, cobre ${ }^{81}$, zinco ${ }^{81}$ ). Há uma diferença essencial entre o íon $\mathrm{Fe}^{2+}$ e os outros metais divalentes: a coprecipitação de soluções de $\mathrm{Fe}^{2+} \mathrm{e} \mathrm{Fe}^{3+}$ (partículas de magnetita) ocorre à temperatura ambiente enquanto no caso de soluções de outros metais divalentes, as nanopartículas de ferrita são obtidas após ebulição. O método de coprecipitação hidrotérmica, assim como a reação de formação da ferrita serão objeto de estudo da Seção 8. 


\subsection{Tratamento de Superfície}

No fim da etapa 1, obtém-se nanopartículas em forma de precipitado, carregados negativamente, devido a alta força iônica presente no seio da dispersão, resultante dos co-íons e contra-1́ons dissociados pelos reagentes envolvidos na síntese. O próximo passo é subdividido em uma limpeza em meio ácido, para remover o excesso de co-íons e contra-íons, promovendo a dissolução de produtos secundários $^{16}$ (2a) e um tratamento químico de superfície das partículas com nitrato férrico $\left(\mathrm{Fe}\left(\mathrm{NO}_{3}\right)_{3}\right)$ a $100^{\circ} \mathrm{C}(2 \mathrm{~b})$. Esse procedimento empírico promove uma proteção do tipo core-shell, onde há um enriquecimento em ferro da superfície da partícula, o que evita sua dissolução em meio ácido ${ }^{15}$.

\subsection{Peptização}

No inicio da etapa 3 observa-se uma alta força iônica impossibilitando a peptização das partículas, devido a adsorção ${ }^{82}$. O excesso de nitrato férrico é então removido por decantação sobre uma placa magnética e as partículas são lavadas com acetona, no intuito de diminuir a força iônica e tornar as soluções mais estáveis antes da aspiração do sobrenadante. Com isso obtém-se uma força iônica suficientemente pequena ao ponto de permitir a dispersão dos nanogrãos dentro de uma solução de pH entre 2 e 3, no meio, estabilizando devido balanço de interações atrativas e repulsivas.

\section{SÍNTESE DE NANOPARTÍCULA POR COPRECIPITAÇÃO HIDROTÉRMICA}

Neste trabalho é utilizado o método de coprecipitação hidrotérmica, pois é mais versátil e efetivo, apresentando grandes vantagens na homogeneidade química, baixa 
temperatura de síntese, economia de tempo, equipamentos para produção de baixo custo, elimina a calcinação, possui elevado grau de pureza, possibilidade de sintetizar grandes quantidades e pode ser automatizado e mecanizado ${ }^{83}$. O que acarreta uma redução significativa nos custos de produção e variedade de aplicações tecnológicas ${ }^{84}$.

\subsection{Método Hidrotérmico}

A técnica de síntese hidrotermal usa uma autoclave para realização das reações químicas, que mantém a temperatura acima da temperatura e pressão ambientes para sintetizar o produto. Nessa condição supercrítica a água atua como um agente da reação, acelerando o processo cinético das reações de hidrólise. Com o aumento da temperatura, a solubilidade das espécies iônicas aumenta muito e com a baixa viscosidade da água exibem maior mobilidade. O aumento da mobilidade permite maior rapidez e uniformidade dos precipitados ${ }^{85}$.

O método hidrotérmico é amplamente utilizado para síntese de materiais cristalinos. A maioria das fases cristalinas que se obtém em condições hidrotermais, sob pressão autógena, é metaestável. Se o tempo de cristalização não for suficiente para a formação dos cristais, muitas fases cristalinas desaparecem e se formam outras de estabilidade relativa.

Este método segue o princípio de preparação de dissolução/precipitação, onde a força motriz para o processo é a diferença de solubilidade de pelo menos um reagente solúvel e o produto insolúvel. Variáveis importantes do processo são: a concentração dos reagentes, o tempo da reação, a temperatura e a pressão ${ }^{86}$, que influenciam no controle da morfologia e no tamanho dos precipitados. Já as condições do precursor e o pH têm um impacto na pureza da fase das nanopartículas ${ }^{87}$.

A transição de leves a severas condições é determinada principalmente pelos limites de corrosão e resistência dos materiais de construção que compreende os recipientes de reação 
hidrotermal. Intensas investigações levaram a um melhor entendimento da química hidrotermais, que reduziu significativamente o tempo de reação, temperatura e pressão de cristalização hidrotermal de materiais, sobre essa perspectiva, esta descoberta fez a síntese hidrotérmica mais econômica já que os processos podem ser projetados usando a tecnologia do reator de custo-eficácia comprovada e de pressão e metodologias já estabelecidas pela indústria química ${ }^{88}$.

\subsection{Método de Coprecipitação}

A Coprecipitação é o transporte para baixo de um precipitado de substâncias normalmente solúveis sob as condições empregadas ${ }^{89}$. Para obtenção de produtos de alta qualidade, efetua-se um rígido controle de $\mathrm{pH}$, temperatura, tipo e concentração de reagentes. Mudanças do $\mathrm{pH}$, do solvente ou a adição de um ânion formador de sal insolúvel favorece a precipitação simultânea. Ela pode ocorrer de duas maneiras

Para prever a formação, ou não, de precipitado, recorre-se ao cálculo de um quociente, denominado Quociente de Reação (Q) e do produto de solubilidade (Kps), que envolve o produto das concentrações dos íons envolvidos ,elevados aos respectivos coeficientes estequiométricos. Compara-se o valor de Q com Kps, podendo ocorrer três casos distintos:

- $\quad$ Se $\mathrm{Q}<\mathrm{Kps}$, não haverá precipitação.

- $\quad$ Se $\mathrm{Q}=\mathrm{Kps}$, a solução está saturada, não havendo precipitação.

- $\quad$ Se Q>Kps, há precipitação.

Ela pode ocorrer de duas maneiras ${ }^{90}$ :

i) Coprecipitação por adsorção superficial: qualquer precipitado tende a arrastar substâncias estranhas em consequência de adsorção superficial. Este tipo de coprecipitação 
tende a ser apreciável no caso de precipitados com grande área superficial, mas não é significativo em precipitados cristalinos.

ii) Coprecipitação por oclusão: a oclusão pode ser de íons na rede cristalina ou de água nas fendas de imperfeição do cristal formado.

Neste trabalho, obtemos as nanopartículas de ferrita de cobalto do tipo espinélio, através de uma reação de coprecipitação hidrotérmica em meio alcalino, referente a etapa 1 do esquema de síntese de fluídos magnéticos do tipo EDL. O balanço da equação global é dada por:

$$
2 \mathrm{Fe}_{(a q)}^{3+}+\mathrm{M}_{(a q)}^{2+}+8 \mathrm{OH}_{(a q)}^{-} \mapsto \mathrm{MFe}_{2} \mathrm{O}_{4(s)}+4 \mathrm{H}_{2} \mathrm{O}_{(l)}
$$

A equação acima traduz um balanço global do processo de síntese da nanopartícula e, portanto, não revela a ocorrência de etapas intermediárias complexas de policondensação inorgânica. Durante essas etapas, que ainda não estão muito bem estabelecidas na literatura, é que se pode controlar o diâmetro final da partícula. Quando metais do tipo d-block são disseminados em água, formam-se aquocomplexos ou aquocátions que sofrem um processo de hidrólise $\mathrm{pH}$ dependente. A reação geral pode ser representada por ${ }^{91}$ :

$$
\left[\mathrm{M}\left(\mathrm{OH}_{2}\right)_{x}\right]^{z+}+a \mathrm{H}_{2} \mathrm{O} \rightleftharpoons\left[\mathrm{M}\left(\mathrm{OH}_{2}\right)_{(x-a)}(-\mathrm{OH})_{a}\right]^{z-a}+a H_{3} \mathrm{O}^{+}
$$

$\mathrm{O}$ aumento do $\mathrm{pH}$ da dispersão acelera a desprotonação dos aquocomplexos que sofrem polimerização com posterior precipitação. As polimerizações ocorrem por meio da formação de pontes do tipo hidroxila, principalmente duplas ${ }^{92}$, entre os aquocomplexos 
durante as etapas intermediárias dos equilíbrios ácido-base envolvidos na hidrólise. Devido a uma dificuldade de isolamento, poucas espécies intermediárias do processo de coordenação têm sido caracterizadas. Especificamente para o íon $\mathrm{Fe}^{3+}$ são conhecidos dois monômeros e um dímero ${ }^{93}$. Este último surge como resultado da formação de pontes hidroxila entre os cátions metálicos. Os dímeros originados podem levar a uma sequiência de reações de condensação conhecidas como olações e oxolações que acarretam geração de sistemas complexos via pontes ${ }^{92}$ hidroxo e oxo, respectivamente representadas pelas equações:

$$
\begin{gathered}
\mathrm{Fe}^{\prime}-\mathrm{OH}+\mathrm{Fe}-\mathrm{OH}_{2} \rightarrow \mathrm{Fe}-\mathrm{OH}-\mathrm{Fe}+\mathrm{H}_{2} \mathrm{O} \\
\mathrm{Fe}-\mathrm{OH}+\mathrm{Fe}-\mathrm{OH} \rightarrow \mathrm{Fe}-\mathrm{O}-\mathrm{Fe}+\mathrm{H}_{2} \mathrm{O}
\end{gathered}
$$

O mecanismo de formação das ferritas passa por um processo de dissolução e cristalização de íons a partir de um precipitado amorfo ou mal estruturado, que é constituído de hidróxidos do metal divalente $\left(\mathrm{M}(\mathrm{OH})_{2}\right)$ e de oxi-hidróxidos de $\mathrm{Fe}^{3+}(\mathrm{FeOOH})^{94}$. Estes últimos conduzem a espécies polinucleares mistas intermediárias que funcionam como germes para o modelo do cristal. Por meio de reações de olação, esses germes originam cadeias e planos cuja associação é promovida pela oxolação das espécies férricas em excesso na dispersão. Em função de parâmetros estéricos e da energia de estabilização do campo cristalino, os cátions metálicos organizam-se nos sítios de uma estrutura tipo espinélio.

Após as sucessivas reações de condensação e decorrentes polimerizações, originamse precipitados particulados, óxidos cristalinos dos metais, que servem como centros iniciais de formação das partículas. Durante essas etapas ocorrem fenômenos de nucleação e de crescimento do cristal, cruciais no controle do tamanho e da polidispersão das partícula.

A nucleação é iniciada logo após a supersaturação das espécies iniciais e cessa quando a concentração destas espécies torna-se bastante pequena, quando o crescimento 
cristalino vem a ser o fenômeno predominante: os precursores condensam-se em torno dos germes existentes. Nessa etapa a difusão é um fator dominante e as variações de concentração e temperatura tornam-se predominantes na velocidade da reação ${ }^{95,96}$. A energia livre para a formação dos núcleos iniciais, consiste na energia ganha no estabelecimento das ligações e o trabalho necessário para criar a interface, de maneira que núcleos só são formados caso a energia de ativação, $\Delta \mathrm{G}^{*}$, seja ultrapassada:

$$
\Delta G^{*}=\frac{16 \pi \gamma^{3} V^{2}}{3\left[k_{B} T \ln \left(a / a_{0}\right)^{2}\right]},
$$

Em que, $\mathrm{K}_{\mathrm{B}}$ é a constante de Boltzmann, $\mathrm{T}$ é a Temperatura, $\mathrm{V}$ o Volume do núcleo, $\gamma$ a tensão interfacial, assumida independentemente do núcleo, a é a concentração dos reagentes dispersos e $\mathrm{a}_{0}$ é a solubilidade desse reagente na temperatura $\mathrm{T}$. De modo que a razão entre a e $a_{0}$ de maior magnitude favorece a nucleação e uma razão de menor magnitude favorece o crescimento cristalino.

Esta barreira energética pode ser interpretada pela expressão da variação da energia de reação referente a formação das partículas:

$$
\begin{gathered}
\Delta G_{R}=\Delta G_{S}+\Delta G_{V} \\
\Delta G_{R}=4 \pi r^{2} \gamma+\frac{4}{3} \pi r^{3} \Delta G_{v}
\end{gathered}
$$

sendo:

$$
\Delta G_{v}=(-R T \ln S) / V_{m}
$$

Onde, $\Delta \mathrm{G}_{\mathrm{R}}$ é a variação da energia livre da reação para a formação de partículas esféricas de raio $\mathrm{r}$ em uma solução supersaturada $\mathrm{S}$, no qual ${ }^{\gamma}$ é a energia de superfície, $\Delta \mathrm{G}_{\mathrm{v}}$ refere-se a 
variação da energia livre entre o soluto em solução e no sólido maciço por unidade de volume e Vm é o volume molar do sólido maciço. $\Delta$ Gs representa a variação de energia relacionada a superfície da partícula e o termo $\Delta \mathrm{Gv}$ a variação de energia relacionada a formação da partícula. Tais equações podem ser rearranjadas para a determinar o raio crítico de nucleação fazendo-se $d \Delta \mathrm{G} / d \mathrm{r}=0$, que pode ser interpretado pelo gráfico da energia livre da reação pelo raio da partícula (Figura 6) ${ }^{97,98}$.

$$
r_{c}=\left(2 \gamma V_{m}\right) /(R T \ln S)
$$

Cada material possui um raio crítico de nucleação a uma dada supersaturação e temperatura onde os núcleos formados com raio a cima do raio crítico, tendem a crescer e núcleos com raio menor tendem a se dissolverem. Logo, três fatores influenciam diretamente no comportamento a nucleação, são eles a supersaturação, a temperatura e a energia de superfície.

A monodispersividade é alcançada quando, primeiramente, a nucleação ocorre rapidamente em um curto período de tempo através de uma solução supersaturada seguida de uma etapa de crescimento lenta sem que uma significante nucleação ocorra novamente, favorecendo a formação de nanopartículas pequenas e monodispersas, processo I. Ou quando pequenas partículas se dissolvem para posterior reposição sobre a superfície das partículas maiores, envelhecimento de Ostwald, processo III. Porém quando acontece processos de maturação e agregação levam a polidispersividade do sistema, processo II, demonstrado na Figura $6 .{ }^{99,100,101,102}$. 

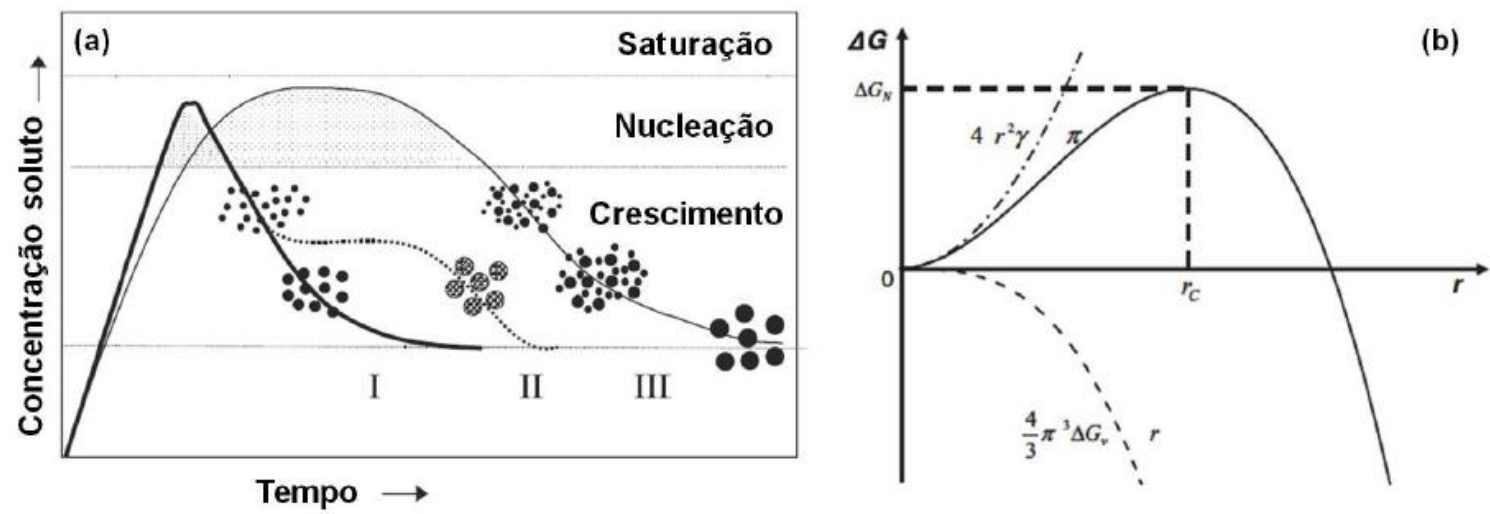

Figura 6- Mecanismo de formação de partículas uniformes baseados no modelo clássico de LaMer e Dinegar ${ }^{102}$.

Através da etapa de nucleação ou de formação de germes cristalinos é que se pode controlar o tamanho e a polidispersão dos objetos a serem obtidos logo após o crescimento cristalino, as taxas relativas com o que estes dois fenômenos acontecem é que vão definir o diâmetro final da partícula. O monitoramento destes dois fenômenos permite o controle de várias propriedades das partículas elaboradas, tais como morfologia e distribuição geométrica. Tanto o crescimento como a nucleação pode ocorrer concomitantemente ${ }^{103}$. Caso a nucleação seja predominante em relação ao crescimento cristalino, é nítida a formação de partículas menores. Caso contrário, partículas maiores são esperadas. Em decorrência, algumas propriedades do fluido resultante como a magnetização de saturação e a anisotropia ótica (birrefringência) também podem ser monitoradas, já que dependem diretamente das características estruturais e morfológicas das nanopartículas sintetizadas. Porém, isso por si só, não determina as propriedades dos materiais uma vez que o monitoramento do $\mathrm{pH}$, rapidez com que os reagentes são adicionados à mistura, a concentração inicial, velocidade de agitação, concentração, temperatura, razão molar, entre outras, vão influenciar diretamente no tamanho da partícula, que afeta diretamente as características da nanopartícula produzida ${ }^{104}$.

Tendo que a velocidade de nucleação é regida pelo grau de supersaturação dos reagentes e a velocidade de crescimento pela difusão dos mesmos até o germe do cristal, 
parâmetros como a velocidade de agitação, temperatura e velocidade de adição da base, concentração de reagentes e $\mathrm{pH}$ tornam-se fatores decisivos no controle de formação e crescimento da nanopartícula ${ }^{101,105}$.

A natureza e a concentração da base utilizada ${ }^{106}$ podem gerar efeitos importantes no produto final obtido, influenciando no tamanho da partícula. Em $\mathrm{pH}$ mais elevado ocorre o favorecimento do crescimento cristalino. Em pH mais baixo, ou seja, na utilização de bases mais fracas ocorre o favorecimento da nucleação.

A velocidade de adição dos reagentes também tem um papel importante no tamanho das partículas. Se a adição é rápida, instantânea, ocorrerá a formação de vários núcleos ao mesmo tempo, com isso há a formação de partículas pequenas. Em contrapartida, se a velocidade de adição dos reagentes for lenta, ocorre primeiramente a formação de núcleos e como a segunda adição será feita em um tempo posterior, ocorrerá o crescimento cristalino sobre esses primeiros núcleos formados, tendo-se assim a formação de partículas grandes ${ }^{107}$.

A temperatura tem um papel importante no alcance da termodinâmica necessária para formação das nanopartículas. Além disso, com o aumento da temperatura de síntese, o movimento das partículas torna-se mais rápido, acelerando a nucleação secundária (fragmentos de cristais que podem transformar-se em novos núcleos), facilitando o crescimento de partículas menores ${ }^{108,109,110}$. E o favorecimento da formação da fase pura do material $^{111}$.

Quando a velocidade de agitação aumenta, o número de colisões também aumenta, ocasionando uma maior quantidade de germes de nucleação, com consequente redução do tamanho médio das partículas ${ }^{101,112}$.

Na literatura são relatados alguns trabalhos com variação dos parâmetros de síntese, tais como: o efeito dos íons $\mathrm{OH}^{-}$na reação de Coprecipitação ${ }^{113}$,variação da agitação no 
processo de síntese ${ }^{114}$, variação da temperatura ${ }^{115}$, o efeito do recozimento ${ }^{116}$, variação no tempo de digestão ${ }^{117}$.

\section{CARACTERIZAÇÃO DAS NANOPARTÍCULAS}

\subsection{Difração de Raio-X}

Em 1895 com a descoberta da radiação denominada por Röntgen de raio-x ${ }^{118}$ houve um grande interesse da comunidade científica e o seu estudo foi largamente difundido. $\mathrm{O}$ estudo dessa radiação levou a compreensão de sua natureza possibilitando a utilização em diversa aplicações, sendo a mais popular na área da medicina para diagnose, a radiografia (Figura 7).

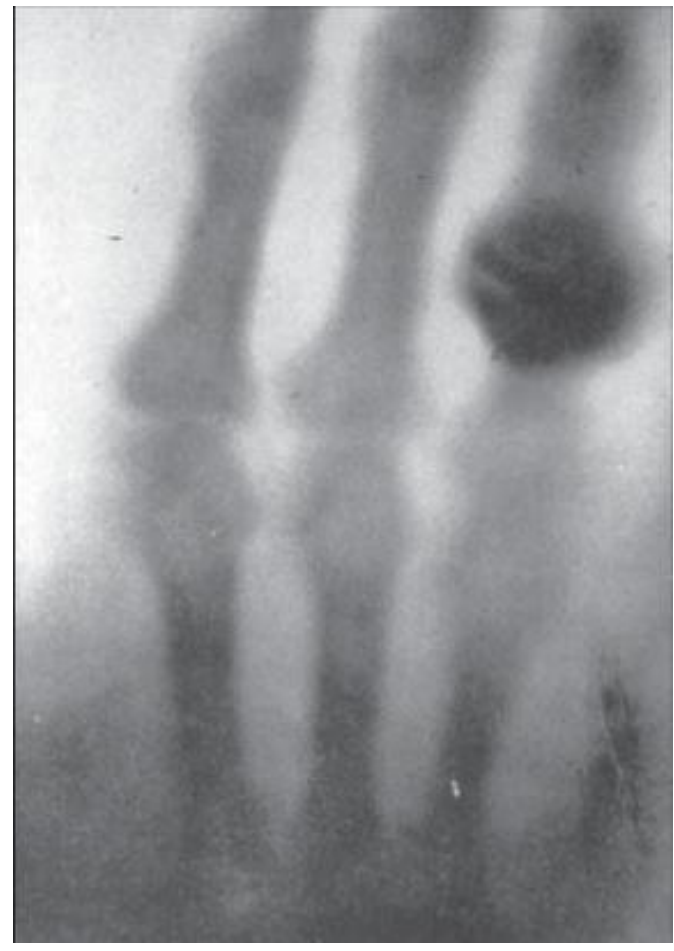

Figura 7- Primeira radiografia humana da mão da esposa de Röntgen ${ }^{119}$ 
Em 1912, Laue apresentou um trabalho ${ }^{34}$ sobre o efeito de interferência com os raios de Röntgen, onde observou que o cristal se comportava como uma rede de difração tridimensional. Iniciando assim o estudo do estado sólido por difração de raios-x, porém com uma analise complexa. Foi então que em 1913, Bragg propôs uma interpretação em termos de reflexão pelos planos cristalinos, facilitando a interpretação introduzida por Laue, em termos de reflexão sobre os planos reticulares do cristal.

A partir de então a técnica de difração de raios-x tornou-se fundamental no estudo da matéria condensada, pois esta permite a investigação do arranjo ordenado dos sólidos (simetria cristalina, parâmetros de rede, distâncias interplanares, defeitos estruturais) ${ }^{16}$, além de se destacar pela simplicidade, rapidez e confiabilidade ${ }^{120}$. Em conseqüência, vem sendo utilizada por muitos pesquisadores como forma de identificação e caracterização dos compostos cristalinos, possibilitando a identificação do diâmetro médio das nanopartículas, que é de fundamental importância, pois as propriedades magnéticas e magneto-óticas, assim como a estabilidade coloidal são diretamente influenciadas pelo volume, proporcional ao cubo do diâmetro da partícula.

Essa técnica é baseada na interação da radiação eletromagnética com a estrutura cristalina, cujas dimensões características são comparáveis com os comprimentos de onda da radiação. Desta forma, assumindo que um feixe de onda eletromagnética altamente energética monocromática, raios-x de comprimento de onda $\lambda$ incida em um sólido cristalino a um ângulo $\theta$, medido entre o raio incidente e o plano cristalino, padrões de difração surgem, como pode ser visto na Figura 8. 


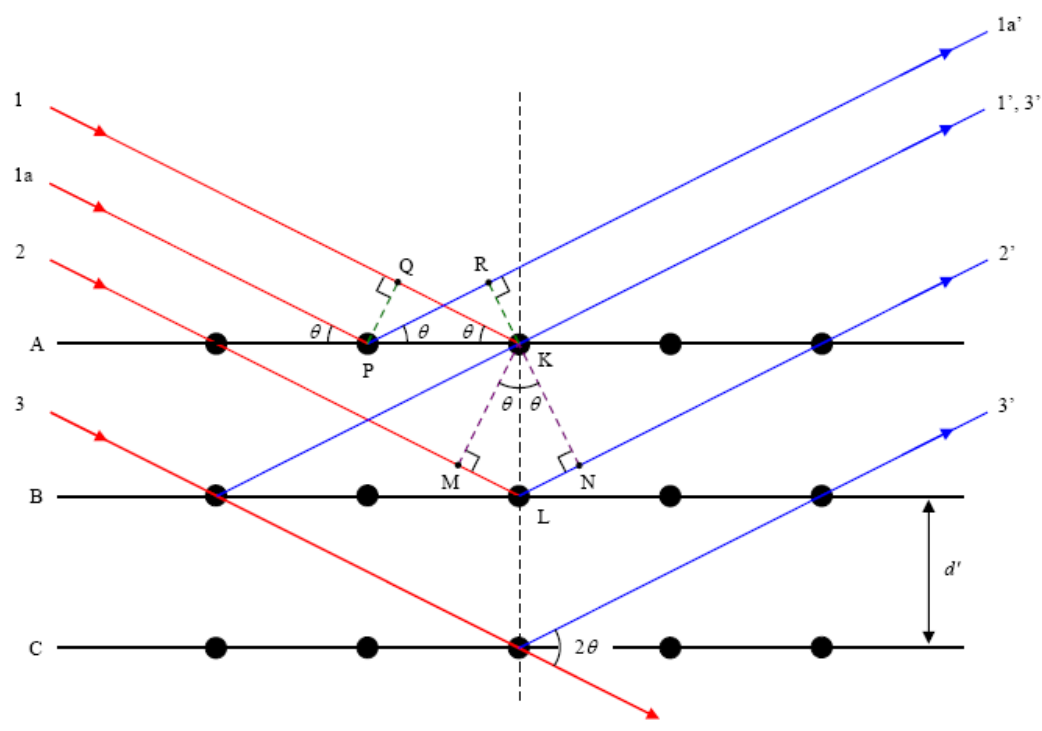

Figura 8- Esquema de difração em um cristal.

Obtém-se raios difratados somente quando os raios refletidos pelos planos paralelos interferem de modo aditivo. Essa diferença de caminho é tal que, para que haja interferência construtiva entre os raios, a diferença deve ser um múltiplo inteiro de comprimentos de onda. A ocorrência da difração é investigada pela lei de $\mathrm{Bragg}^{121}$, que relaciona o ângulo de difração $(\theta)$, o comprimento de onda $(\lambda)$ da radiação e as distâncias interplanares da rede $\left(\mathrm{d}_{\mathrm{hkl}}\right)$ de uma família de planos reticulares $\{h k l\}$ :

$$
2 \mathrm{~d}_{\mathrm{hkl}} \operatorname{sen} \theta=n \lambda
$$

onde $\mathrm{n}$ é a ordem da interferência. As distâncias interplanares, calculadas pela expressão anterior, e a intensidade relativa dos picos de difração são comparados aos valores ASTM (American Society for Testing Materials) para a ferrita de cobalto ${ }^{122}$, com o objetivo de identificar a estrutura cristalina da nanopartícula.

A magnitude das distâncias entre os dois planos de átomos adjacentes e paralelos é uma função dos índices de Miller (h, k e l) ${ }^{123}$. Os índices h, k e 1 definem as famílias de 
planos cristalinos em uma rede de difração. Para as estruturas cristalinas de simetria cúbica do tipo espinélio, a relação entre a distância interplanar e os índices de Miller é feita através da expressão:

$$
d_{h k l}=\frac{a}{\sqrt{h^{2}+k^{2}+l^{2}}}
$$

em que $a$ representa o parâmetro da rede cristalina.

Uma rede cristalina é composta pela repetição infinita e periódica de uma base, de forma que, a intensidade difratada corresponde a uma linha infinitamente fina. A redução da extensão do cristal, conduz a um alargamento do pico de difração, demonstrando uma relação entre o tamanho do cristal e a largura do pico de difração, dados pelo formalismo de Scherrer.

Utilizando-se o formalismo de Scherrer, difratogramas obtidos em amostras policristalinas (pó) conduzem à determinação do diâmetro médio das partículas. Os picos de difração indexados são característicos da estrutura cúbica do tipo espinélio. A largura dos picos está fundamentalmente ligada à dimensão nanométrica das partículas. A equação de Scherrer ${ }^{124,125}$ tem por base a condição de que se um cristal de tamanho $D_{R X}$ (assumido aqui como esférico) possui um número de planos refletores limitados, o feixe difratado é modificado de tal maneira que o tamanho do cristal passa a depender da largura a meia altura do pico de maior intensidade. A equação de Scherrer é:

$$
D_{R X}=\frac{K \lambda}{\beta \cos \theta}
$$

em que $\beta$ é a largura a meia altura do pico de difração (de Bragg em radianos) ${ }^{121}$; $\mathrm{k}$ é igual a 0,9 , para estruturas esféricas; $\lambda$ é o comprimento de onda da radiação usada ; $\theta$ é o ângulo de difração de Bragg do ponto máximo do pico mais intenso, que neste caso, equivale a difração dos planos[311] para estrutura do tipo espinélio. 
Essa fórmula é válida para estimar tamanhos de grãos menores que 100 nm, uma vez que os valores da largura da meia altura do pico de máxima intensidade decrescem com o aumento do tamanho de grão, sendo praticamente nulos quando o tamanho da partícula é maior que $100 \mathrm{~nm}^{41}$.

Observa-se que os diâmetros obtidos por difração de raios-x, são geralmente maiores do que aqueles provenientes de microscopia eletrônica. Este fato é inerente ao método utilizado, pois na difração de raios-x todas as partículas cristalinas contribuem de maneira idêntica à largura do feixe difratado, enquanto que, na microscopia eletrônica eventuais agregados, assim como partículas maiores, não são levados em conta ${ }^{16}$.

\subsection{Espectroscopia por Energia Dispersiva de Raios-X}

A espectroscopia por energia dispersiva de raios-x (EDX) é uma técnica utilizada para fazer a análise química de materiais maciços e permite a caracterização estequiométrica de uma amostra. Neste trabalho, utilizaremos a técnica, para determinar as razões entre as concentrações dos elementos $\mathrm{Fe} / \mathrm{Co}$. No caso da ferrita de cobalto essa relação estequiométrica é dada por uma fração molar do metal divalente onde o resultado ideal $\chi_{\mathrm{M}}$ é aproximadamente 0,33 , dada por:

$$
\chi_{M}=\frac{\left[\mathrm{Co}^{+2}\right]}{\left[\mathrm{Co}^{+2}\right]+\left[\mathrm{Fe}^{+3}\right]}=\frac{1}{3}
$$

Para essa análise, utilizaremos de um espectrômetro de EDX da Shimadzu, modelo EDX-720, que analisa a faixa de elementos que vai do sódio $\left({ }_{11} \mathrm{Na}\right)$ ao urânio $\left({ }_{92} \mathrm{U}\right)$. Seu funcionamento baseia-se na medida das intensidades dos raios $\mathrm{x}$ característicos (número de 
raios $\mathrm{x}$ detectados por uma unidade de tempo) emitidos pelos elementos que constituem a amostra, quando devidamente excitada ${ }^{126}$.

Para que ocorra a excitação de um átomo de um elemento presente na amostra, e a emissão de raios-x característicos, um feixe de partículas focalizado, de alta energia carregadas de raios-x, é bombardeado na amostra estudada. Ocasionando a ejeção dos elétrons dos níveis mais internos, de menor energia, o que consequentemente fará com que os elétrons mais externos, de maior energia, realizem um salto quântico afim de preencher a vacância deixada pelo elétron ejetado. Cada transição eletrônica constitui uma perda de energia para o elétron, e esta energia é emitida na forma de um fóton de raio $\mathrm{x}$, de energia característica e bem definida para cada elemento.

Sendo assim, partindo do principio que cada elemento possui uma única estrutura atômica, o número e a energia dos raios-x emitidos a partir de uma amostra podem ser medidos por um espectro de energia dispersiva. Como a energia dos raios-x característicos fornece a diferença de energia entre os dois orbitais e portanto a estrutura atômica do elemento a partir do qual foram emitidos, permite que a composição química da amostra seja identificada.

\subsection{Espectrometria de Absorção Atômica}

Os metais quando excitados por uma fonte de calor absorvem radiação em um determinado comprimento de onda característico para cada material. Cada elemento tem um número específico de elétrons associados com seu núcleo. A configuração mais estável de um átomo é denominada estado de energia mais baixo ou estado fundamental e representa a forma como este é comumente encontrado no estado gasoso. Se uma determinada quantidade de energia é aplicada sobre o átomo e esta é absorvida, um dos elétrons mais internos será 
promovido a um nível energético superior, levando o átomo a uma configuração energética menos estável denominada estado excitado. Uma vez que esta configuração é instável, após alguns nanosegundos os átomos excitados relaxam para seu estado fundamental, liberando a energia absorvida sob a forma de luz. Este processo de absorção é explorado, com fins analíticos, através das técnicas de espectroscopia de emissão atômica-AAS (Atomic Absorption Spectrometry).

A espectrometria de absorção atômica, foi introduzida em 1955 por Walsh na Austrália e por AlKemade e Milatz na Holanda. E em 1959 foi comercializado o primeiro espectrômetro de absorção atômica, que atraiu bastante interesse, mostrado pelo crescente número de publicações a partir de 1960, devido a sua simplicidade, efetividade e baixo custo de operação. Este interesse é mais evidenciado analisando-se o número de laboratórios que adquiriram este equipamento, principalmente os laboratórios industriais. Considerada como uma técnica analítica bem sucedida é uma das mais utilizadas na determinação do teor dos elementos em baixas concentrações, através da medição da absorção de radiação por parte da amostra, seguindo a lei de Lambert-Beer ${ }^{127}$.

$$
\mathrm{A}=\varepsilon b c
$$

em que $\varepsilon$ é a absortividade molar, b é o comprimento de onda emitido pela chama e c a concentração do analito. No geral, é construída uma curva de calibração a partir de soluções padrão dos analitos e determina-se sua concentração através da equação da reta obtida experimentalmente. Neste trabalho esta técnica foi utilizada para determinar a concentração de Fe e Co nas amostras desta dissertação.

Para se determinar os elementos é necessário levar os analitos, por meio de chamas a altas temperaturas, a condição de uma dispersão atômica gasosa através da qual se faz passar, 
então, o feixe de radiação de uma fonte apropriada. A fonte é uma lâmpada de catodo oco que emite radiação na região do comprimento de onda na qual a espécie química absorve. A absorção se processa a custa de transições eletrônicas do estado fundamental a um estado energético mais alto. Devido as transições eletrônicas envolvendo os elétrons mais externos, é possível determinar um espectro de absorção formado por uma série de estreitas raias características para cada espécie atômica. Sendo a energia quantizada, a diferença entre a radiação emitida pela lâmpada e a que chega ao registrador nos dá o valor da absorbância da amostra estudada, portanto, proporcional a concentração do analito ali presente.

As análises químicas do material foram realizadas no laboratório de química do Grupo de Fluidos Complexo, no Instituto de Física da Universidade de Brasília. Os teores dos metais foram determinados por meio da técnica de espectroscopia de absorção atômica de chama, utilizando um espectrômetro Thermo SCIENTIFIC, modelo Solar S4, equipado com lâmpada multielementos para determinar ferro e cobalto. A chama utilizada para a atomização foi obtida pela mistura de ar e gás acetileno. Para a determinação de ferro, o comprimento de onda foi selecionado em $372 \mathrm{~nm}$ e a altura do queimador em 6,2 mm. Já para a dosagem de cobalto, esses parâmetros foram ajustados em 240,7 nm e 7,8 mm, respectivamente. As curvas de calibração foram confeccionadas a partir de padrões 1000 ppm de ferro e cobalto, com os pontos das curvas variando as concentrações entre 0 e 5 ppm para o ferro e 0 e 2,5 ppm para o cobalto. A partir das curvas de calibração, foram determinadas as concentrações dos metais que formam as amostras investigadas. As amostras analisadas neste trabalho se encontram na forma de pó e a preparação de cada uma delas foi feita de acordo o seguinte procedimento:

$105 \mathrm{mg}$ da amostra ECoB200, 102mg da amostra ECoB250, 101mg da amostra ECoBG 250, 100mg da amostra ECoB2G250 e 102mg da amostra ECoBA250,foram digeridas separadamente com $10 \mathrm{~mL}$ de ácido clorídrico $(\mathrm{HCl})$ concentrado e sob fervura. Em 
seguida cada solução resultante foi resfriada e diluída em balões volumétricos de $500 \mathrm{~mL}$, com solução de $\mathrm{HNO}_{3} 2 \%$.

Alíquotas das amostras foram separadas e analisadas no espectrômetro de absorção atômica medindo-se o teor de $\mathrm{Fe}^{3+}$ em presença de cobalto e o teor de $\mathrm{Co}^{2+}$ em presença de ferro, em ambas as amostras.

Foram obtidos valores de absorbância para as soluções preparadas. As medidas realizadas com os pontos da curva de calibração são expressas pelos gráficos de absorbância versus concentração da espécie. As curvas de calibração construídas para determinar os metais nas amostras são expressas pelas Figuras 9 e 10:

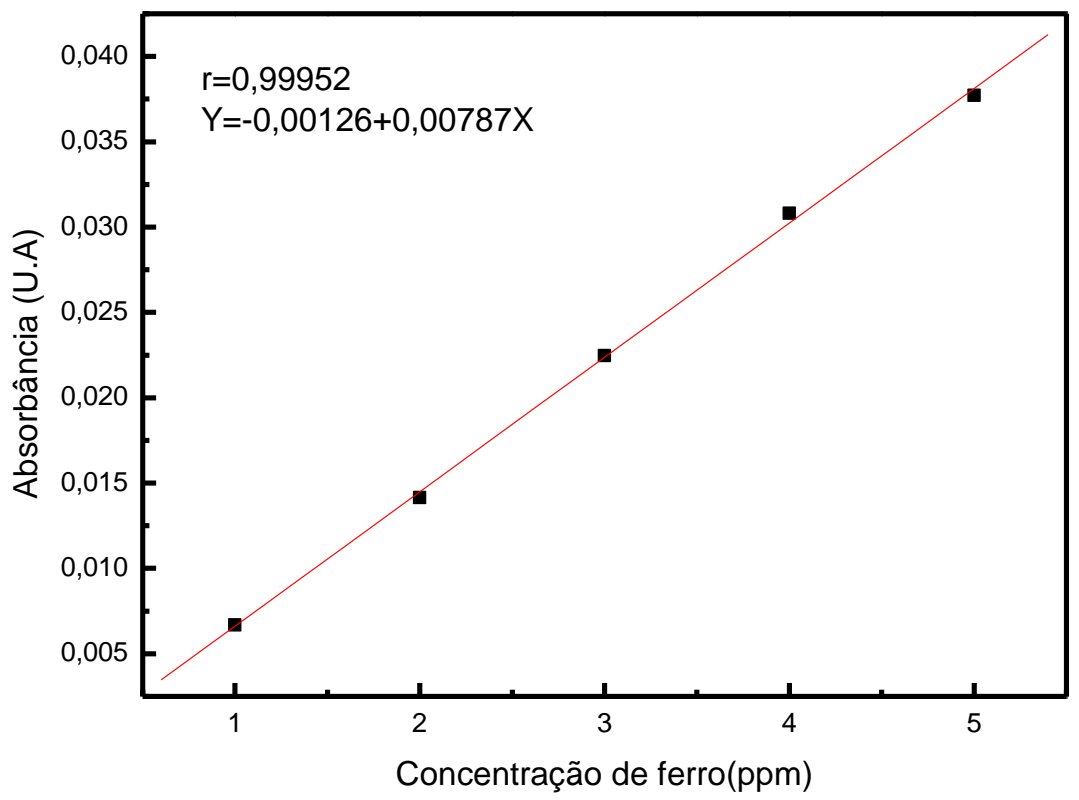

Figura 9- Curva de calibração com respectiva equação linear da reta obtida na determinação de ferro. 


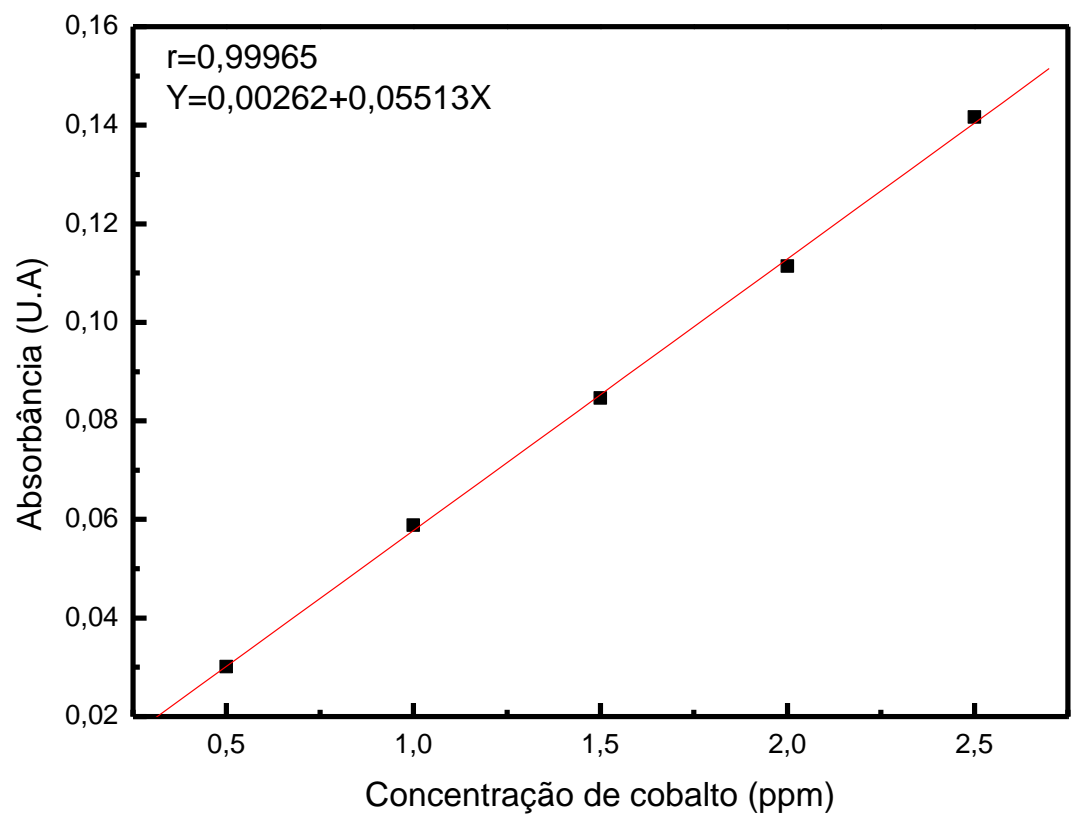

Figura 10- Curva de calibração com respectiva equação linear da reta obtida na determinação de cobalto.

Tabela 1- Resultado de AAS para as amostras selecionadas

\begin{tabular}{|c|c|c|c|}
\hline Amostra & {$[\mathrm{Fe}] \mathrm{mol} / \mathrm{l}$} & {$[\mathrm{Co}] \mathrm{mol} / \mathrm{l}$} & Relação $\left(\chi_{\text {AAS }}\right)$ \\
\hline ECoB200 & 0,087003 & 0,041438 & 0,322623 \\
\hline ECoB250 & 0,081735 & 0,040431 & 0,330951 \\
\hline ECoBG250 & 0,087632 & 0,037959 & 0,302243 \\
\hline ECoB2G250 & 0,082805 & 0,036092 & 0,303557 \\
\hline ECoBA250 & 0,077965 & 0,038035 & 0,327888 \\
\hline
\end{tabular}

\subsection{Microscopia Eletrônica de Transmissão- TEM}

O conhecimento sobre a estrutura dos matérias sempre esteve atrelado ao desenvolvimento de técnicas e equipamentos experimentais, passando pelas primeiras lupas rudimentares até o microscópio eletrônico, proposto por Knoll e Ruska em 1932. Desta forma, hoje, a microscopia eletrônica de transmissão é uma das técnicas mais usadas e uma das mais eficientes e versáteis ferramentas para caracterização de materiais, já que permite 
não só visualizar morfologia como também permite identificar defeitos, estrutura cristalina, relações de orientação entre fases ${ }^{128}$. E quando associado a técnicas espectroscópicas de dispersão de energia característica de raios-x (EDS) o TEM se converte num instrumento poderoso para análise química, qualitativa e semi-quantitativa, com alta resolução espacial.

Um microscópio moderno de transmissão possui cinco ou seis lentes magnéticas, além de várias bobinas eletromagnéticas de deflexão e aberturas localizadas ao longo do caminho do feixe eletrônico. Entre estes componentes, destacam-se os três seguintes pela sua importância com respeito aos fenômenos de difração eletrônica: lente objetiva, abertura objetiva e abertura seletiva de difração. A função das lentes projetor é apenas a produção de um feixe paralelo e de suficiente intensidade incidente na superfície da amostra.

O fundamento do TEM consiste na geração de um feixe de elétrons, guiado por um conjunto de lentes magnéticas, o qual é transmitido através de uma amostra suficientemente fina (transparente ao feixe) sofrendo diversos tipos de espalhamentos que dependem das características do material $^{128}$ (Figura 11). Assim, os feixes transmitidos e difratados, são recombinados na construção da imagem que é projetada na tela do microscópio e capturada por uma única câmara digital, tendo projeções bidimensionais ${ }^{129}$.

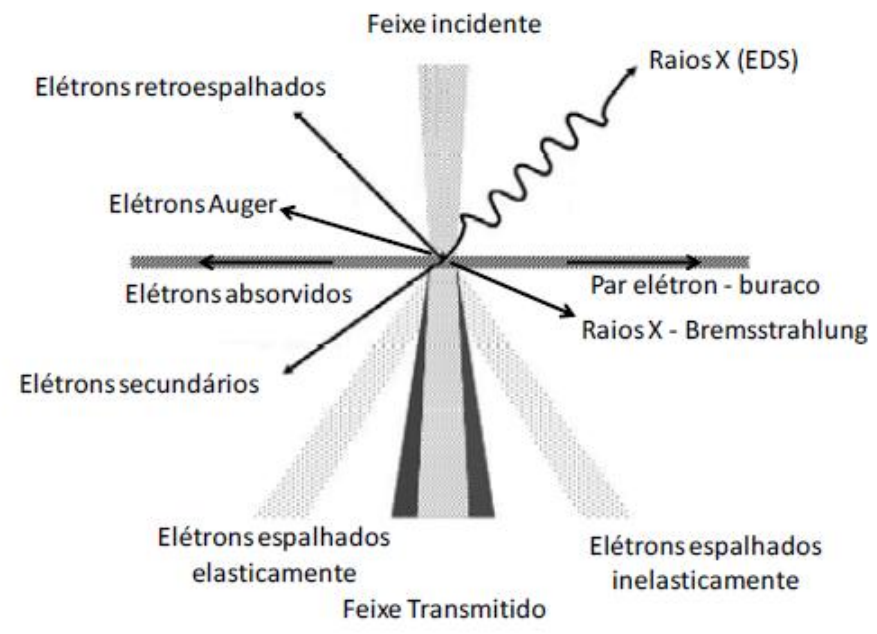


Dentro dos vários fenômenos provenientes da interação dos elétrons do feixe com a amostra, apresentados na Figura 11, encontra-se a emissão de raios x característicos da amostra, os quais podem sem utilizados para realização de uma análise química.

A emissão de raios $\mathrm{x}$ é característica para cada elemento. Atendendo a esta especificidade, a emissão de raios x pode ser utilizada na analise química e na formação de uma imagem composicional. Os métodos de dispersão de energia são assim, especialmente adequados a integração com os microscópios eletrônico, pois permitem associar a micro analise por raios x a observação com alta resolução de amostras de morfologia complexa, permitindo determinar quais os elementos presentes numa amostra e em que proporções.

Neste trabalho, as medidas foram feitas com um microscópio eletrônico de transmissão da marca JEOL, modelo JEM-2100 equipado com EDS, no Laboratório Multiusuário de Microscopia de Alta Resolução da Universidade Federal de Goiás. As medidas de TEM foram utilizadas, para levantar informações a respeito da morfologia do material, composição e sua distribuição em tamanho.

Os colóides magnéticos apresentam polidispersão em tamanho, independentemente da rota de elaboração. Mostramos anteriormente que o DRX fornece um tamanho médio e nenhuma informação sobre a polidispersão em tamanho. A microscopia eletrônica de transmissão complementa a difração de raios x e permite a visualização dos nanogrãos, bem como proceder às determinações da polidispersão em tamanho. Essa distribuição de tamanho pode ser ajustada por uma função de distribuição do tipo log-normal, obtendo-se um diâmetro característico $\mathrm{D}_{0}$ a partir do qual é possível então obter o diâmetro médio: 


$$
P(D)=\frac{1}{\sqrt{2 \pi} s D} \exp \left[-\frac{1}{2 s^{2}}\left(\ln \frac{D}{D_{0}}\right)^{2}\right]
$$

onde $\mathrm{P}(\mathrm{D})$ é a densidade de probabilidade da partícula ter um diâmetro $\mathrm{D}, \mathrm{D}_{0}$ é o diâmetro médio (mediana diâmetro característico $\left(\ln \mathrm{D}_{0}=\langle\ln \mathrm{D}\rangle\right.$ ) e $\mathrm{s}$ é a largura característica da polidispersão relacionada à distribuição. É possível também obter o diâmetro mais provável para a distribuição, dado por $\operatorname{Dmp}=\mathrm{D}_{0} \exp \left(-\mathrm{s}^{2}\right)$ e também o diâmetro médio, $<\mathrm{D}>=\mathrm{D}_{0} \exp \left(-\mathrm{s}^{2} / 2\right)$.

\section{MATERIAIS E MÉTODOS}

As nanopartículas de ferritas de cobalto são obtidas através do método químico da coprecipitação hidrotérmica. As sínteses realizadas nesse trabalho foram realizadas de acordo com a etapa 01 do processo de elaboração de colóides magnéticos do tipo EDL, anteriormente relatada, com a utilização de um reator Hidrotermal da Par(Figura 12). O sal de ferro utilizado foi o nitrato férrico, e o sal de cobalto e como base, para a reação que ocorre em meio básico, foi usado hidróxido de sódio $(\mathrm{NaOH})$. A Tabela 2 descreve os materiais usados nas sínteses:

Tabela 2- Descrição dos materiais usados nas sínteses

\begin{tabular}{|l|l|l|l|l|}
\hline Elemento & Fórmula & Massa Molar [g/mol] & Fornecedor & $\begin{array}{l}\text { Pureza } \\
{[\%]}\end{array}$ \\
\hline Nitrato de Cobalto & $\mathrm{Co}\left(\mathrm{NO}_{3}\right)_{2} \cdot 6 \mathrm{H}_{2} \mathrm{O}$ & 291,03 & Dinâmica & 98,0 \\
\hline Nitrato Férrico & $\mathrm{Fe}\left(\mathrm{NO}_{3}\right)_{3} \cdot 9 \mathrm{H}_{2} \mathrm{O}$ & 404,00 & Vetec & 98,0 \\
\hline $\begin{array}{l}\text { Hidróxido de } \\
\text { Sódio }\end{array}$ & $\mathrm{NaOH}$ & 40,00 & Vetec & 97,0 \\
\hline Glicerol & $\mathrm{C}_{3} \mathrm{H}_{8} \mathrm{O}_{3}$ & 92,09 & Vetec & 99,5 \\
\hline Acido Cítrico & $\mathrm{C}_{6} \mathrm{H}_{8} \mathrm{O}_{7} \cdot \mathrm{H}_{2} \mathrm{O}$ & 210,14 & Vetec & 99,5 \\
\hline Etanol & $\mathrm{C}_{2} \mathrm{H}_{6} \mathrm{O}$ & 46,07 & Vetec & 99,5 \\
\hline
\end{tabular}




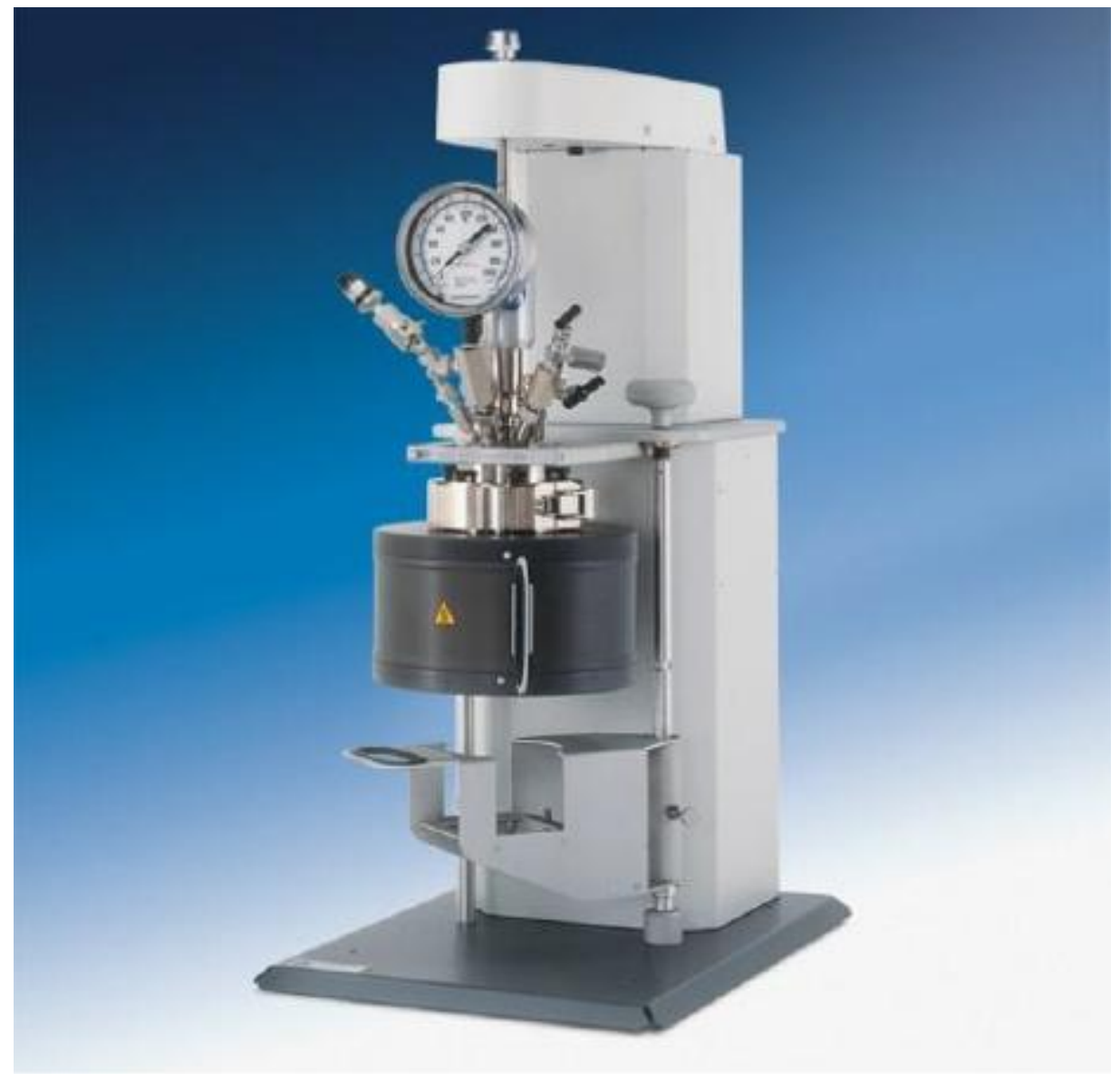

Figura 12- Reator Hidrotermal da Parr usado nas Sínteses - pertencente ao Laboratório de Fluidos Complexos do Instituto de Física da Universidade de Brasília (UnB).

Soluções preparadas para o uso nas sínteses:

a) Pesou-se 40g de hidróxido de sódio e o solubilizou para $1000 \mathrm{~mL}$ de água destilada gerando uma solução estoque de 1,0 mol/L.

b) Pesou-se 582,06g de nitrato cobalto, adicionamos $100 \mathrm{ml}$ de $\mathrm{HNO}_{3} 2 \mathrm{~mol} / \mathrm{L}$ e o solubilizou para $1000 \mathrm{~mL}$ com água destilada gerando uma solução estoque de 2,0 mol/L.

c) Pesou-se $808 \mathrm{~g}$ de nitrato de ferro III nonahidratado, adicionamos $100 \mathrm{ml}$ de $\mathrm{HNO}_{3}$ 2mol/L e o solubilizou para $1000 \mathrm{~mL}$ com água destilada gerando uma solução estoque de 2,0 $\mathrm{mol} / \mathrm{L}$

d) Pesou-se 105,07g ácido cítrico e o solubilizou para $500 \mathrm{~mL}$ de água destilada gerando uma solução estoque de $1,0 \mathrm{~mol} / \mathrm{L}$. 
e) Pesou-se $80 \mathrm{~g}$ de hidróxido de sódio e o solubilizou para $1000 \mathrm{~mL}$ de água destilada gerando uma solução estoque de 2,0 mol/L.

Foram realizados vários experimentos, no reator, sendo dezoito os que resultaram na formação de precipitados, separados em cinco conjuntos de síntese que iremos detalhar em seguida e serão apresentados na

Tabela 3.

\section{$1^{\circ}$ Conjunto de Sínteses}

No primeiro conjunto foi realizado a mistura estequiométrica dos metais, que formaria a ferrita de cobalto, em pH ácido, com a variação da temperatura em $150^{\circ} \mathrm{C}, 200^{\circ} \mathrm{C} \mathrm{e}$ $250^{\circ} \mathrm{C}$, nomeou-se as amostras em ECo150, ECo200 e ECo250 respectivamente. As sínteses foram realizadas seguido os seguintes procedimentos:

1. Misturou-se as soluções estoque dos sais: $20 \mathrm{~mL}$ da solução estoque de nitrato de cobalto e 40mL nitrato de ferro no copo do reator, em pH ácido, a frio com agitação e, em seguida, adicionou $420 \mathrm{~mL}$ de água destilada tipo 02;

2. Posicionou-se o copo do reator na base, fechou-se e ligou-se o reator para iniciar o aquecimento e também a agitação. Usou-se o aquecimento rápido e a agitação de 300 RPM;

3. Alcançando a temperatura desejada, cronometrou-se 30min como o tempo de reação, que após alcançado, desligou-se o reator e aguardou a temperatura e pressão abaixarem até que se pudesse abrir;

4. Retirou-se os produtos formados e os acondicionou em um béquer de $1 \mathrm{~L}$ para refrigerar e decantar o produto final. O corpo de fundo da reação foi o produto final;

5. Lavou-se o precipitado com água destilada; 
6. Coletou-se uma alíquota do precipitado que decantou. Colocando-a em uma placa de Petri, levou à estufa até secar. Raspou-se o material seco na placa e caracterizou-se o pó.

\section{$2^{\circ}$ Conjunto de Sínteses}

No segundo conjunto foi realizado a mistura estequiométrica dos metais na presença da base $\mathrm{NaOH}$ em uma relação molar de 1:2:10,5, com a variação da temperatura em $100^{\circ} \mathrm{C}$, $150^{\circ} \mathrm{C}, 200^{\circ} \mathrm{C}$ e $250^{\circ} \mathrm{C}$, nomeou-se as amostras em ECoB100, ECoB150, ECoB200 e ECoB250 respectivamente. As sínteses foram realizadas seguido os seguintes procedimentos:

1. Misturou-se as soluções dos sais: $20 \mathrm{~mL}$ da solução estoque de nitrato de cobalto e 40mL nitrato de ferro no copo do reator, a frio com agitação e, em seguida adicionou-se 420 mL da solução de hidróxido de sódio 1,0 mol/L com adição rápida e agitação;

2. Posicionou-se o copo do reator na base, fechou-se e ligou-se o reator para iniciar o aquecimento e também se ligou a agitação. Usou-se o aquecimento rápido e a agitação de 300 RPM;

3. Alcançando a temperatura desejada, cronometrou-se 30min como o tempo de reação, que após alcançado, desligou-se o reator e aguardou a temperatura e pressão abaixarem até que se pudesse abrir;

4. Retirou-se os produtos formados e os acondicionou em um béquer de $1 \mathrm{~L}$ para refrigerar e decantar o produto final. O corpo de fundo da reação foi o produto final;

5. Lavou-se o precipitado com água destilada;

6. Coletou-se uma alíquota do precipitado que decantou. Colocando-a em uma placa de Petri, levou à estufa até secar. Raspou-se o material seco na placa e caracterizou-se o pó.

\section{$3^{\circ}$ Conjunto de Sínteses}


No terceiro conjunto foi realizado a mistura dos metais na presença de $\mathrm{NaOH}$ e Glicerol a 43,55\% em uma relação molar de 1:2:5,25, com a variação da temperatura em $100^{\circ} \mathrm{C}, 150^{\circ} \mathrm{C}, 200^{\circ} \mathrm{C}$ e $250^{\circ} \mathrm{C}$, nomeou-se as amostras em ECoBG100, ECoBG150, ECoBG200 e ECoBG250 respectivamente. As sínteses foram realizadas seguido os seguintes procedimentos:

1. Misturou-se as soluções dos sais: $20 \mathrm{~mL}$ da solução estoque de nitrato de cobalto e 40mL nitrato de ferro no copo do reator, a frio com agitação. Em seguida adicionou-se 210 $\mathrm{mL}$ da solução o hidróxido de sódio $1,0 \mathrm{~mol} / \mathrm{L}$ com adição rápida e agitação, em seguida adicionou-se $210 \mathrm{~mL}$ de Glicerol;

2. Posicionou-se o copo do reator na base, fechou-se e ligou-se o reator para iniciar o aquecimento e também se ligou a agitação. Usou-se o aquecimento rápido e agitação de 300 RPM;

3. Alcançando a temperatura desejada, cronometrou-se 30min como o tempo de reação, que após alcançado, desligou-se o reator e aguardou a temperatura e pressão abaixarem até que se pudesse abrir;

4. Retirou-se os produtos formados e os acondicionou em um béquer de $1 \mathrm{~L}$ para refrigerar e decantar o produto final. O corpo de fundo da reação foi o produto final;

5. Lavou-se o precipitado com álcool etílico;

6. Lavou-se o precipitado com água destilada;

7. Coletou-se uma alíquota do precipitado que decantou. Colocando-a em uma placa de Petri, levou à estufa até secar. Raspou-se o material seco na placa e caracterizou-se o pó.

\section{$4^{\circ}$ Conjunto de Sínteses}


No quarto conjunto foi realizado a mistura dos metais na presença do $\mathrm{NaOH}$ e Glicerol a 43,55\% em uma relação molar de 1:2:10,5 com a variação da temperatura em $100^{\circ} \mathrm{C}, 150^{\circ} \mathrm{C}, 200^{\circ} \mathrm{C}$ e $250^{\circ} \mathrm{C}$, nomeou-se as amostras em ECoB2G100, ECoB2G150, ECoB2G200 e ECoB2G250 respectivamente. As sínteses foram realizadas seguido os seguintes procedimentos:

1. Misturou-se as soluções dos sais: $20 \mathrm{~mL}$ da solução estoque de nitrato de cobalto e 40mL nitrato de ferro no copo do reator, a frio com agitação e, em seguida adicionou-se 210 $\mathrm{mL}$ da solução de hidróxido de sódio 2,0 mol/L com adição rápida e agitação, em seguida adicionou-se $210 \mathrm{~mL}$ de Glicerol;

2. Posicionou-se o copo do reator na base, fechou-se e ligou-se o reator para iniciar o aquecimento e também se ligou a agitação. Usou-se o aquecimento rápido até e agitação de 300 RPM;

3. Alcançando a temperatura desejada, cronometrou-se 30min como o tempo de reação, que após alcançado, desligou-se o reator e aguardou a temperatura e pressão abaixarem até que se pudesse abrir;

4. Retiraram-se os produtos formados e os acondicionaram em um béquer de $1 \mathrm{~L}$ para refrigerar e decantar o produto final. O corpo de fundo da reação foi o produto final;

5. Lavou-se o precipitado com álcool etílico;

6. Lavou-se o precipitado com água destilada;

7. Coletou-se uma alíquota do precipitado que decantou. Colocando-a em uma placa de Petri, levou à estufa até secar. Raspou-se o material seco na placa e caracterizou-se o pó.

\section{$5^{\circ}$ Conjunto de Sínteses}


No quinto conjunto foi realizado a mistura dos metais na presença de $\mathrm{NaOH}$ e do Ácido Cítrico em uma relação molar de 1:2:11:10, com a variação da temperatura em $100^{\circ} \mathrm{C}$, $150^{\circ} \mathrm{C}, 200^{\circ} \mathrm{C}$ e $250^{\circ} \mathrm{C}$, nomeou-se as amostras em, ECoBA150, ECoBA200 e ECoBA250 respectivamente. As sínteses foram realizadas seguido os seguintes procedimentos:

1. Misturou-se as soluções dos sais: $20 \mathrm{~mL}$ da solução estoque de nitrato de cobalto e 40mL nitrato de ferro no copo do reator, a frio com agitação e, em seguida adicionou-se 210 $\mathrm{mL}$ da solução o hidróxido de sódio 2,0 mol/L com adição rápida e agitação, em seguida adicionou-se $210 \mathrm{~mL}$ de ácido cítrico 1,0 mol/L;

2. Posicionou-se o copo do reator na base, fechou-se e ligou-se o reator para iniciar o aquecimento e também se ligou a agitação. Usou-se o aquecimento rápido e agitação de 300 RPM;

3. Alcançando a temperatura desejada, cronometrou-se 30min como o tempo de reação, que após alcançado, desligou-se o reator e aguardou a temperatura e pressão abaixarem até que se pudesse abrir;

4. Retiraram-se os produtos formados e os acondicionaram em um béquer de $1 \mathrm{~L}$ para refrigerar e decantar o produto final. O corpo de fundo da reação foi o produto final;

5. Lavou-se o precipitado com água destilada;

6. Coletou-se uma alíquota do precipitado que decantou. Colocando-a em uma placa de Petri, levou à estufa até secar. Raspou-se o material seco na placa e caracterizou-se o pó.

Um resumo das condições de síntese adotadas é apresentado na

Tabela 3. 
Tabela 3- Metodologia do processo de síntese no reator de hidrometalurgia

\begin{tabular}{|c|c|c|c|c|c|}
\hline \multicolumn{6}{|c|}{ Reator Hidrotermal } \\
\hline Metodologia & Nome & $\begin{array}{c}\text { Temperatura } \\
\left({ }^{\circ} \mathrm{C}\right)\end{array}$ & $\begin{array}{l}\text { Tempo } \\
\text { de } \\
\text { Rampa }\end{array}$ & $\begin{array}{l}\text { Tempo } \\
\text { de } \\
\text { Reação }\end{array}$ & RPM \\
\hline \multirow{3}{*}{$\begin{array}{c}1: 2 \\
\mathrm{Co}: \mathrm{Fe}\end{array}$} & ECo150 & 150 & $25 \mathrm{~min}$ & $30 \mathrm{~min}$ & 300 \\
\hline & ECo200 & 200 & $33 \mathrm{~min}$ & $30 \mathrm{~min}$ & 300 \\
\hline & ECo250 & 250 & $1 \mathrm{~h} 51 \mathrm{~min}$ & $30 \mathrm{~min}$ & 300 \\
\hline \multirow{4}{*}{$\begin{array}{c}1: 2: 10,5 \\
\mathrm{Co}: \mathrm{Fe}: \mathrm{NaOH}\end{array}$} & ECoB100 & 100 & $26 \min$ & $30 \mathrm{~min}$ & 300 \\
\hline & ECoB150 & 150 & $34 \mathrm{~min}$ & 30min & 300 \\
\hline & ECoB200 & 200 & $1 \mathrm{~h} 5 \mathrm{~min}$ & 30min & 300 \\
\hline & ECoB250 & 250 & 1h54min & 30min & 300 \\
\hline \multirow{4}{*}{$\begin{array}{c}1: 2: 5,25 \\
\text { Co: } \mathrm{Fe}: \mathrm{NaOH}+ \\
\text { Glicerol 43,55\% }\end{array}$} & ECoBG100 & 100 & $27 \mathrm{~min}$ & $30 \mathrm{~min}$ & 300 \\
\hline & ECoBG150 & 150 & $33 \mathrm{~min}$ & $30 \mathrm{~min}$ & 300 \\
\hline & ECoBG200 & 200 & $59 \mathrm{~min}$ & $30 \mathrm{~min}$ & 300 \\
\hline & ECoBG250 & 250 & $1 \mathrm{~h} 56 \mathrm{~min}$ & $30 \mathrm{~min}$ & 300 \\
\hline \multirow{4}{*}{$\begin{array}{c}1: 2: 10,5 \\
\text { Co: Fe: } \mathrm{NaOH}+ \\
\text { Glicerol 43,55\% }\end{array}$} & ECoB2G100 & 100 & $23 \mathrm{~min}$ & 30min & 300 \\
\hline & ECoB2G150 & 150 & $36 \mathrm{~min}$ & $30 \mathrm{~min}$ & 300 \\
\hline & ECoB2G200 & 200 & $50 \mathrm{~min}$ & $30 \mathrm{~min}$ & 300 \\
\hline & ECoB2G250 & 250 & $1 \mathrm{~h} 53 \mathrm{~min}$ & 30min & 300 \\
\hline \multirow{3}{*}{$\begin{array}{c}1: 2: 11: 10 \\
\text { Co: Fe: NaOH: Ácido } \\
\text { Cítrico }\end{array}$} & ECoBA150 & 150 & $34 \mathrm{~min}$ & $30 \mathrm{~min}$ & 300 \\
\hline & ECoBA200 & 200 & $1 \mathrm{~h} 5 \mathrm{~min}$ & $30 \mathrm{~min}$ & 300 \\
\hline & ECoBA250 & 250 & 1h54min & $30 \mathrm{~min}$ & 300 \\
\hline
\end{tabular}

\section{RESULTADOS E DISCUSSÕES}

Os resultados das sínteses de coprecipitação hidrotérmica realizadas no reator de hidrometalurgia serão apresentados em cinco conjuntos, separados de acordo com os parâmetros utilizados em cada síntese. No primeiro conjunto foi realizado a mistura estequiométrica dos metais que formaria a ferrita de cobalto, em pH ácido, com a variação da 
temperatura em $150^{\circ} \mathrm{C}, 200^{\circ} \mathrm{C}$ e $250^{\circ} \mathrm{C}$. No segundo conjunto foi realizado a mistura estequiométrica dos metais na presença da base $\mathrm{NaOH}$ em uma relação molar de 1:2:10,5, com a variação da temperatura em $100^{\circ} \mathrm{C}, 150^{\circ} \mathrm{C}, 200^{\circ} \mathrm{C}$ e $250^{\circ} \mathrm{C}$. No terceiro conjunto foi realizado a mistura dos metais na presença da base $\mathrm{NaOH}$ e Glicerol a 43,55\% em uma relação molar de $1: 2: 5,25$, com a variação da temperatura em $100^{\circ} \mathrm{C}, 150^{\circ} \mathrm{C}, 200^{\circ} \mathrm{C}$ e $250^{\circ} \mathrm{C}$. No quarto conjunto foi realizado a mistura dos metais na presença da base $\mathrm{NaOH}$ e Glicerol a 43,55\% em uma relação molar de 1:2:10,5 com a variação da temperatura em $100^{\circ} \mathrm{C}, 150^{\circ} \mathrm{C}$, $200^{\circ} \mathrm{C}$ e $250^{\circ} \mathrm{C}$. No quinto conjunto foi realizado a mistura dos metais na presença da base $\mathrm{NaOH}$ e do Ácido Cítrico em uma relação molar de 1:2:11:10, com a variação da temperatura em $100^{\circ} \mathrm{C}, 150^{\circ} \mathrm{C}, 200^{\circ} \mathrm{C}$ e $250^{\circ} \mathrm{C}$. Em todos os experimentos foi utilizada a velocidade de agitação em 300RPM.

O tempo de rampa não pode ser constante para todas as temperaturas devido as características do reator, que não permite determinar um tempo fixo para chegar a temperatura desejada. Contudo, o tempo de reação, após atingirmos a temperatura desejada, foi mantido constante e igual a 30 minutos.

As razões entre as concentrações dos elementos $\mathrm{Fe} / \mathrm{Co}$ foram calculadas pelo valor de $\chi_{M}$. No caso da ferrita de cobalto essa relação estequiométrica é dada por uma fração molar do metal divalente onde o resultado ideal $\chi_{M}$ é aproximadamente 0,33 , dada por:

$$
\chi_{M}=\frac{\left[\mathrm{Co}^{+2}\right]}{\left[\mathrm{Co}^{+2}\right]+\left[\mathrm{Fe}^{+3}\right]}=\frac{1}{3}
$$

Os picos dos difratogramas foram indexados usando o software EVA Bruker-AXS (DIFFRAC.EVA).

$1^{\circ}$ Conjunto- Mistura de Cobalto e Ferro 
Tabela 4- Resultado de $\mathrm{D}_{\mathrm{RX}}$ do $1^{\circ}$ conjunto-mistura de cobalto e ferro em $\mathrm{pH}$ ácido.

\begin{tabular}{|c|c|c|c|}
\hline Metodologia & Nome & $\begin{array}{c}\text { Temperatura } \\
\left({ }^{\circ} \mathrm{C}\right)\end{array}$ & $\begin{array}{c}\mathrm{D}_{\mathrm{RX}} \\
(\mathrm{nm})\end{array}$ \\
\hline \multirow{2}{*}{$\begin{array}{c}1: 2 \\
\mathrm{Co}: \mathrm{Fe}\end{array}$} & ECo150 & 150 & 43,90 \\
\cline { 2 - 4 } & ECo200 & 200 & 41,11 \\
\cline { 2 - 4 } & ECo250 & 250 & 39,49 \\
\hline
\end{tabular}
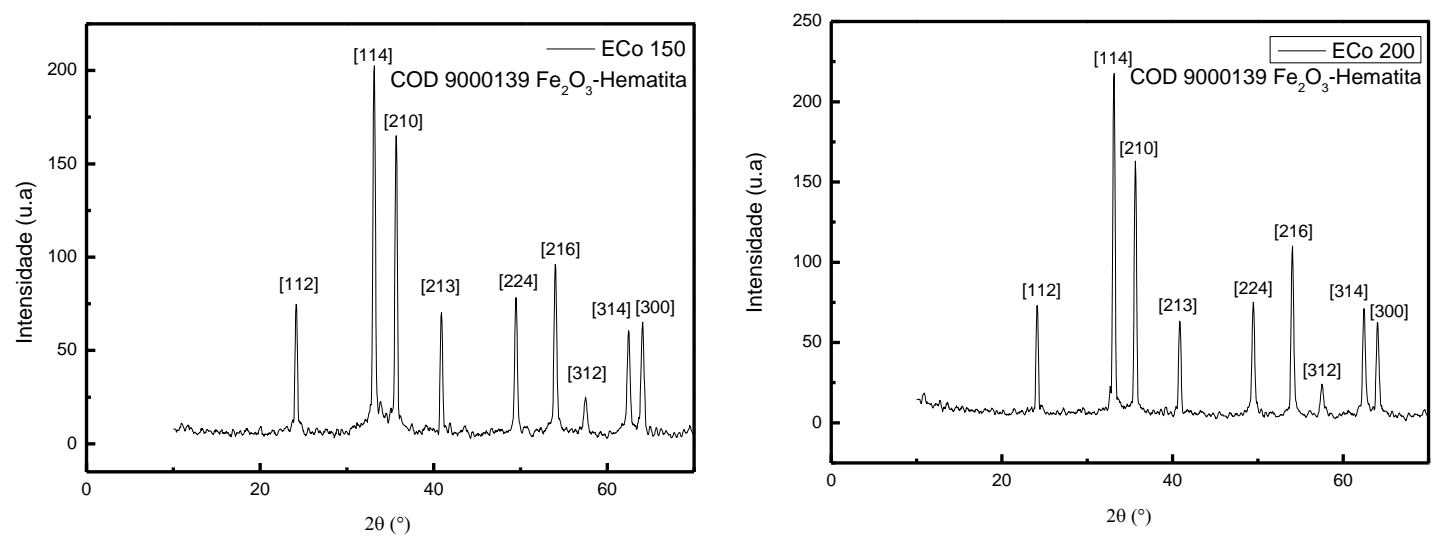

a)

b)

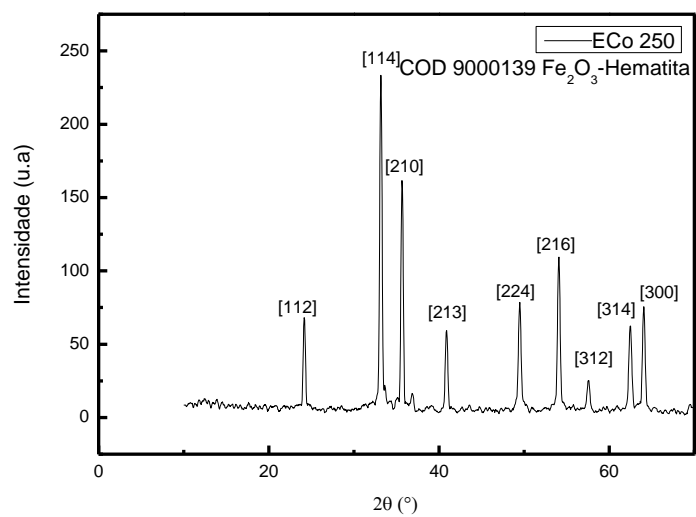

c)

Figura 13-Difratogramas das sínteses realizadas no reator de hidrometalurgia a partir da mistura estequiométrica de Fe e Co: amostra ECo 150(a), ECo150(b) e ECo 250(c)

Verifica-se, em todos os casos, a formação de fase única hematita de estrutura hexagonal. Os diâmetros foram obtidos, através do formalismo de Sherrer, que é o método utilizado pelo Software de analise e identificação utilizado, com valores de 43,90nm; 
41,11nm; 39,49nm para as amostras ECo150, ECo200, ECo250 respectivamente(Tabela 4), evidenciando um leve decréscimo no tamanho cristalino com um aumento da temperatura. Este resultado, esta de bom acordo com a literatura para a síntese de ferrita de cobalto, por coprecipitação hidrotérmica, que apenas verifica a precipitação a partir de $\mathrm{pH}$ básico ${ }^{80}$, de fato, verificamos apenas a formação da hematita que possui entalpia de formação do cristal $\Delta \mathrm{H}_{\mathrm{f}}$ menor que de formação de óxido de ferro de estrutura espinélio ${ }^{130}$.

Tabela 5- Resultado de EDX do $1^{\circ}$ conjunto- mistura de cobalto e ferro

\begin{tabular}{|c|c|c|c|c|c|}
\hline \multicolumn{6}{|c|}{ EDX } \\
\hline Metodologia & Nome & Fe(\%) & Co(\%) & $\begin{array}{c}\text { Outros } \\
(\%)\end{array}$ & $\begin{array}{c}\chi_{\mathrm{M}} \\
\text { EDX }\end{array}$ \\
\hline \multirow{2}{*}{$\begin{array}{c}\text { Co: Fe } \\
\text { CoCo150 }\end{array}$} & ECo200 & 99,94 & 0 & 0,06 & 0,00 \\
\cline { 2 - 7 } & ECo250 & 91,15 & 1,44 & 7.39 & 0,015 \\
\cline { 2 - 7 } & & & 0,38 & 0,34 & 0,00 \\
\hline
\end{tabular}

A técnica de EDX, mostra um leve aumento da porcentagem de cobalto com o aumento da temperatura. O que possibilita a presença, ou o inicio da formação de pequenos grãos da ferrita de cobalto. Logo, tanto no que se refere aos resultados de DRX quanto os do EDX é possível observar que a temperatura é um parâmetro extremamente importante para formação da ferrita favorecendo sua termodinâmica de formação

Essas amostras não foram selecionadas para realização de medidas de TEM por não haver a formação de ferrita de cobalto em uma relação significativa.

$2^{\circ}$ Conjunto- Mistura estequiométrica de $\mathrm{Fe}$ e $\mathrm{Co}$ na presença de $\mathrm{NaOH}$ 
Tabela 6- Resultados de $D_{\mathrm{RX}}$ do $2^{\circ}$ conjunto- mistura estequiométrica de Fe e Co na presença de $\mathrm{NaOH}$

\begin{tabular}{|c|c|c|c|}
\hline Metodologia & Nome & $\begin{array}{c}\text { Temperatura } \\
\left({ }^{\circ} \mathrm{C}\right)\end{array}$ & $\begin{array}{c}\mathrm{D}_{\mathrm{RX}} \\
(\mathrm{nm})\end{array}$ \\
\hline \multirow{3}{*}{$\begin{array}{c}1: 2: 10,5 \\
\mathrm{Co}: \mathrm{Fe}: \mathrm{NaOH}\end{array}$} & ECoB100 & 100 & 14,93 \\
\cline { 2 - 4 } & $\mathrm{ECoB} 150$ & 150 & 14,28 \\
\cline { 2 - 4 } & $\mathrm{ECoB} 200$ & 200 & 13,46 \\
\cline { 2 - 4 } & $\mathrm{ECoB} 250$ & 250 & 13,84 \\
\hline
\end{tabular}

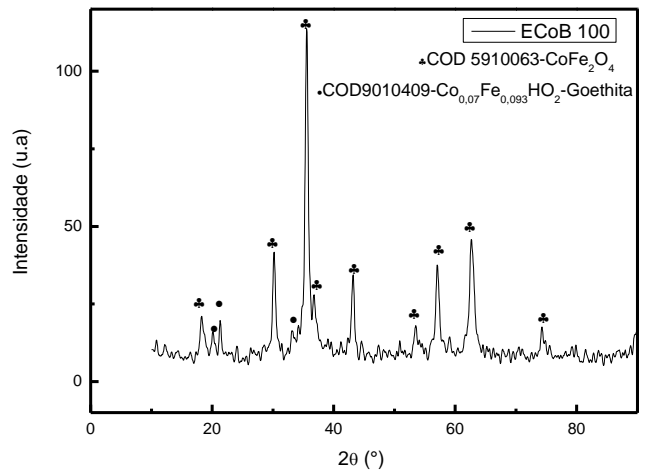

a)

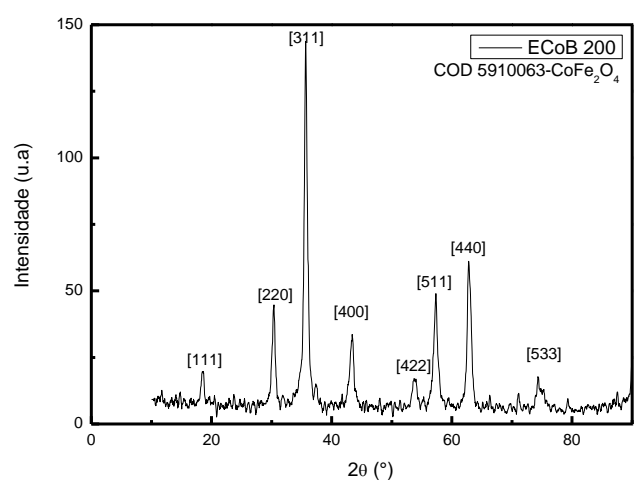

c)

Figura 14- Difratogramas das sínteses realizadas no reator de hidrometalurgia a partir da mistura estequiométrica de $\mathrm{Fe}$ e $\mathrm{Co}$ na presença de $\mathrm{NaOH}$ : amostra $\mathrm{ECoB}$ 100(a), ECoB150(b), ECoB 200(c) e ECoB 250(c)

A Figura 14-a apresenta duas fases, a fase predominante ferrita de cobalto- $\mathrm{CoFe}_{2} \mathrm{O}_{4}$, de estrutura cúbica e uma fase minoritária goethita- $\mathrm{Co}_{0,07} \mathrm{Fe}_{0,93} \mathrm{OOH}$ de estrutura hexagonal. A Figura 14-b apresenta duas fases, a fase predominante ferrita de cobalto- $\mathrm{CoFe}_{2} \mathrm{O}_{4}$, de estrutura cúbica e uma fase minoritária goethita- $\mathrm{Co}_{0,05} \mathrm{Fe}_{0,95} \mathrm{OOH}$ de estrutura ortorrômbica. 
Nas Figuras14-c e 14-d as amostras apresentam apenas a fase ferrita de cobalto- $\mathrm{CoFe}_{2} \mathrm{O}_{4}$, de estrutura cúbica.

Os tamanhos médios dos cristais foram calculados utilizando a equação de Scherrer para estruturas esféricas. Foram obtidos os valores 14,93nm; 14,28nm; 13,46nm; 13,84nm, para as amostras ECoB100, ECoB150, ECoB200, ECoB250 respectivamente (Tabela 6).

Tabela 7- Resultado de EDX e AAS do $2^{\circ}$ conjunto- mistura estequiométrica de Fe e Co na presença de $\mathrm{NaOH}$

\begin{tabular}{|c|c|c|c|c|c|c|}
\hline Metodologia & Nome & $\mathrm{Fe}(\%)$ & $\mathrm{Co}(\%)$ & Outros(\%) & $\begin{array}{c}\chi_{\mathrm{M}} \\
\text { EDX }\end{array}$ & $\begin{array}{c}\chi_{\mathrm{M}} \\
\text { AAS }\end{array}$ \\
\hline \multirow{3}{*}{$\begin{array}{c}1: 2: 10,5 \\
\mathrm{Co}: \mathrm{Fe}: \mathrm{NaOH}\end{array}$} & $\mathrm{ECoB} 100$ & 63,25 & 36,29 & 0,49 & 0,365 & - \\
\cline { 2 - 7 } & $\mathrm{ECoB} 150$ & 62,07 & 37,64 & 0,29 & 0,377 & - \\
\cline { 2 - 7 } & $\mathrm{ECoB} 200$ & 62,94 & 36,73 & 0,33 & 0,369 & 0,32 \\
\cline { 2 - 7 } & $\mathrm{ECoB} 250$ & 62,91 & 36,76 & 0,33 & 0,369 & 0,33 \\
\hline
\end{tabular}

O EDX mostra que há um certo aumento da quantidade de Co do que o esperado para ferrita de cobalto (Tabela 7), ou seja, $\chi_{M}$ maior que 0,33. Então resolvemos realizar a técnica de Espectrometria de Absorção Atômica para verificar esse resultado, porém só realizamos para as amostras ECoB 200 e ECoB250, pois estas apresentaram os difratogramas com apenas a fase ferrita de cobalto. A técnica AAS apresentou uma relação próxima da esperada com valores de $\chi_{\mathrm{M}} 0,32$ e 0,33 para as amostrasECoB200, ECoB250 respectivamente, como esperado para ferrita espinélio.

Foram realizadas medidas de TEM e EDS para todo esse conjunto de amostras. Afim de verificar a morfologia e composição das amostras. 
a)

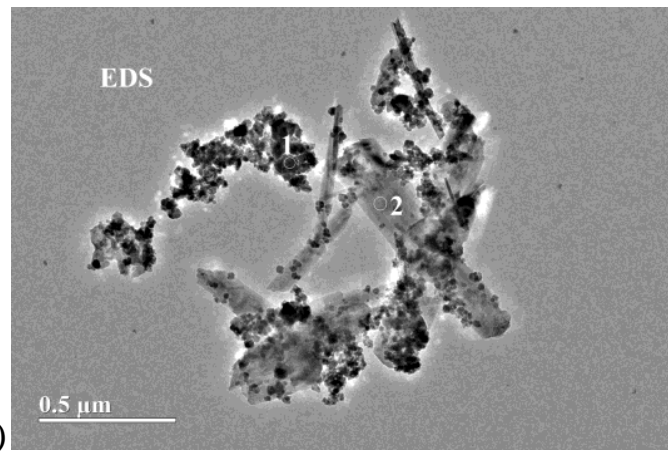

b)

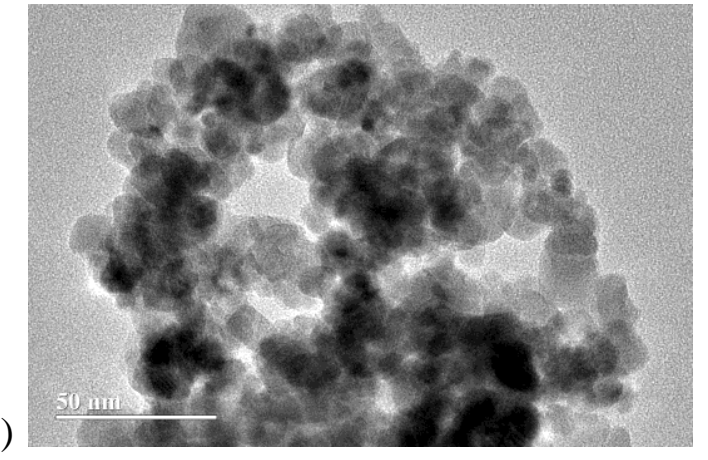

d)
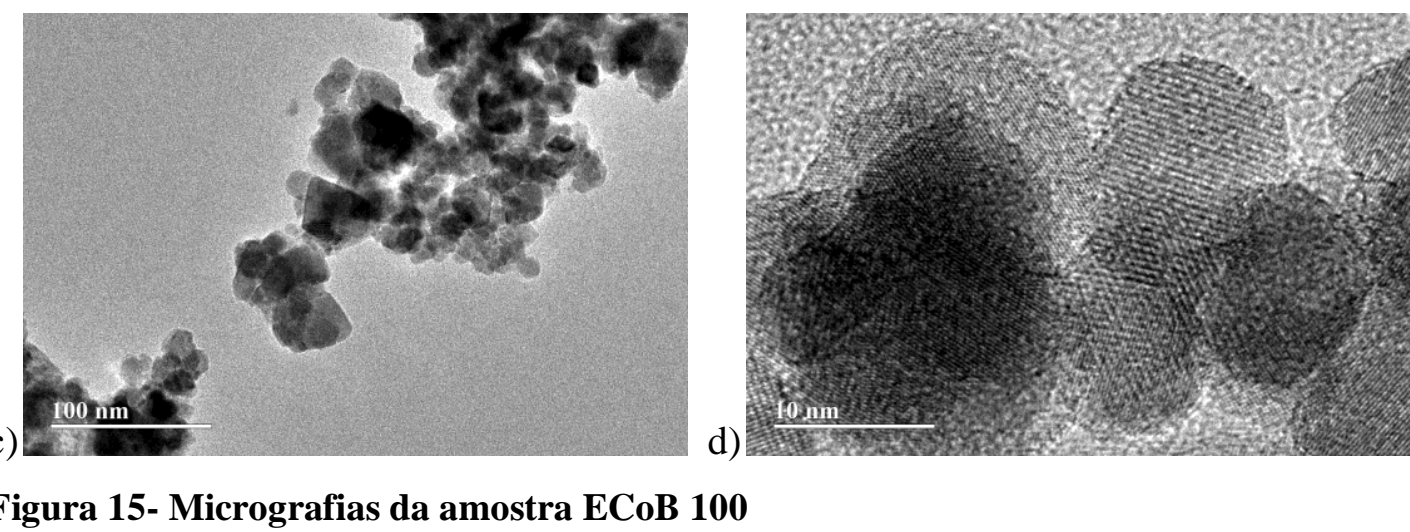

Figura 15- Micrografias da amostra ECoB 100

Foram realizadas medidas de EDS nas imagens da Figura 15-a nas regiões 1 e 2, para verificar a composição das amostras. Na região 1 da Figura 15-a apresentam os elementos Fe e Co em $\chi_{M}$ de 0,39, na região 2 apresenta apenas um óxido de Fe. Verifica-se, um bom acordo com os resultados de difratometria para amostra ECoB100, a presença de duas fases, uma do tipo goetita (bastões) e outra do tipo ferrita de cobalto (partículas aproximadamente esféricas). 
a)

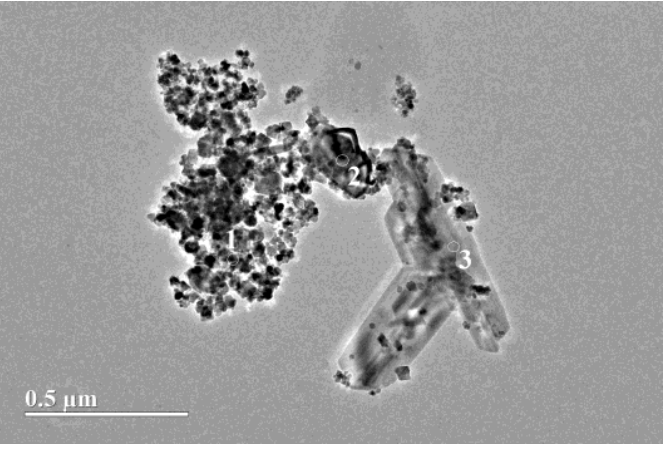

b)

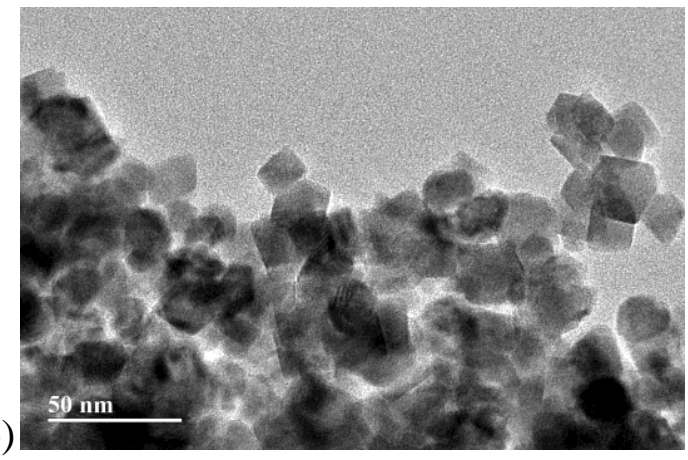

d)

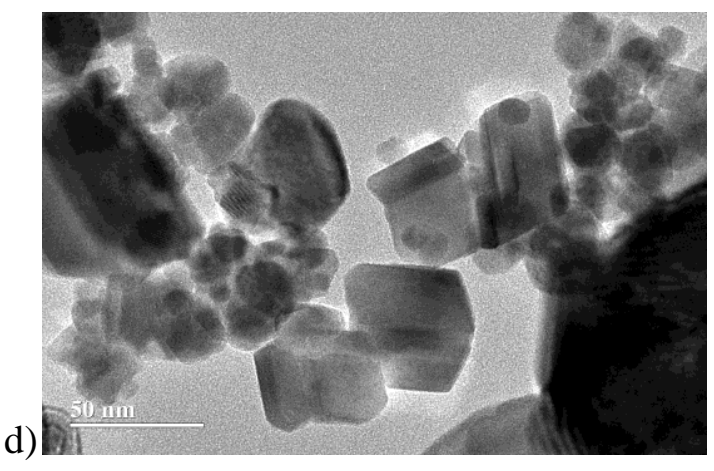

c)

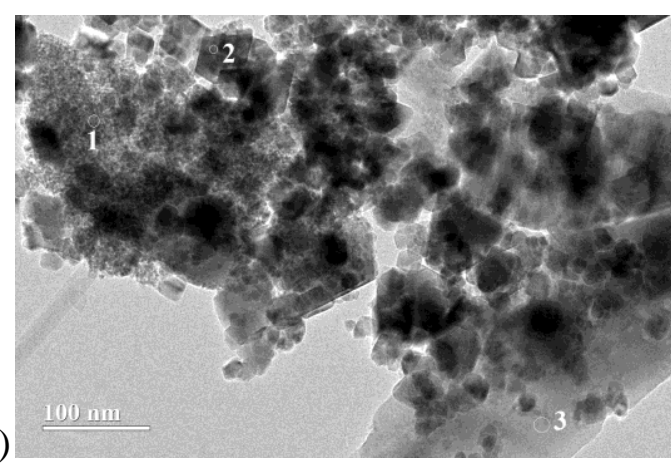

Figura 16-Micrografias da amostra ECoB 150

Foram realizadas medidas de EDS nas imagens da Figura 16-a nas regiões 1, 2 e 3 e na Figura 16-c nas regiões 1, 2 e 3, para verificar a composição das amostras. Na região 1 da Figura 16-a apresentam os elementos $\mathrm{Fe}$ e Co em $\chi_{M}$ de 0,41, na região 2 apresentam os elementos Fe e Co em $\chi_{M}$ de 0,41 , na região 3 apresenta apenas um óxido de Fe. Na região 1 da Figura 16-c apresentam os elementos Fe e Co em $\chi_{M}$ de 0,22, na região 2 apresentam os elementos Fe e Co em $\chi_{M}$ de 0,36, na região 3 apresenta apenas um óxido de Fe. Neste caso novamente, verifica-se a presença de duas fases, uma do tipo goetita (bastões) e outra do tipo ferrita de cobalto (partículas aproximadamente esféricas). 
a)

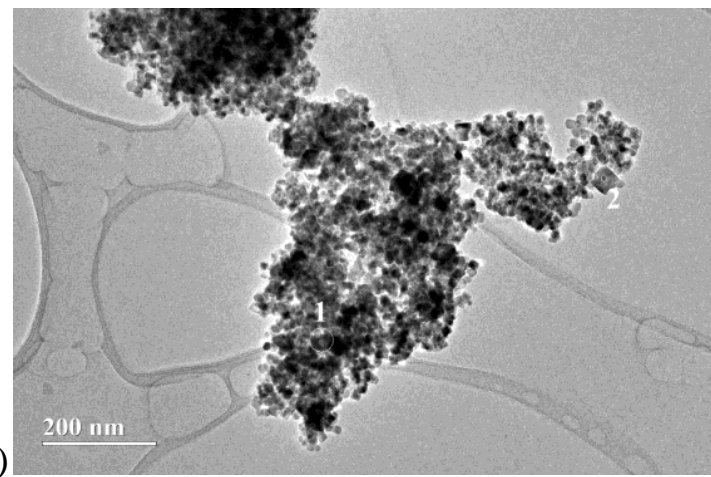

c)

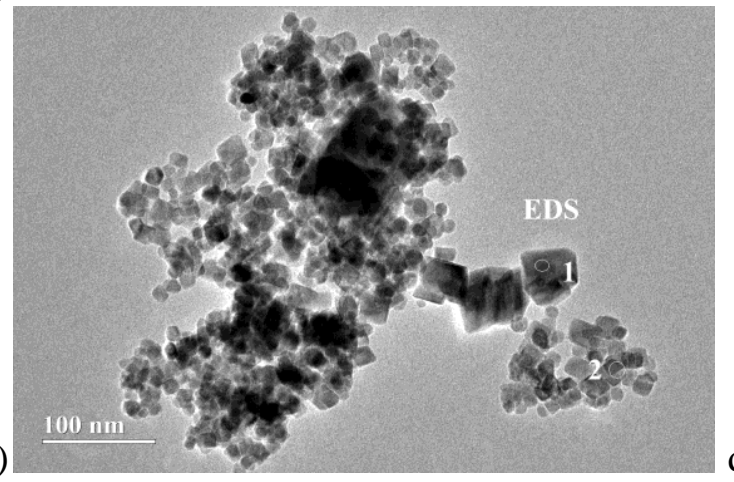

b)
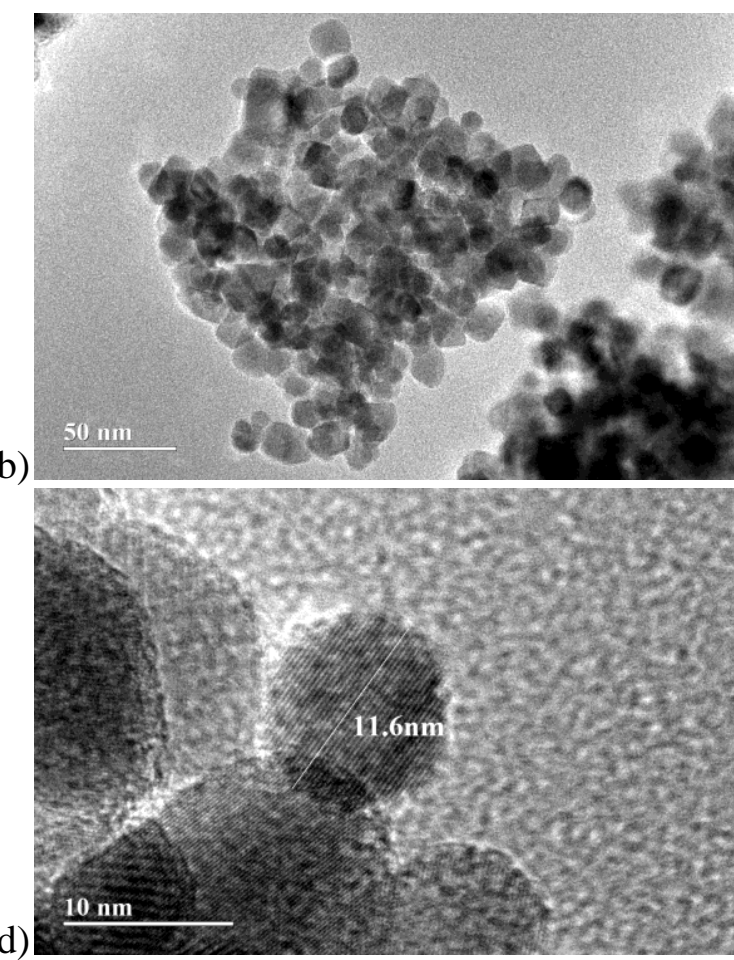

Figura 17- Micrografias da amostra ECoB 200

Foram realizadas medidas de EDS nas imagens da Figura 17-a nas regiões 1e 2 e na Figura 17-c nas regiões 1 e 2, para verificar a composição das amostras. Na região 1 da Figura 17-a apresentam os elementos Fe e Co em $\chi_{M}$ de 0,35, na região 2 apresentam os elementos Fe e Co em $\chi_{M}$ de 0,36. Na região 1 da Figura 17-c apresentam os elementos Fe e Co em $\chi_{M}$ de 0,30 , na região 2 apresentam os elementos Fe e Co em $\chi_{M}$ de 0,34 . Neste caso, não foi detectada a presença da goetita, entretanto na figura $17 \mathrm{c}$, verificamos partículas de tamanhos maiores e mais ricas em Fe, que podem ter sido originalmente goetitas que sofreram envelhecimento, pelo processo de Ostwald, e geraram ferritas. 
a)

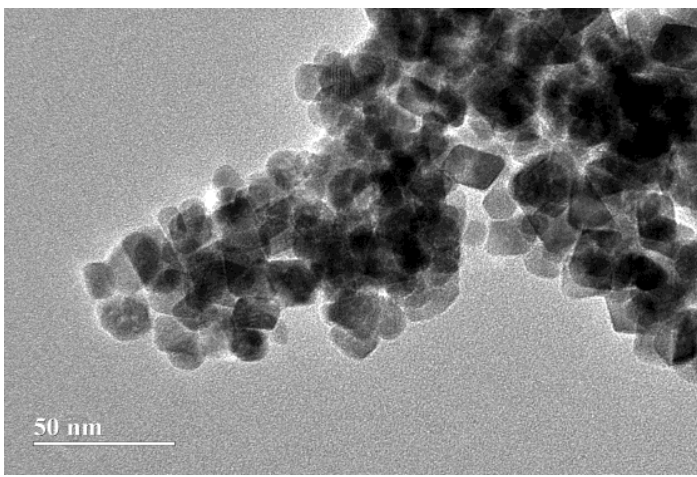

c)

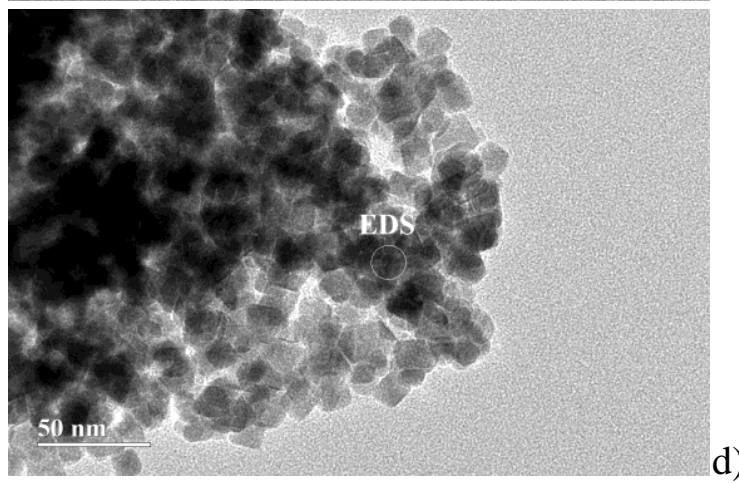

b)

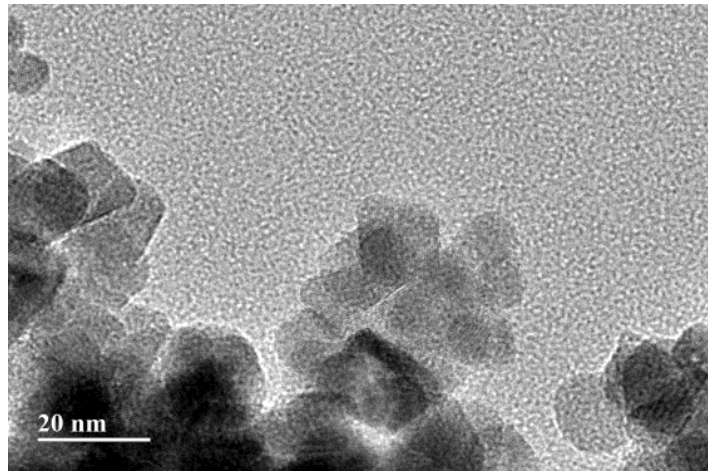

d)

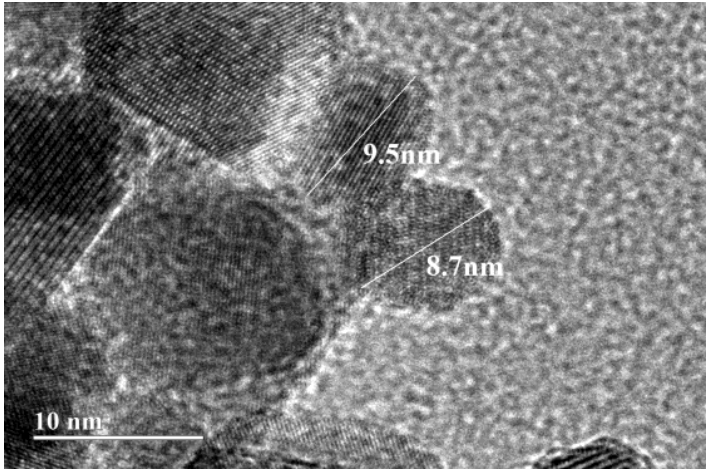

Figura 18-Micrografias da amostra ECoB 250

Foi realizada medida de EDS na imagem da Figura 18-c que apresenta os elementos Fe e Co na proporção de $\chi_{\mathrm{M}}$ de 0,37 . Neste caso, o EDS também difere do valor determinado por AAS, considerando a possibilidade interferência nas raias do Fe e Co. Podemos notar, apenas a formação de partículas de tamanhos da ordem de uma dezena de nanômetros e de forma angulosa, semelhantes a cubos que estão se tornando esferas, com distribuição de tamanho próximas, além de algumas partículas esféricas.

\section{$3^{\circ}$ Conjunto- mistura estequiométrica de $\mathrm{Fe}$ e $\mathrm{Co}$ na presença de $\mathrm{NaOH}$ e} glicerol $43,55 \%$.

As sínteses abaixo foram realizadas com uma mistura de sais de metais na presença de $\mathrm{NaOH}$ em uma solução 43,55\% de glicerol, numa diluição de 1:2:5,25. A base foi utilizada em uma concentração molar menor que a utilizada para síntese de fluidos magnéticos e o glicerol foi utilizado para diminuir a velocidade de difusão da síntese. 
Tabela 8- Resultado de $D_{\text {Rx }}$ para o $3^{\circ}$ conjunto- mistura estequiométrica de Fe e Co na presença de $\mathrm{NaOH}$ e glicerol $43,55 \%$

\begin{tabular}{|c|c|c|c|}
\hline Metodologia & Nome & $\begin{array}{c}\text { Temperatura } \\
\left({ }^{\circ} \mathrm{C}\right)\end{array}$ & $\begin{array}{c}\mathrm{D}_{\mathrm{RX}} \\
(\mathrm{nm})\end{array}$ \\
\hline \multirow{2}{*}{$\begin{array}{c}1: 2: 5,25 \\
\mathrm{Co}: \mathrm{Fe}: \mathrm{NaOH}+\end{array}$} & ECoBG100 & 100 & - \\
\cline { 2 - 4 } Glicerol 43,55\% & ECoBG150 & 150 & - \\
\cline { 2 - 4 } & ECoBG200 & 200 & - \\
\cline { 2 - 4 } & ECoBG250 & 250 & 11,70 \\
\hline
\end{tabular}

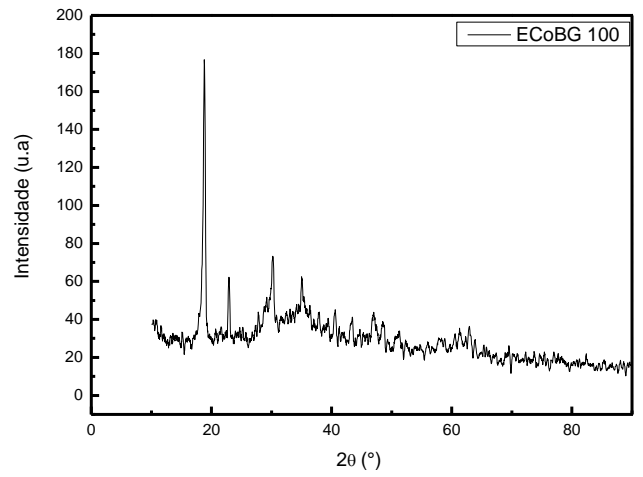

a)

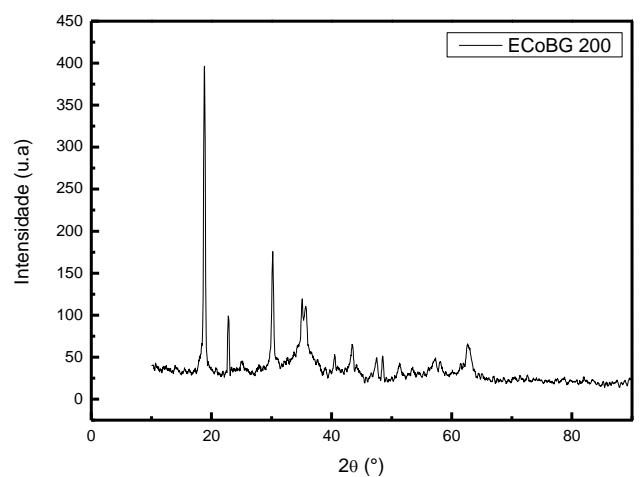

c)

Figura 19- Difratogramas das sínteses realizadas no reator de hidrometalurgia a partir da mistura estequiométrica de Fe e Co na presença de $\mathrm{NaOH}$ em uma solução $43,55 \%$ em glicerol: amostra ECoBG100(a), ECoBG150(b), ECoBG200(c) e ECoBG250(d)

Nas Figuras 19-a, 19-b e 19-c não foi possível identificar um padrão correspondente para essas amostras com o software. Porém nas Figuras 20-b e 20-c observa-se a presença de um pico localizado próximo a 35 graus, região equivalente ao pico mais intenso da ferrita de 
cobalto, o que sugere o inicio do processo de formação da ferrita. Na Figura 20-d apresenta apenas a fase ferrita de cobalto $\mathrm{CoFe}_{2} \mathrm{O}_{4}$, de estrutura cúbica.

Só foi possível realizar o cálculo do tamanho médio dos cristais para amostra ECoBG250, utilizando a equação de Scherrer, foi obtido o valor de 11,70nm (Tabela 8).

Tabela 9- Resultado de EDX e AAS do $3^{\circ}$ Conjunto- Mistura estequiométrica de Fe e Co na presença de $\mathrm{NaOH}$ e glicerol $43,55 \%$

\begin{tabular}{|c|c|c|c|c|c|c|}
\hline Metodologia & Nome & $\mathrm{Fe}(\%)$ & $\mathrm{Co}(\%)$ & $\begin{array}{c}\text { Outros } \\
(\%)\end{array}$ & $\begin{array}{c}\chi_{\mathrm{M}} \\
\text { EDX }\end{array}$ & $\begin{array}{c}\chi_{\mathrm{M}} \\
\text { AAS }\end{array}$ \\
\hline \multirow{2}{*}{$\begin{array}{c}1: 2: 5,25 \\
\mathrm{Co}: \mathrm{Fe}: \mathrm{NaOH}+\end{array}$} & ECoBG100 & 79,75 & 20,25 & 0,00 & 0,202 & - \\
\cline { 2 - 7 } \begin{tabular}{c} 
Glicerol 43,55\% \\
\cline { 2 - 7 }
\end{tabular} & ECoBG150 & 76,48 & 23,39 & 0,13 & 0,234 & - \\
\cline { 2 - 7 } & ECoBG200 & 60,84 & 39,07 & 0,09 & 0,391 & - \\
\cline { 2 - 7 } & ECoBG250 & 65,91 & 33,96 & 0,13 & 0,340 & 0,30 \\
\hline
\end{tabular}

O EDX das amostras ECoBG 100 e ECoBG 150 existe uma quantidade de ferro e cobalto muito próximas, mas com um leve aumento da quantidade de cobalto na amostra ECoBG150, com o aumento da temperatura. A amostra ECoBG 200 apresenta um teor de cobalto elevado, em relação ao esperado parra ferrita de cobalto, com $\chi_{M}$ 0,39. A amostra ECoBG250 apresentou um teor de cobalto um pouco a cima do esperado para estequiometria da ferrita, identificada pelo resultado do difratograma de raio $\mathrm{x}$, logo para verificar esse valor no resultado do EDX, foi realizada a técnica de Espectrometria de Absorção Atômica, apresentando o valor de $\chi_{M} 0,30$ (Tabela 9).

As Amostras ECoBG150, ECoBG200 e ECoBG250 foram escolhidas para realização de Microscopia Eletrônica de Transmissão com EDS. Para verificar a morfologia e composição das amostras. 
a)
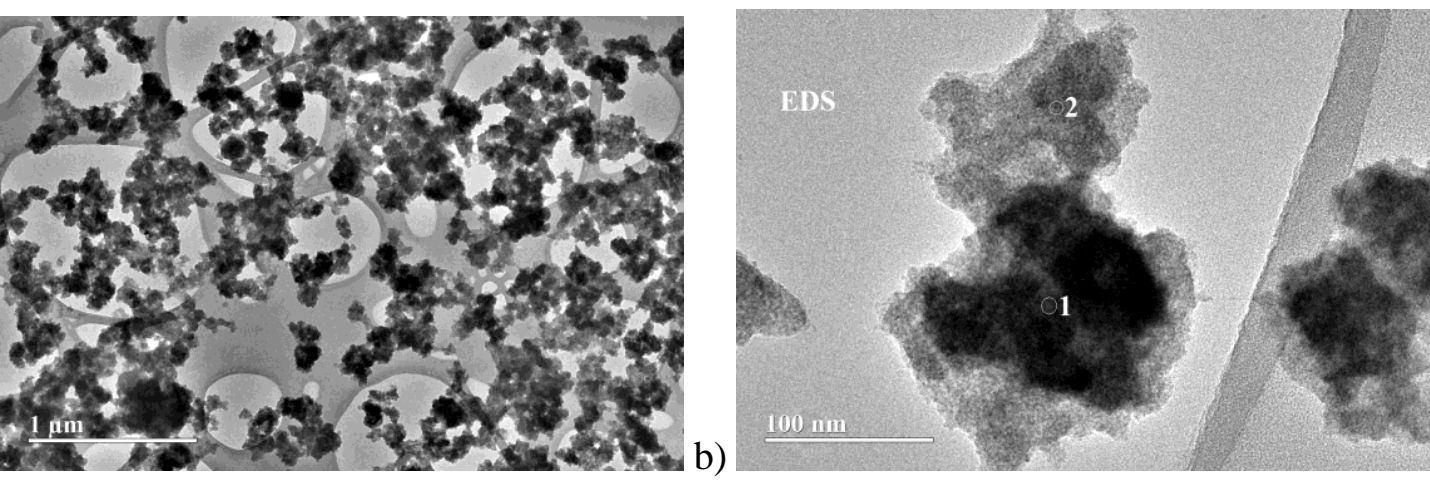

Figura 20- Micrografias da amostra ECoBG 150

Foram realizadas medidas de EDS nas imagens da Figura 20-b nas regiões 1e 2. Na região 1 da Figura 20-b apresentam os elementos Fe e Co em $\chi_{M}$ de 0,09, na região 2 apresentam os elementos Fe e Co em $\chi_{\mathrm{M}}$ de 0,10 . O conjunto de resultados de DRX, EDX, TEM e EDS nos mostram que a amostra ECoBG 150, é amorfa, com um baixo teor de cobalto, podendo ser um estágio inicial da formação dos óxidos suscetíveis de serem sintetizados, entre eles a goetita e a ferrita de cobalto.
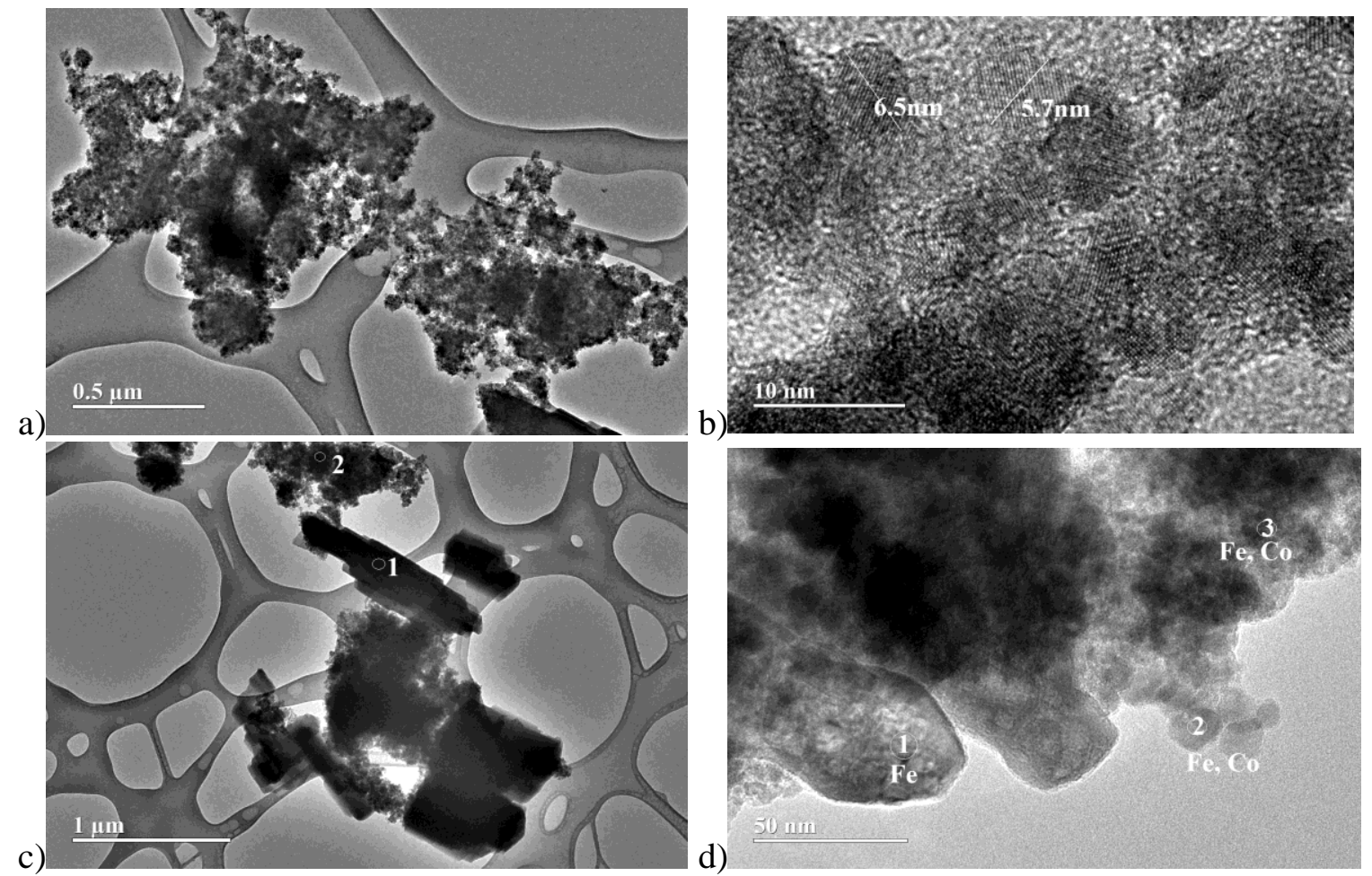

Figura 21-Micrografias da amostra ECoBG 200 
Foram realizadas medidas de EDS nas imagens da Figura 21-c nas regiões 1e 2 e na Figura 21-d nas regiões 1, 2 e 3 para verificar a composição das amostras. Na região 1 da Figura 21-c apresenta apenas um óxido de cobalto, na região 2 apresentam os elementos Fe e Co em $\chi_{M}$ de 0,15 . Na região 1 da Figura 21-d apresenta apenas um óxido de ferro, na região 2 apresentam os elementos $\mathrm{Fe}$ e Co em $\chi_{M}$ de 0,32 , na região 3 apresentam os elementos $\mathrm{Fe}$ e Co em $\chi_{\mathrm{M}}$ de 0,15 .

A amostra ECoBG 200, possui três regiões distintas, a primeira que possui partículas esféricas da ordem de $6 \mathrm{~nm}$ com uma proporção de ferro e cobalto próxima da esperada para ferrita espinélio, uma segunda região com morfologias variadas e quantidades de ferro e cobalto com $\chi_{\mathrm{M}}$ da ordem de 0,12 . E uma terceira região com a presença apenas de um óxido de ferro.

a)

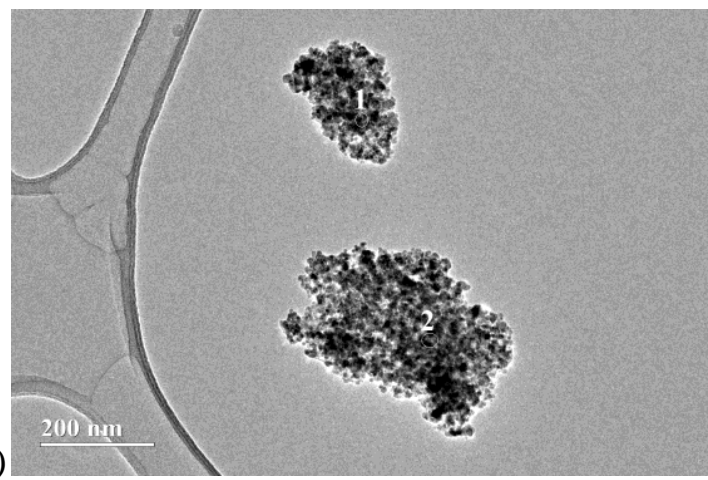

c)

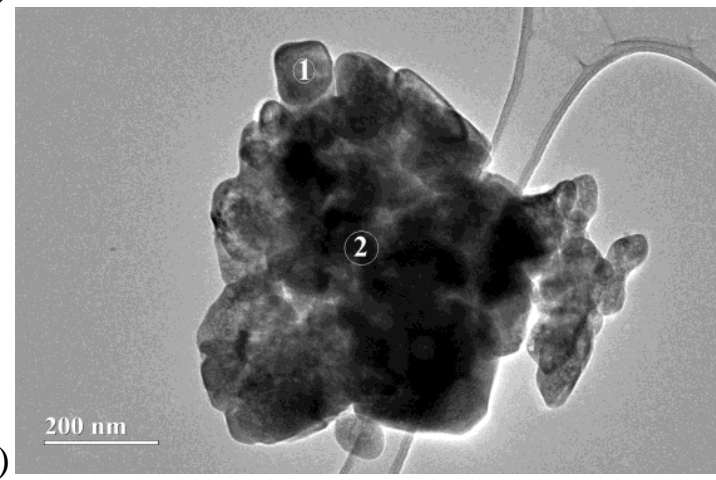

b)

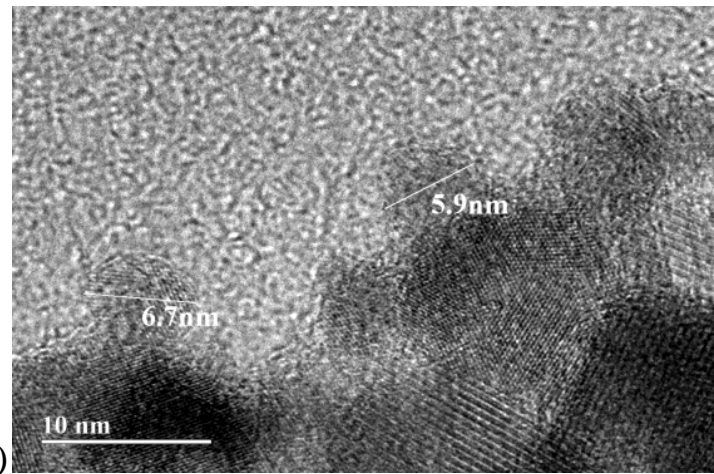

d)

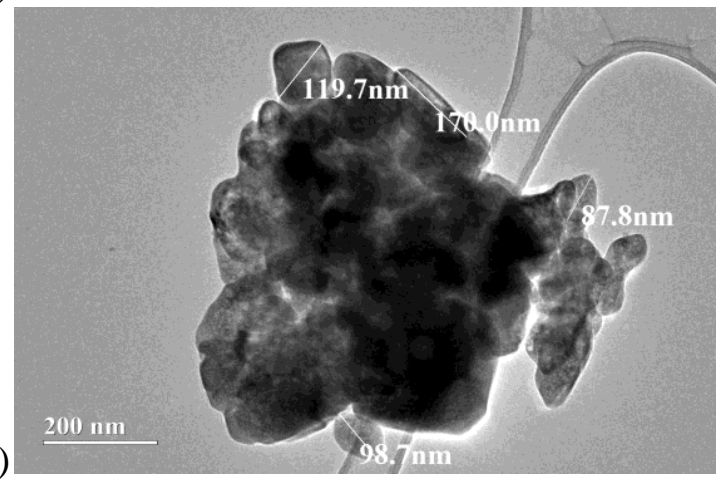

Figura 22-Micrografias da amostra ECoBG 250

Foram realizadas medidas de EDS nas imagens da Figura 22-a nas regiões 1e 2 e na Figura 22-c nas regiões 1 e 2 para verificar a composição das amostras. Na região 1 da Figura 
22-a apresentam os elementos Fe e Co em $\chi_{M}$ de 0,32, na região 2 apresentam os elementos Fe e Co em $\chi_{M}$ de 0,31. Nas regiões 1 e2 da Figura 22-c apresenta apenas um óxido de ferro.

A amostra ECoBG 250, possui duas regiões distintas, a primeira que possui partículas esféricas da ordem de 6nm com uma proporção de ferro e cobalto próxima da esperada para ferrita espinélio, uma segunda região com morfologias variadas com a presença apenas de um óxido de ferro com tamanhos da ordem de 100nm.

\section{$4^{\circ}$ Conjunto- Mistura estequiométrica de $\mathrm{Fe}$ e $\mathrm{Co}$ na presença de $\mathrm{NaOH}$ e}

\section{Glicerol 43,55\%}

Essas sínteses foram realizadas como uma tentativa de realizar a etapa de coprecipitação hidrotérmica que é realizada na síntese dos ferrofluidos, na presença do Glicerol a 43,22\%. No caso deste conjunto a concentração de base foi aumentada em relação ao conjunto anterior, assim utilizamos uma mistura dos sais de metais na presença de $\mathrm{NaOH}$ em uma solução 43,55\% de Glicerol, numa diluição de 1:2:10,5, com a concentração da base sendo utilizada na mesma concentração das sínteses convencionais. O glicerol foi utilizado para diminuir a velocidade de difusão da síntese.

Tabela 10- Resultado de $\mathrm{D}_{\mathrm{RX}}$ do $4^{\circ}$ conjunto- mistura estequiométrica de Fe e Co na presença de $\mathrm{NaOH}$ e glicerol $43,55 \%$

\begin{tabular}{|c|c|c|c|}
\hline Metodologia & Nome & $\begin{array}{c}\text { Temperatura } \\
\left({ }^{\circ} \mathrm{C}\right)\end{array}$ & $\mathrm{D}_{\mathrm{RX}}$ \\
\hline \multirow{2}{*}{$\begin{array}{c}1: 2: 10,5 \\
\mathrm{Co}: \mathrm{Fe}: \mathrm{NaOH}+\end{array}$} & ECoB2G100 & 100 & - \\
\cline { 2 - 4 } Glicerol 43,55\% & ECoB2G150 & 150 & - \\
\cline { 2 - 4 } & ECoB2G200 & 200 & 5,38 \\
\cline { 2 - 4 } & ECoB2G250 & 250 & 10,52 \\
\hline
\end{tabular}




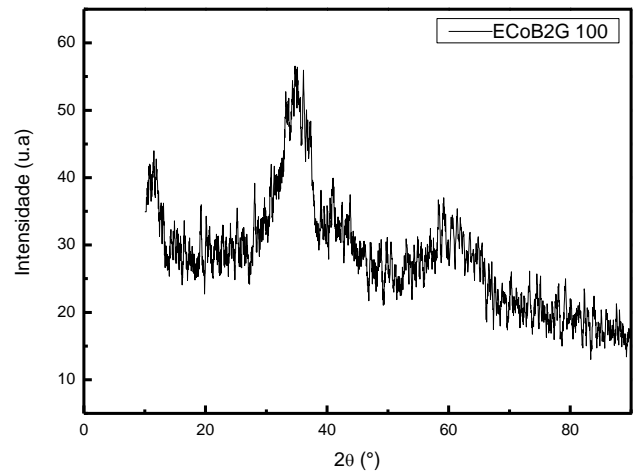

a)

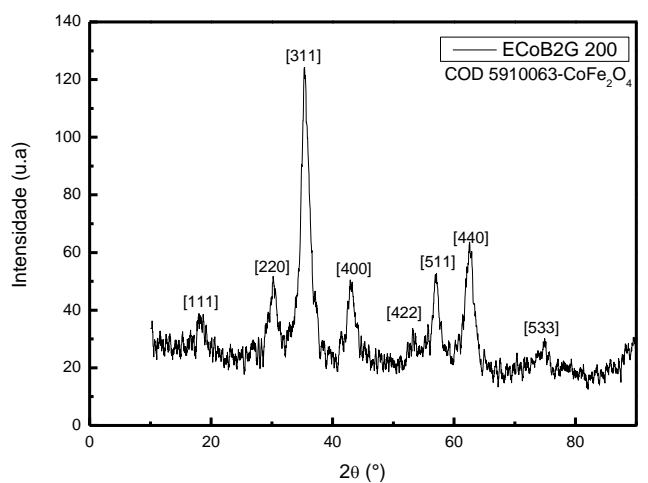

c)

Figura 23- Difratogramas das sínteses realizadas no reator de hidrometalurgia a partir da mistura estequiométrica de Fe e Co na presença de $\mathrm{NaOH}$ em uma solução 43,55\% em glicerol: amostra ECoBG100(a), ECoB2G150(b), ECoB2G200(c) e ECoBG250(c)

Nas Figuras 23-a, 23-b não foi possível identificar um padrão correspondente para essas amostras com o software. Nas Figuras 23-c e 23-d apresenta apenas a fase ferrita de Cobalto- $\mathrm{CoFe}_{2} \mathrm{O}_{4}$, de estrutura cúbica.

Os tamanhos médios dos cristais foram calculados utilizando a equação de Scherrer para estruturas esféricas. Foram obtidos os valores 5,38nm; 10,52nm, para as amostras ECoB2G200, ECoB2G250 respectivamente (Tabela 10). 
Tabela 11- Resultado de EDX e AAS do $4^{\circ}$ Conjunto- Mistura estequiométrica de Fe e Co na presença de $\mathrm{NaOH}$ e glicerol $43,55 \%$

\begin{tabular}{|c|c|c|c|c|c|c|}
\hline Metodologia & Nome & $\mathrm{Fe}(\%)$ & $\mathrm{Co}(\%)$ & $\begin{array}{c}\text { Outros } \\
(\%)\end{array}$ & $\begin{array}{c}\chi_{\mathrm{M}} \\
\text { EDX }\end{array}$ & $\begin{array}{c}\chi_{\mathrm{M}} \\
\text { AAS }\end{array}$ \\
\hline $\begin{array}{c}1: 2 \\
\mathrm{Co}: \mathrm{Fe}+ \\
\mathrm{NaOH} / \mathrm{L}+ \\
\mathrm{Glicerol}\end{array}$ & ECoB2G100 & 62,42 & 36,56 & 0,02 & 0,369 & - \\
\cline { 2 - 7 } & ECoB2G150 & 64,77 & 35,09 & 0,14 & 0,351 & - \\
\cline { 2 - 7 } & ECoB2G200 & 63,13 & 36,71 & 0,16 & 0,368 & - \\
\cline { 2 - 7 } & ECoB2G250 & 65,33 & 34.56 & 0,11 & 0,346 & 0,30 \\
\hline
\end{tabular}

O EDX mostra que em todas amostras há presença de Fe e Co com $\chi_{\mathrm{M}}$ acima de 0,33, que é o esperado para a ferrita. O valor que mais se aproxima do valor esperado é o da amostra ECoB2G 250 (Tabela 11). Foi realizada a técnica de Espectrometria de Absorção Atômica para essa amostra, que apresentou uma relação inferior a esperada apresentando o valor de $\chi_{M} 0,30$

As Amostras ECoB2G200 e ECoB2G250 foram escolhidas para realização de Microscopia Eletrônica de Transmissão com EDS.

a)

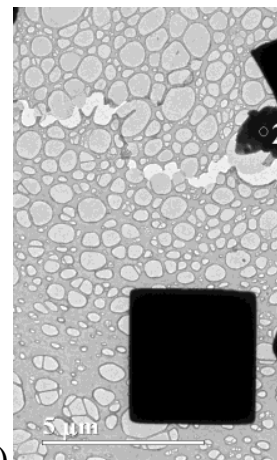

$$
\text { a) }
$$

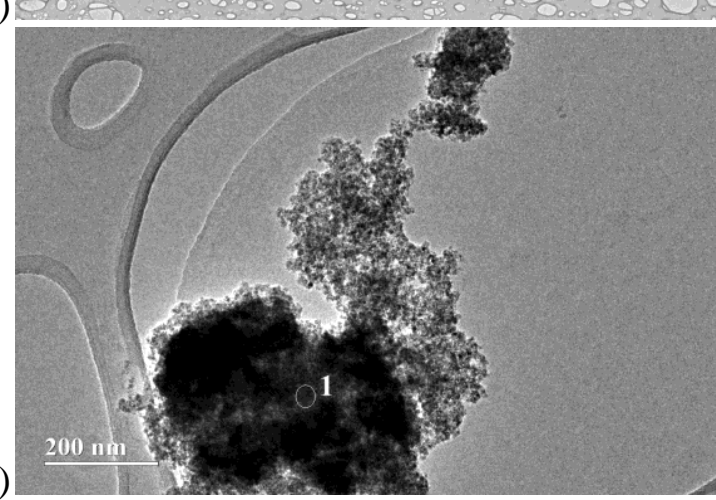

b)

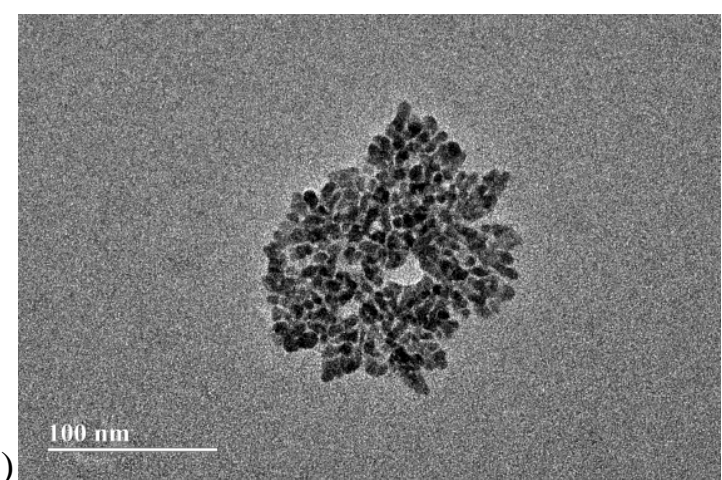

d)

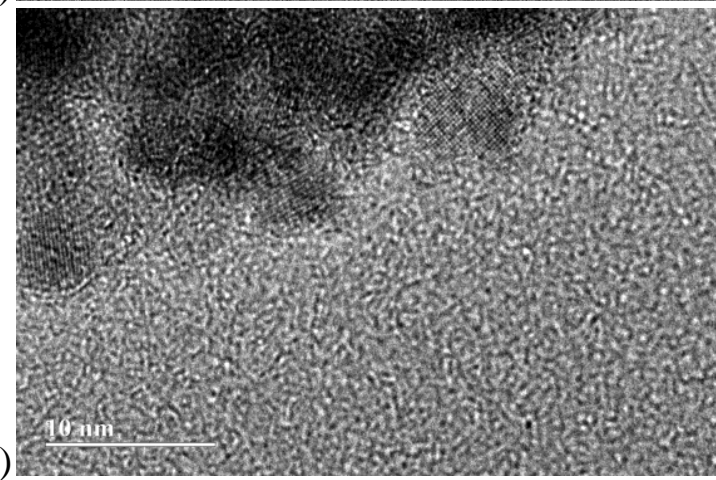

Figura 24-Micrografias da amostra ECoB2G 200 
Foram realizadas medidas de EDS nas imagens da Figura 24-a nas regiões 1e 2 e na Figura 24-c na regiões 1 para verificar a composição das amostras. A região 1 da Figura 24-a apresenta apenas Co metálico, a região 2 apresenta os elementos Fe e Co em $\chi_{M}$ de 0,99. A região 1 da Figura 24-c apresenta os elementos Fe e Co em $\chi_{M}$ de 0,33

As imagens apresentam duas regiões distintas, a primeira com morfologia cúbica com tamanhos da ordem de 500nm formada apenas pelo elemento cobalto, entretanto este tipo e tamanho de estrutura não foram evidenciadas nos difratogramas, podendo significar que a sua presença é estatisticamente pequena. Ainda temos uma segunda região com morfologia parcialmente esférica com um $\chi_{M}$ de 0,33 , que é uma relação esperada para ferrita de cobalto. 
a)
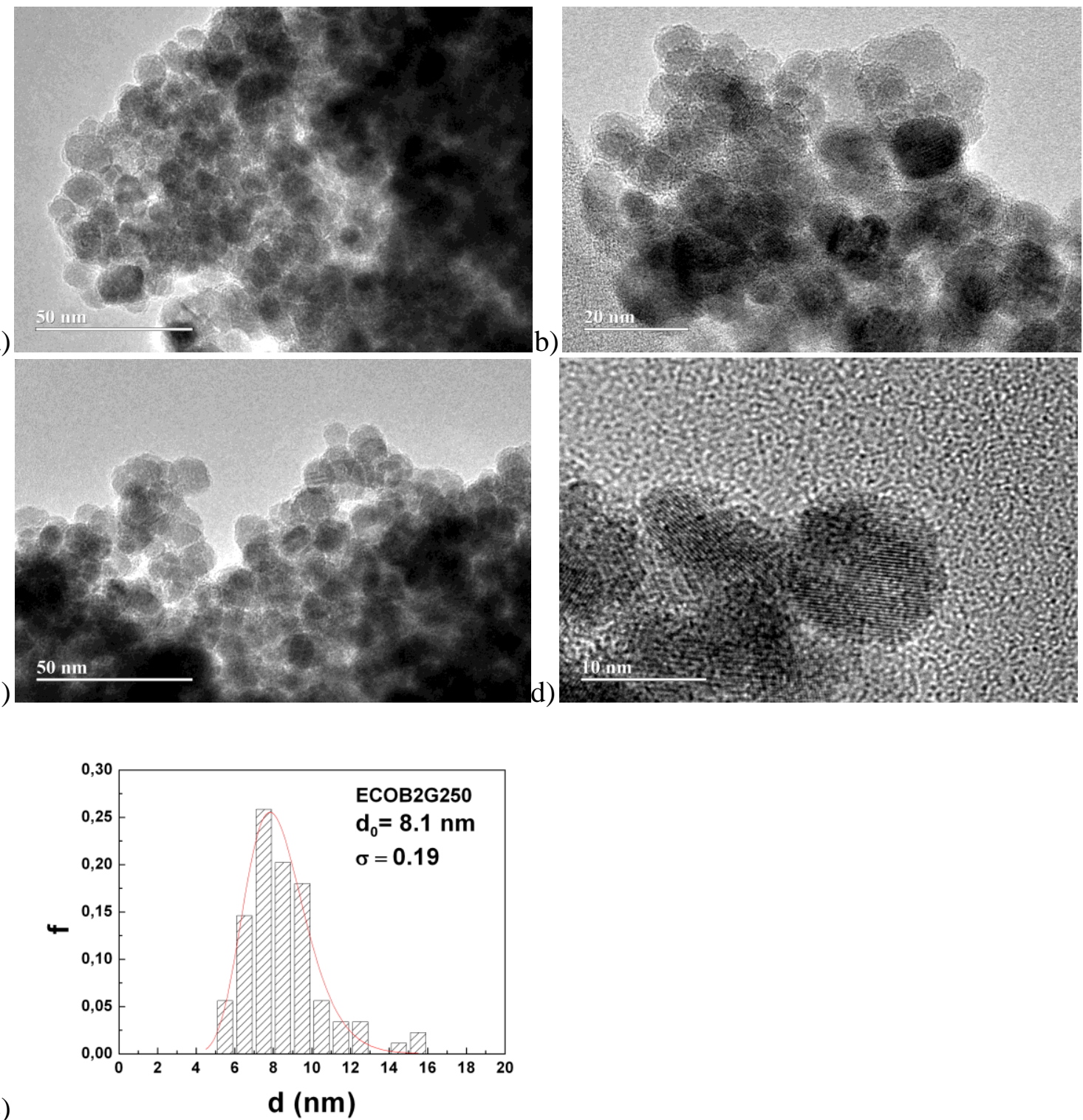

e)

Figura 25-Micrografias da amostra ECoB2G 250 e o histograma de distribuição em tamanho

Foi realizada medida de EDS em uma imagem para verificar a composição das amostras, que apresenta os elementos Fe e Co em $\chi_{\mathrm{M}}$ de 0,32 .

As imagens apresentam uma amostra predominantemente esférica da ordem de 10nm com uma distribuição de tamanho próxima. De fato, para esta amostra foi possível obter um histograma de distribuição em tamanhos, com tamanho característicos de 8,1 nm e índice de polidispersão de 0,19 , indicando uma amostra muito pouco polidispersa. A baixa polidispersão e forma perfeitamente esférica da amostra pode ser um resultado do aumento da viscosidade do meio que vai favorecer a formação homogênea de núcleos. 
$5^{\circ}$ Conjunto-mistura dos metais na presença da base $\mathrm{NaOH}$ e do ácido cítrico em uma relação molar de 1:2:11:10

Essas sínteses foram realizadas como uma tentativa de realizar a etapa de coprecipitação hidrotérmica que é realizada na síntese dos ferrofluidos, na presença de ácido cítrico, utilizado como agente complexante. E foram realizadas a partir de uma mistura de sais de metais na presença de $\mathrm{NaOH}$, em uma relação molar de 1:2:11:10.

Tabela 12- Resultado de $\mathrm{D}_{\mathrm{Rx}}$ do $5^{\circ}$ conjunto-mistura dos metais na presença de $\mathrm{NaOH}$ e do Ácido Cítrico em uma relação molar de 1:2:11:10

\begin{tabular}{|c|c|c|c|}
\hline Metodologia & Nome & $\begin{array}{c}\text { Temperatura } \\
\left({ }^{\circ} \mathrm{C}\right)\end{array}$ & $\mathrm{D}_{\mathrm{RX}}$ \\
\hline \multirow{2}{*}{$\begin{array}{c}\text { Co: Fe: NaOH: Ácido } \\
\text { Cítrico }\end{array}$} & ECoBA150 & 150 & - \\
\cline { 2 - 4 } & ECoBA200 & 200 & - \\
\cline { 2 - 4 } & ECoBA250 & 250 & 7,98 \\
\hline
\end{tabular}




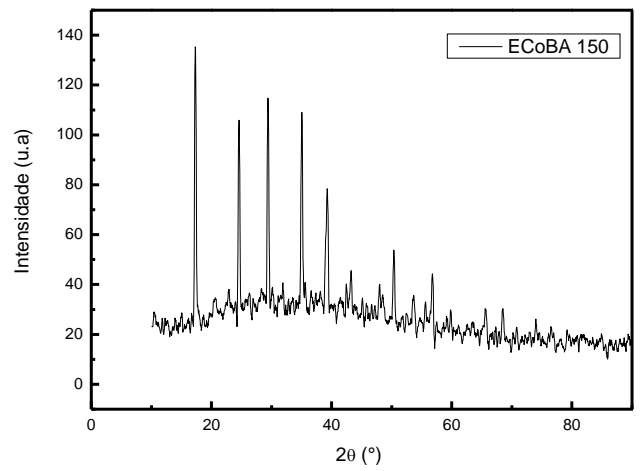

a)

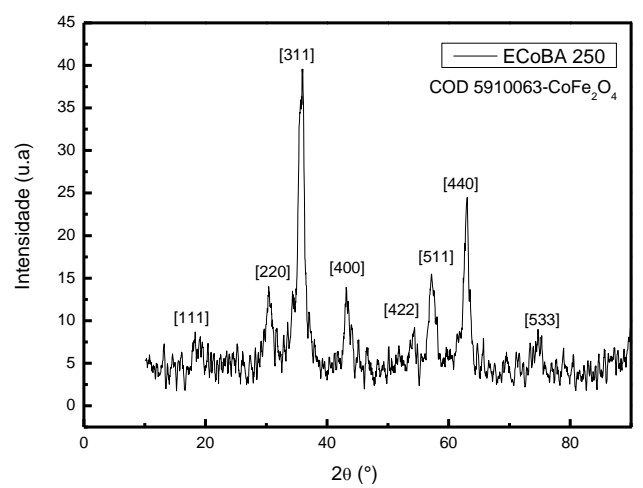

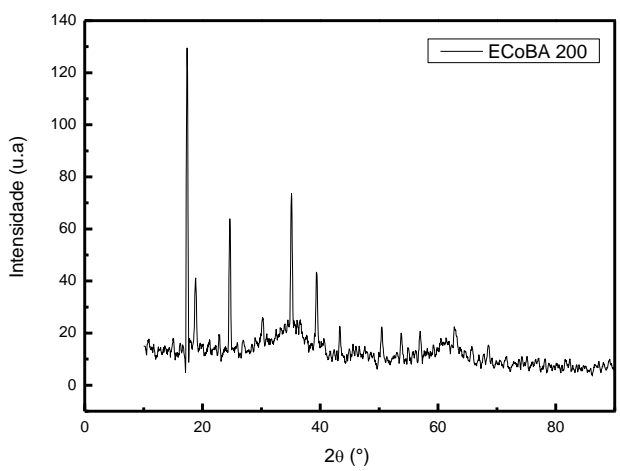

b)

c)

Figura 26- Difratogramas das sínteses realizadas no reator de hidrometalurgia a partir da mistura estequiométrica de $\mathrm{Fe}$ e $\mathrm{Co}$ na presença de $\mathrm{NaOH}$ e ácido cítrico em uma solução 43,55\% em glicerol: amostra, ECoBA150(a), ECoBA200(b) e ECoBA250(c)

Nas figuras 26-a e 26-b não possível identificar um padrão correspondente para essas amostras. Porém nas Figuras 26-a e 26-b observa-se um alargamento do pico que se encontra próximo a 35 graus, região essa que se encontra o pico mais intenso da ferrita de cobalto, que sugere o inicio do processo de formação da ferrita. Na Figura 26-c apresenta apenas a fase ferrita de Cobalto- $\mathrm{CoFe}_{2} \mathrm{O}_{4}$, de estrutura cúbica.

Os tamanhos médios dos cristais foram calculados utilizando a equação de Scherrer para estruturas esféricas. Foram obtidos os valores 7,88nm, para as amostras ECoBA250 (Tabela 12). 
Tabela 13- Resultado de EDX $5^{\circ}$ Conjunto-mistura dos metais na presença de $\mathrm{NaOH}$ e do Ácido Cítrico em uma relação molar de 1:2:11:10

\begin{tabular}{|c|c|c|c|c|c|c|}
\hline Metodologia & Nome & $\mathrm{Fe}(\%)$ & $\mathrm{Co}(\%)$ & $\begin{array}{c}\text { Outros( } \\
\%)\end{array}$ & $\begin{array}{c}\chi_{\mathrm{M}} \\
\text { EDX }\end{array}$ & $\begin{array}{c}\chi_{\mathrm{M}} \\
\text { AAS }\end{array}$ \\
\hline $1: 2$ & ECoBA150 & 0,55 & 98.58 & 0,87 & 0,994 & - \\
$\mathrm{Co}: \mathrm{Fe}+$ & ECoBA200 & 73.41 & 26,12 & 0,47 & 0,262 & - \\
\cline { 2 - 7 } $\begin{array}{c}\mathrm{NaOH} 0,875 \mathrm{~mol} / \mathrm{L}+ \\
\text { Ácido Cítrico }\end{array}$ & ECoBA250 & 63,02 & 36,89 & 0,09 & 0,369 & 0,33 \\
\hline
\end{tabular}

O EDX mostra que na amostra ECoBA150 apresenta uma elevada quantidade de cobalto em um $\chi_{\mathrm{M}}$ de 0,99 . E um aumento da quantidade de cobalto com o aumento da temperatura nas amostras ECoBA 200 e ECoBA 250. Foi realizada a técnica de Espectrometria de Absorção Atômica para amostra ECoBA 250, que apresentou uma relação de $\chi_{M} 0,33$, como a esperada para ferrita de cobalto do tipo espinélio.

A Amostra EcoBA250 foi escolhida para realização de Microscopia Eletrônica de Transmissão com EDS. Para verificar a morfologia e composição das amostras.

a)
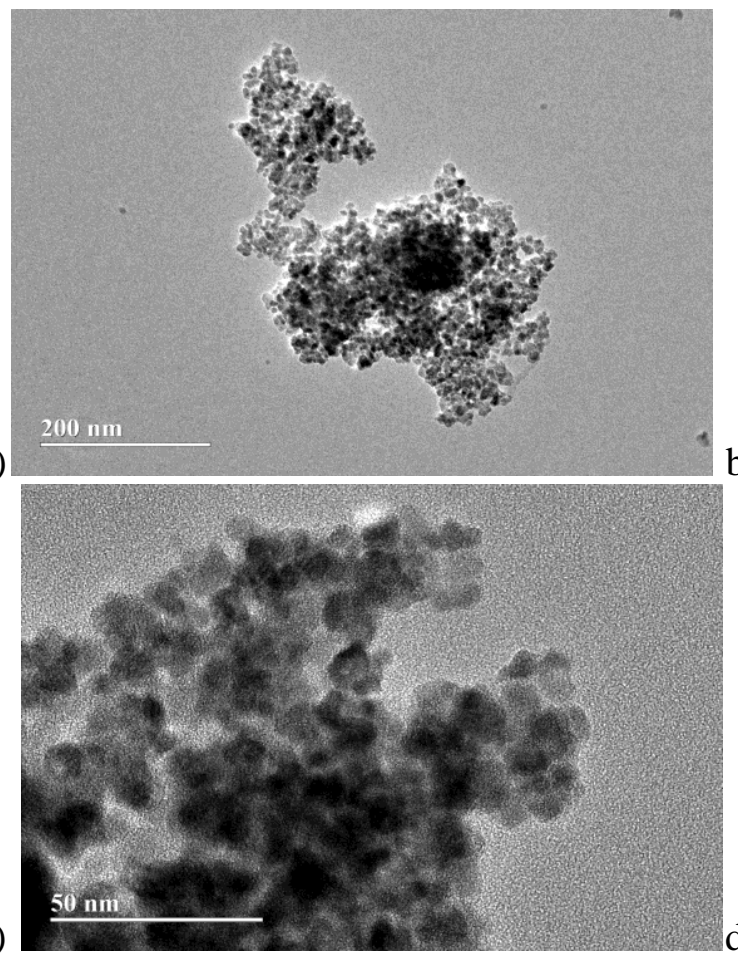

b)

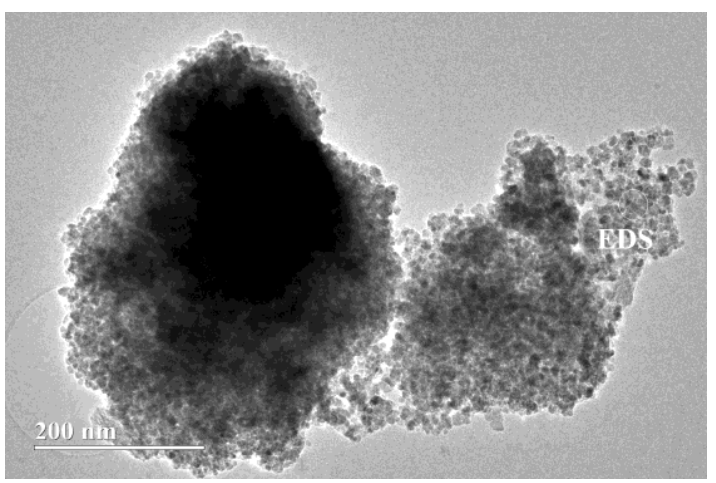

d)

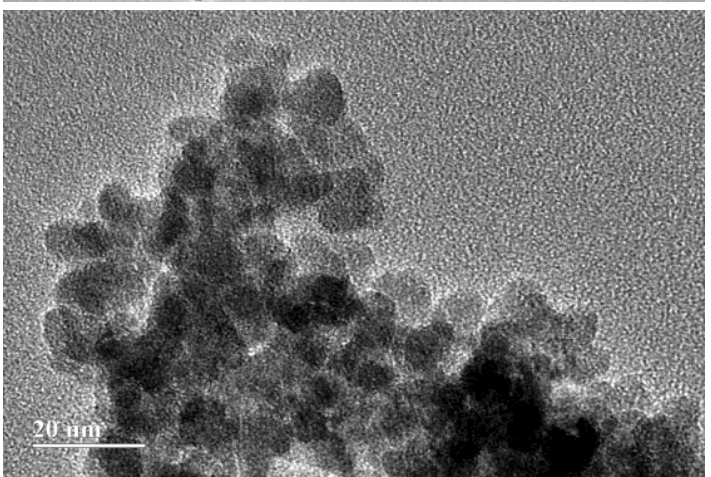

Figura 27-Micrografias da amostra ECoBA 250 
Foi realizada medida de EDS nas imagens da Figura 27-b nas regiões para verificar a composição das amostras. A região 1 da Figura 27-b apresenta os elementos Fe e Co em $\chi_{M}$ de 0,36. As imagens apresentam uma amostra predominantemente esférica da ordem de $6 \mathrm{~nm}$ com uma distribuição de tamanho próxima, entretanto as partículas estavam muito aglomeradas e não foi possível levantar a distribuição em tamanhos.

Podemos destacar que nas mesmas condições de concentração da base e temperatura a presença do ácido cítrico diminuiu o tamanho médio das partículas de 10,52 nm, para amostra ECoB2G250, para 7,88 nm, para a amostra ECoBA250, evidenciando o favorecimento no processo de nucleação pela presença do ácido cítrico como complexante. 


\section{CONCLUSÕES E PERSPECTIVAS}

Apresentamos neste trabalho a investigação da síntese de nanoparticulas de ferrita de cobalto por precipitação hidrotérmica. As sínteses foram realizadas em reator de hidrometalurgia em temperaturas entre 100 e $250^{\circ} \mathrm{C}$. Os principais parâmetros investigados foram temperatura de síntese, composição do meio reacional, concentração da base e presença de agente complexante. Inicialmente, foi realizado a mistura estequiométrica dos metais Fe:Co (2:1), em pH ácido. Em seguida a mistura estequiométrica dos metais foi feita na em meio básico. Ainda, foi investigada a presença de glicerol na mistura reacional, bem como a presença de um agente complexante.

Somente foram obtidas amostras compostas unicamente de ferrita de cobalto, para sínteses realizadas em $250{ }^{\circ} \mathrm{C}$ em meio básico. As sínteses realizadas em meio reacional com $43,55 \%$ de glicerol e a $250{ }^{\circ} \mathrm{C}$ em diferentes concentrações de $\mathrm{NaOH}$, evidenciaram o papel preponderante a base na obtenção da condição de supersaturação relativa que favorece a formação do precipitado. Ainda, a presença do glicerol reduziu a velocidade de difusão no meio levando a um produto com forma mais homogênea e menor polidispersão. De fato, a amostra ECoB2G250 apresenta $d_{R X}=10,52 \mathrm{~nm}$ e histograma de distribuição em tamanhos, com tamanho característico de $8,1 \mathrm{~nm}$ e índice de polidispersão de 0,19 , indicando uma amostra muito pouco polidispersa. Por fim, verificamos que nas mesmas condições de concentração da base e temperatura a presença do ácido cítrico diminuiu o tamanho médio das partículas, evidenciando o favorecimento no processo de nucleação pela presença do ácido cítrico como complexante.

Neste contexto, como perspectivas para esse trabalho, procuraremos realizar a elaboração de fluidos magnéticos à base das nanoparticulas obtidas nas sínteses ECoB2G250 e ECoBA250. Estas partículas, possuem tamanhos da ordem de uma dezena de nanômetros e 
reduzida polidispersão, representando um objeto de estudo muito interessante para elucidar as propriedades magnéticas e magneto-óticas das nanopartículas, bem como no design de produtos para aplicações tecnológicas e biotecnológicas. 


\section{REFERÊNCIAS BIBLIOGRÁFICAS}

\footnotetext{
${ }^{1}$ ROCO, Mihail C. Broader societal issues of nanotechnology. Journal of Nanoparticle Research, v. 5, n. 3-4, p. 181-189, 2003.

${ }^{2}$ KOTLER, Philip; SIMON, Françoise. A construção de biomarcas globais: levando a biotecnologia ao mercado. 2004.

${ }^{3}$ ITO, Akira et al. Medical application of functionalized magnetic nanoparticles. Journal of bioscience and bioengineering, v. 100, n. 1, p. 1-11, 2005.

${ }^{4}$ ROSENSWEIG, R. E. Ferrohydrodynamics. Cambridge University Press, Cambridge, 1985

${ }^{5}$ HANNICKEL, A. Estudo de Nanopartículas de Magnetita Obtidas Pelos Métodos de Coprecipitação, Biossíntese e Moagem. Dissertação de Mestrado, Instituto Militar de Engenharia - Rio de Janeiro, 2010

${ }^{6}$ KNOBEL, M. Partículas finas: Superparamagnetismo e Magnetoresitência gigante. Revista Brasileira de Ensino de Física. vol. 22, n.03, p.387-395. 2000.

7 WOLHFARTH, E. P.; Ferromagnetic Materials, Volume III, North-Holland Publishing Company: Amsterdan, 1982.

${ }^{8}$ BITTER, Francis. Experiments on the nature of ferromagnetism. Physical Review, v. 41, n. 4, p. 507, 1932.

${ }^{9}$ ELMORE, W. C. The magnetization of ferromagnetic colloids. Physical Review, v. 54, n. 12, p. $1092,1938$.

${ }^{10}$ ROSENSWEIG, Ronald E. Study of ferromagnetic liquid. National Aeronautics and Space Administration, 1969.

${ }^{11}$ KHALAFALLA, S. E.; REIMERS, G. W.; US Patent 3764540, 1973

${ }^{12}$ MASSART, R.; IEEE Trans. Magnetics, MAG-17 (2), p. 1247, 1981.

${ }^{13}$ TOURINHO, F. A.; DEPEYROT, J.; DA SILVA, G. J.; LARA, M. C. F. L.; Braz J Phys, 28 (4), $413,1998$.

${ }^{14}$ CABUIL, V., Tese de Doutorado, Universidade Paris VI, 1987.

15 TOURINHO, F.A.; Thèse de Doctorat D'Etat ès Sciences Physiques, Universidade Paris VI, França, 1988.

${ }^{16}$ AQUINO, R.;Tese de doutorado, Universidade de Brasília, Brasil, 2003

${ }^{17}$ ZIOLO, R. F. U. S. Patent 4,474,866, 1984.
}

${ }^{18}$ ODENBACH, S. Ferrofluids-magnetically controlled suspensions. Colloids and Surfaces A: Physicochemical and Engineering Aspects, v. 217, n. 1, p. 171-178, 2003.

${ }^{19}$ NGATU, G. T. et al. Dimorphic magnetorheological fluids: exploiting partial substitution of microspheres by nanowires. Smart Materials and Structures, v. 17, n. 4, p. 045022, 2008.

${ }^{20}$ RAJ, K.; MOSKOWITZ, B.; CASCIARI, R. Advances in ferrofluid technology. Journal of magnetism and magnetic materials, v. 149, n. 1, p. 174-180, 1995

${ }^{21}$ OGDEN, Frank. The Last Book You'll Ever Read: And Other Lessons from the Future. Macfarlane Walter \& Ross, 1993.

${ }^{22}$ BACRI, J.C.; PERZYNSKI, R.; SALIN, D.; La Recherche 118, 1149, 1987.

23 GALlO, James M.; HAFELI, Urs. Correspondence re: AS Lübbe et al., Preclinical Experiences with Magnetic Drug Targeting: Tolerance and Efficacy. Cancer Res., 56: 4694-4701, 1996; and Clinical Experiences with Magnetic Drug Targeting: A Phase I Study with 4'-Epidoxorubicin in 14 Patients with Advanced Solid Tumors. Cancer Res., 56: 4686-4693, 1996 Letter. Cancer Research, v. 57, n. 14, p. 3063-3064, 1997.

24 NUNEZ, L. et al. Actinide separation of high-level waste using solvent extractants on magnetic microparticles. Separation science and technology, v. 31, n. 10, p. 1393-1407, 1996.

${ }^{25}$ JAIN, Kewal K. Nanotechnology in clinical laboratory diagnostics. Clinica Chimica Acta, v. 358, n. 1 , p. $37-$ 54, 2005.

${ }^{26}$ VAN HECKE, Paul et al. Experimental study of the pharmacokinetics and dose response of ferrite particles used as a contrast agent in MRI of the normal liver of the rabbit. Investigative radiology, v. 24, n. 5, p. 397-399, 1989.

27 JORDAN, Andreas et al. Magnetic fluid hyperthermia (MFH): Cancer treatment with AC magnetic field induced excitation of biocompatible superparamagnetic nanoparticles. Journal of Magnetism and Magnetic Materials, v. 201, n. 1, p. 413-419, 1999

${ }^{28}$ HÄFELI, Urs et al. Radiolabeling of magnetic particles with rhenium-188 for cancer therapy. Journal of magnetism and magnetic materials, v. 225, n. 1, p. 73-78, 2001. 
${ }^{29}$ HÄFELI,U. Radiolabeled Magnetic Microcapsules for Magnetically Targeted Radionuclide Therapy, In MML Series, Vol. 3, Citus Ltda, Londres, 2000.

${ }^{30}$ BACRI, J. C. Workshop on Magnetic Fluids, Brasília, Brazil Sept 2000.

${ }^{31}$ BACRI, Jean-Claude; PERZYNSKI, Regine; SALIN, Dominique. Magnetic liquids. Endeavour, v. 12, n. 2, p. 76-83, 1988

32 BACRI, J.-C. et al. "Negative-viscosity" effect in a magnetic fluid. Physical review letters, v. 75, n. 11, p. $2128,1995$.

${ }^{33}$ A. Halbreich, J. Roger, J.-N Ponds, M. F. da Silva, E. Hasmonay, M. Roudier, M. Boynard, C, Sestier, A, Amri, D. Geldweth, B. Fertil, J.-C. Bacri, D. Saborovic, in Scientific and Clinical Applications of Magnetic Carriers. (Eds) U. Häfeli, W. Schütt, J. Teller, M. Zborowski, PlenuM Press, New York ,1997.

${ }^{34}$ KITTEL, C.; Introducion a lá física del estado sólido, $2^{\mathrm{a}}$ edição, Ed. Reverté S.A: Espanha, 1975.

${ }^{35}$ BENOIT, H.; Ann. Phys. Paris, 12,6,1951.

${ }^{36}$ ROSENSWEIG, Ronald E. Ferrohydrodynamics. Cambridge University Press, New York, 1985.

${ }^{37}$ H. W. Davies, J. P. Llewellyn, J. Phys. D12, 311, 1979.

38 SHAW, Duncan James. Introdução à Química dos Colóides e de Superfícies. E. Blücher, 1975. tradução:Juergen Heinrich Maar. São Paulo: Edgard Blücher, Ed. da Universidade de São Paulo,1987.

39 VALENZUELA, R. Chemistry of Solid State Materials:Magnetic Ceramics. New York: Cambridge University Press, v.4, 1994

${ }^{40}$ SHRIVER, D. F.; ATKINS, P. W.; LANGFORD, C.H.; Inorganic Chemistry, $2^{\mathrm{a}}$ ed. Oxford University Press: London, 1995.

${ }^{41}$ CULLITY, A. D. Introduction to magnetic materials. Reading: Addison-Wesley, 1972.

${ }^{42}$ GOLDMAN, Alex. Modern ferrite technology. Springer Science \& Business Media, 2006.

${ }^{43}$ SCHWERTMANN, Udo; CORNELL, Rochelle M. The Iron Oxides. John Wiley \& Sons, New York, 1997.

${ }^{44}$ SUZUKI, Masatsugu; SUZUKI, Itsuko S. Lecture note on solid state physics Superexchange interaction. Binghamton, New York, p. 13902-6000, 2009.

${ }_{45}$ WOLHFARTH, E.P. Ferromagnetic Materials, Volume III, North-Holland Publishing Company, Amsterdan, 1982.

${ }^{46}$ KIM, Chul Sung et al. Growth of ultrafine Co-Mn ferrite and magnetic properties by a sol-gel method. Journal of applied physics, v. 85, n. 8, p. 5223-5225, 1999.

${ }^{47}$ CHIKAZUMI, Soshin. Physics of Ferromagnetism, Oxford University Press, New York, 1999.

${ }^{48}$ ZHANG Y., YANG Z., YIN D., LIU Y.,FEI C. L., XIONG R., SHI J. e YAN G. L., Composition and magnetic properties of cobalt ferrite nanoparticles prepared by the co-precipitation method. J. Magn. Magn. Mater., v. 322, p. 3470-3475, 2010.

${ }^{49}$ MCCURRIE, Rs A. Ferromagnetic materials. Academic Press, Inc., San Diego, Califórnia, 1994.

${ }^{50}$ CULLITY B. D. e GRAHAM C. D. Introduction to Magnetic Materials. 2nd edition. Wiley, New Jersey, 2009.

${ }^{51}$ YAN, Chunhua et al. Sol-gel synthesis, magnetic and magneto-optical properties of $\mathrm{CoFe}_{2}-\mathrm{x} \mathrm{Tb}_{\mathrm{x} \mathrm{O}}$ nanocrystalline films. Journal of magnetism and magnetic materials, v. 192, n. 3, p. 396-402, 1999.

${ }^{52}$ XIAO, Shun Hua; LUO, Kun; ZHANG, Lin. The structural and magnetic properties of cobalt ferrite nanoparticles formed in situ in silica matrix. Materials Chemistry and Physics, v. 123, n. 2, p. 385-389, 2010.

${ }^{53}$ KNELLER, Eckart F.; HAWIG, Reinhard. The exchange-spring magnet: a new material principle for permanent magnets. Magnetics, IEEE Transactions on, v. 27, n. 4, p. 3588-3560, 1991.

54 GARCÍA-CERDA, L. A. et al. Preparación de compósitos magnéticos mediante la síntesis in situ de nanopartículas. Superficies y vacío, v. 19, n. 1, p. 20-24, 2006.

55 VARMA, P. et al. Magnetic properties of $\mathrm{CoFe}_{2} \mathrm{O}_{4}$ synthesized by solid state, citrate precursor and polymerized complex methods: A comparative study. Journal of Alloys and Compounds, v. 453, n. 1-2, p. 298-303, 2008

${ }^{56}$ SUGIMOTO, Mitsuo. The past, present, and future of ferrites. Journal of the American Ceramic Society, v. 82, n. 2, p. 269-280, 1999.

${ }^{57}$ FREESTONE, Ian et al. The Lycurgus cup —a roman nanotechnology. Gold Bulletin, v. 40, n. 4, p. 270-277, 2007.

${ }^{58}$ CARDOSO, Lucia Helena Guimarães. Nanopartículas magnéticas de ferritas mistas de cobalto e zinco. Tese de Doutorado. IME, Rio de Janeiro, 2011

${ }^{59}$ FEYNMAN, Richard P. There's plenty of room at the bottom. Engineering and science, v. 23, n. 5, p. 22-36, 1960.

${ }^{60}$ LIU, Xian-Ming; FU, Shao-Yun; ZHU, Lu-Ping. High-yield synthesis and characterization of monodisperse sub-microsized $\mathrm{CoFe}_{2} \mathrm{O}_{4}$ octahedra. Journal of Solid State Chemistry, v. 180, n. 2, p. 461-466, 2007. 
${ }^{61}$ MENDELOVICI, E.; VILLALBA, R.; SAGARZAZU, A. Distinctive cobalt ferrites prepared by the thermaltransformation alkoxide route. Thermochimica acta, v. 318, n. 1, p. 51-56, 1998.

${ }^{62}$ LIMAYE, Mukta V. et al. High coercivity of oleic acid capped $\mathrm{CoFe}_{2} \mathrm{O}_{4}$ nanoparticles at room temperature. The Journal of Physical Chemistry B, v. 113, n. 27, p. 9070-9076, 2009.

${ }^{63}$ SATO, Toshihiko et al. Magnetic properties of ultrafine ferrite particles. Journal of Magnetism and Magnetic Materials, v. 65, n. 2, p. 252-256, 1987.

${ }^{64}$ LI, Jian et al. Properties of ferrofluid nanoparticles prepared by coprecipitation and acid treatment. Journal of Nanoparticle Research, v. 4, n. 3, p. 261-264, 2002.

${ }^{65}$ RAJENDRAN, M. et al. Magnetic properties of nanocrystalline CoFe $2 \mathrm{O} 4$ powders prepared at room temperature: variation with crystallite size. Journal of Magnetism and Magnetic Materials, v. 232, n. 1, p. 7183, 2001.

${ }^{66}$ PECHINI, M.P. U.S. Patent no.3330, 697, 1967.

${ }^{67}$ CHEN, Dong-Hwang; HE, Xin-Rong. Synthesis of nickel ferrite nanoparticles by sol-gel method. Materials Research Bulletin, v. 36, n. 7, p. 1369-1377, 2001.

${ }^{68}$ ALFAYA, Antonio AS; KUBOTA, Lauro T. A utilização de materiais obtidos pelo processo de sol-gel na construção de biossensores. Química Nova, v. 25, n. 5, p. 835-841, 2002.

${ }^{69}$ MERON, Tal et al. Synthesis and assembly of high-quality cobalt ferrite nanocrystals prepared by a modified sol-gel technique. Journal of Magnetism and Magnetic Materials, v. 292, p. 11-16, 2005.

70 BENSEBAA, F. et al. Microwave synthesis and characterization of Co-ferrite nanoparticles. Journal of colloid and interface science, v. 277, n. 1, p. 104-110, 2004.

${ }^{71}$ DA SILVA BORGES, Sivanildo; KORN, Mauro. Geração Sonoquímica de oxidantes em solução aquosa saturada de tetracloreto de carbono. Quim. Nova, v. 25, n. 4, p. 558-562, 2002.

72 SHAFI, Kurikka VPM et al. Sonochemical preparation and size-dependent properties of nanostructured CoFe2O4 particles. Chemistry of Materials, v. 10, n. 11, p. 3445-3450, 1998.

73 KOMMAREDDI, Nagesh S. et al. Synthesis of superparamagnetic polymer-ferrite composites using surfactant microstructures. Chemistry of materials, v. 8, n. 3, p. 801-809, 1996.

${ }^{74}$ MOUMEN, N.; VEILLET, P.; PILENI, M. P. Controlled preparation of nanosize cobalt ferrite magnetic particles. Journal of magnetism and magnetic materials, v. 149, n. 1, p. 67-71, 1995.

${ }^{5}$ NGO, A. T.; BONVILLE, P.; PILENI, M. P. Nanoparticles of: Synthesis and superparamagnetic properties. The European Physical Journal B-Condensed Matter and Complex Systems, v. 9, n. 4, p. 583-592, 1999.

${ }^{76}$ LIU, Chao et al. Chemical control of superparamagnetic properties of magnesium and cobalt spinel ferrite nanoparticles through atomic level magnetic couplings. Journal of the American Chemical Society, v. 122, n. 26, p. 6263-6267, 2000.

77 BLUMS, Elmars; MAIOROV, M. M.; KRONKALNS, G. Thermomagnetic properties of ferrofluids containing chemically coprecipitated Mn-Zn ferrite particles. Magnetics, IEEE Transactions on, v. 29, n. 6, p. 3267-3269, 1993.

78 ARULMURUGAN, R. et al. Mn-Zn ferrite nanoparticles for ferrofluid preparation: Study on thermalmagnetic properties. Journal of magnetism and magnetic materials, v. 298, n. 2, p. 83-94, 2006.

${ }^{79}$ AUZANS, E. et al. Synthesis and properties of Mn-Zn ferrite ferrofluids. Journal of materials science, v. 34, n. 6, p. 1253-1260, 1999.

${ }^{80}$ TOURINHO, F. et al. Synthesis and mangeitc properties of managanese and cobalt ferrite ferrite ferrofluids. In: Trends in Colloid and Interface Science III. Steinkopff, 1989. p. 128-134..

${ }^{81}$ SOUSA, Marcelo Henrique et al. New electric double-layered magnetic fluids based on copper, nickel, and zinc ferrite nanostructures. The Journal of Physical Chemistry B, v. 105, n. 6, p. 1168-1175, 2001.

${ }^{82}$ CAMPOS, A. F. C. et al. Nanoparticles superficial density of charge in electric double-layered magnetic fluid: A conductimetric and potentiometric approach. The European Physical Journal E, v. 6, n. 1, p. 29-35, 2001.

83 BERKOVSKY, B. Thermomechanics of magnetic fluids: Theory and applications; Proceedings of the International Advanced Course and Workshop, Udine, Italy, October 3-7, 1977. In: Thermomechanics of Magnetic Fluids: Theory and applications. 1978.

${ }^{84}$ BERKOVSKY, B. M.; MEDVEDEV, Vitalii Fedorovich; KRAKOV, Mikhail Samuilovich. Magnetic fluids. Oxford Univ. Press, 1993.

${ }^{85}$ SCHETTINO JR, M. A. Obtenção e caracterização de nanopartículas magnéticas inseridas em materiais carbonosos porosos a partir da decomposição do pentacarbonil ferro. Tese de Doutorado. UFES. 2009.

${ }^{86}$ GARCIA, L. M. P. Síntese citrato-hidrotermal e caraterização eletro-química de LSCF para aplicação como cátodo em célula a combustível de temperatura intermediária, Tese de Doutorado. Universidade Federal do Rio Grande do Norte.2012.

${ }^{87}$ DYAKONOV, Alexander J. et al. Magnetic materials based on iron dispersed in graphitic matrices II. High temperatures and mesophase pitch. Journal of magnetism and magnetic materials, v. 167, n. 1, p. 115-122, 1997. 
${ }^{88}$ MIKHAILIK, V. B.; KRAUS, H,; KAPUSTYANYK, V.; PANASYUK, M.; PROTS, YU.; TSYBUKSKYI, V.. VASYLECHKO, L. Structure, luminescence and scintillation properties of the $\mathrm{MgWO}_{4}-\mathrm{MgMoO}_{4}$ system. J. Phys.: Condens. Matter, vol. 20. 2008.

${ }^{89}$ PATNAIK, Pradyot; DEAN, John Aurie. Dean's analytical chemistry handbook. 2004.

${ }^{90}$ MATOS, Maria Auxiliadora Costa. Gravimetria. Universidade Federal de Juiz de Fora. Disponível em: < http://www.ufjf.br/nupis/files/2011/04/aula-9-Gravimetria-2011.1-NUPIS.pdf>. Acesso em 05 setembro 2014.

${ }_{91}$ AQUINO, R. et al. Size control of $\mathrm{MnFe}_{2} \mathrm{O}_{4}$ nanoparticles in electric double layered magnetic fluid synthesis. Journal of magnetism and magnetic materials, v. 252, p. 23-25, 2002.

${ }^{92}$ COTTON, F. A.; Wilkinson G.; Advanced Inorganic Chemistry, Wiley-Interscience:New York, 1982.

${ }^{93}$ OHLWEILER, O. A.; Química Analítica Quantitativa Vol. 2, Livros técnicos e Científicos Editora S.A.: Rio de Janeiro, 1976.

${ }^{94}$ JOLIVET, Jean-Pierre; LIVAGE, Jacques; HENRY, Marc. De la solution a l'oxide. L'Editeur: EDP Sciences, 1994.

${ }^{95}$ SONG, Qing; ZHANG, Z. John. Shape control and associated magnetic properties of spinel cobalt ferrite nanocrystals. Journal of the American Chemical Society, v. 126, n. 19, p. 6164-6168, 2004.

${ }^{96}$ ZHANG, X. et al. Influence of precipitator agents $\mathrm{NaOH}$ and $\mathrm{NH}_{4} \mathrm{OH}$ on the preparation of $\mathrm{Fe}_{3} \mathrm{O}_{4}$ nanoparticles synthesized by electron beam irradiation. Journal of radioanalytical and nuclear chemistry, $\mathrm{v}$. 270, n. 2, p. 285-289, 2006.

${ }^{97}$ KWON, Soon Gu; HYEON, Taeghwan. Formation Mechanisms of Uniform Nanocrystals via Hot-Injection and Heat-Up Methods. Small, v. 7, n. 19, p. 2685-2702, 2011.

${ }^{98}$ PARK, Jongnam et al. Synthesis of monodisperse spherical nanocrystals. Angewandte Chemie International Edition, v. 46, n. 25, p. 4630-4660, 2007.

${ }^{99}$ SOUZA JUNIOR, João Batista. Nanopartículas magnéticas de cobalto metálico e ferrita de cobalto recobertas com ouro como materiais biocompatíveis visando aplicações em biomedicina. Tese de Doutorado. Universidade de São Paulo, 2012.

${ }^{100}$ LU, An-Hui; SALABAS, E. emsp14L; SCHÜTH, Ferdi. Magnetic nanoparticles: synthesis, protection, functionalization, and application. Angewandte Chemie International Edition, v. 46, n. 8, p. 1222-1244, 2007.

101 LAMER, Victor K.; DINEGAR, Robert H. Theory, production and mechanism of formation of monodispersed hydrosols. Journal of the American Chemical Society, v. 72, n. 11, p. 4847-4854, 1950.

102 TARTAJ, Pedro et al. The preparation of magnetic nanoparticles for applications in biomedicine. Journal of Physics D: Applied Physics, v. 36, n. 13, p. R182, 2003.

${ }^{103}$ GOMES, J. A., Étude des propriétés structurelles locales de liquides magnétiques: de la nanoparticule à la solution, Tese de Doutorado, Universidade de Brasília, Brasil - Université Paris VI, França, 2007

${ }_{104}$ JANASI, S. R. et al. The effects of synthesis variables on the magnetic properties of coprecipitated barium ferrite powders. Journal of Magnetism and Magnetic materials, v. 238, n. 2, p. 168-172, 2002.

${ }^{105} \mathrm{KIM}, \mathrm{D}$. K. et al. Synthesis and characterization of surfactant-coated superparamagnetic monodispersed iron oxide nanoparticles. Journal of Magnetism and Magnetic Materials, v. 225, n. 1, p. 30-36, 2001.

106 VAYSSIERES, Lionel et al. Size tailoring of magnetite particles formed by aqueous precipitation: An example of thermodynamic stability of nanometric oxide particles. Journal of colloid and interface science, $v$. 205, n. 2, p. 205-212, 1998.

107 COPPOLA, P. Elaboração e Caracterização de Nanocoloides Magnéticos em Elevadas Frações Volumétricas. 2010, 104 f. Dissertação de Mestrado. Instituto de Química, Universidade de Brasília, 2010.

${ }^{108}$ FANG, Jiye et al. Nanoneedles of maghemite iron oxide prepared from a wet chemical route. Materials research bulletin, v. 38, n. 3, p. 461-467, 2003.

${ }^{109} \mathrm{YU}$, Wen-Guang et al. Effects of synthetical conditions on octahedral magnetite nanoparticles. Materials Science and Engineering: B, v. 136, n. 2, p. 101-105, 2007.

${ }_{110}$ GNANAPRAKASH, G. et al. Effect of initial pH and temperature of iron salt solutions on formation of magnetite nanoparticles. Materials chemistry and Physics, v. 103, n. 1, p. 168-175, 2007.

${ }^{111}$ SOUZA, Aryane Tofanello de. Síntese e caracterização de nanopartículas magnéticas de óxido de ferro para aplicações biomédicas - um estudo citotóxico em linhagem celular de carcinoma cervical humano (células HeLa). 2011. 111 f. Dissertação (mestrado) - Universidade Estadual Paulista, Instituto de Biociências, Letras e Ciências Exatas, 2011

${ }^{112}$ TARTAJ, Pedro et al. The preparation of magnetic nanoparticles for applications in biomedicine. Journal of Physics D: Applied Physics, v. 36, n. 13, p. R182, 2003.

${ }^{113}$ CHINNASAMY, C. N. et al. Synthesis of size-controlled cobalt ferrite particles with high coercivity and squareness ratio. Journal of colloid and interface science, v. 263, n. 1, p. 80-83, 2003.

${ }^{114}$ MORAIS, P. C. et al. Synthesis and characterization of size-controlled cobalt-ferrite-based ionic ferrofluids. Journal of Magnetism and Magnetic Materials, v. 225, n. 1, p. 37-40, 2001. 
115 KIM, Yeong Il; KIM, Don; LEE, Choong Sub. Synthesis and characterization of $\mathrm{CoFe}_{2} \mathrm{O}_{4}$ magnetic nanoparticles prepared by temperature-controlled coprecipitation method. Physica B: Condensed Matter, v. 337, n. 1, p. 42-51, 2003.

116 KUMAR, Vinod et al. Size-induced effect on nano-crystalline $\mathrm{CoFe}_{2} \mathrm{O}_{4}$. Journal of Magnetism and Magnetic Materials, v. 320, n. 11, p. 1729-1734, 2008.

117 GNANAPRAKASH, G. et al. Effect of digestion time and alkali addition rate on physical properties of magnetite nanoparticles. The Journal of Physical Chemistry B, v. 111, n. 28, p. 7978-7986, 2007

${ }_{118}$ COMPTON, A. H; ALLISON, S. K.. X-ray in theory and experiment. D. Van Nostrand Company. New Jersey USA, 1954.

${ }^{119}$ FÖLSING, Albrecht. Wilhelm Conrad Röntgen: Aufbruch ins Innere der Materie. C. Hanser, 1995.

${ }^{120}$ ALBERS, A. P. F. et al. Um método simples de caracterização de argilominerais por difração de raios X (A simple method for the characterization of clay minerals by X-ray diffraction). Cerâmica, v. 48, n. 305, p. 34, 2002

${ }^{121}$ HAMMOND, C; The basics of Crystallography and diffraction, Oxford University Press: New York, 1997

122 ASTM card: $\mathbf{2 2 - 1 0 8 6 . ~}$

${ }^{123}$ KLUG, Harold Philip et al. X-ray diffraction procedures. New York: Wiley, 1954.

${ }^{124}$ Berkovski, B. e Bashtovoy, V., Magnetic Fluids and Applications Handbook, New York: Begell House 1996.

125 SCHERRER, P. Estimation of the size and internal structure of colloidal particles by means of röntgen. Nachr. Ges. Wiss. Göttingen, v. 2, p. 96-100, 1918.

${ }^{126}$ BERTIN, Eugene P. Principles and practice of X-ray spectrometric analy sis. Plenum Press, 1975.

${ }^{127}$ HARVEY, David. Modern analytical chemistry. New York: McGraw-Hill, 2000.

${ }^{128}$ MANNHEIMER, W., Microscopia dos Materiais - Uma Introdução, Sociedade Brasileira de Microscopia e Microanálise, E-papers, 2002.

${ }^{129}$ ALVES, T.M. Síntese e caracterização de nanopartículas de óxido de ferro para aplicações biomédicas. Dissertação (Mestrado) - Instituto de Física, Universidade Estadual de Campinas, 2007

${ }^{130}$ TROMANS, D.; MEECH, J. A.; Minerals Engineering, v. 15, p. 1027-1041 (2002) 